\title{
Amino Acid Derived Enamides: Synthesis and Aminopeptidase Activity
}

\author{
Richard R. Cesati III,* Greg Dwyer, Reinaldo C. Jones, Megan P. Hayes, Padmaja \\ Yalamanchili and David S. Casebier \\ Pharmaceutical Research and Development, Bristol-Myers Squibb Medical Imaging, North \\ Billerica, Massachusetts 01862
}

\section{Supporting Information}

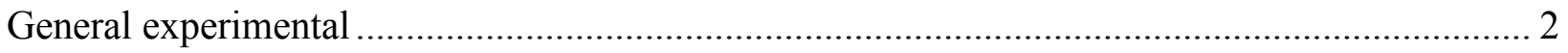

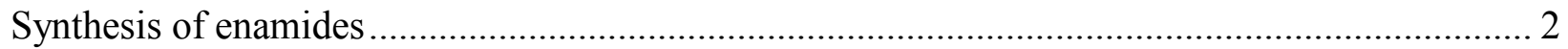

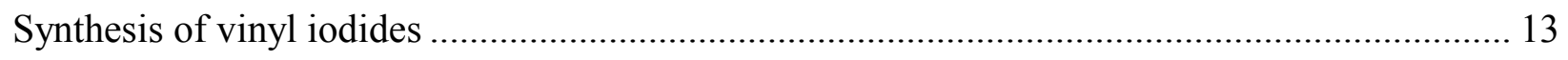

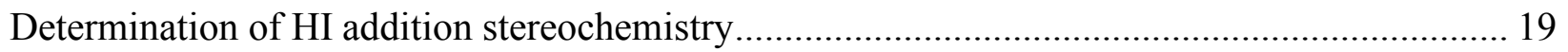

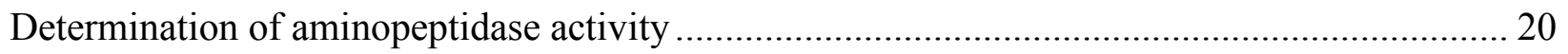

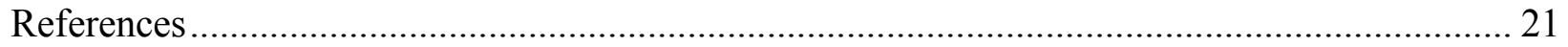

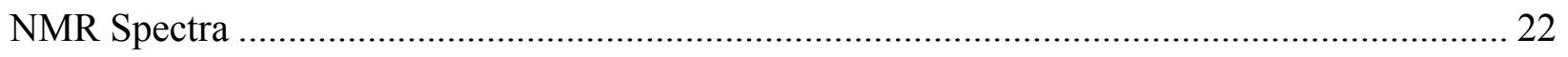




\section{General experimental}

${ }^{1} \mathrm{H}$ NMR spectra were recorded on a Bruker Avance $(600 \mathrm{MHz}$ and $300 \mathrm{MHz})$ spectrometer. Chemical shifts are reported in ppm from tetramethylsilane with the residual solvent resonance resulting from incomplete deuteration as the internal standard $\left(\mathrm{CDCl}_{3}: \delta 7.25 \mathrm{ppm}, \mathrm{DMSO}-d_{6}: \delta\right.$ $2.54 \mathrm{ppm})$. Data are reported as follows: chemical shift, integration, multiplicity $(\mathrm{s}=$ singlet, $\mathrm{d}=$ doublet, $\mathrm{t}=$ triplet, $\mathrm{q}=$ quartet, $\mathrm{br}=$ broad, $\mathrm{m}=$ multiplet), and coupling constants. ${ }^{13} \mathrm{C} \mathrm{NMR}$ spectra were recorded on a Bruker Avance $(150 \mathrm{MHz}$ or $75 \mathrm{MHz}$ ) with complete proton decoupling. Chemical shifts are reported in ppm from tetramethylsilane with the solvent as the internal reference $\left(\mathrm{CDCl}_{3}: \delta 77.0 \mathrm{ppm}, \mathrm{DMSO}-d_{6}: \delta 39.5 \mathrm{ppm}\right)$. Enantiomer ratios were determined by chiral GLC analysis (Alltech Associates Chiralsil-Val column (25 m x $0.25 \mathrm{~mm})$ ) through comparison with the authentic racemic amino acids. ${ }^{1}$ Low-resolution mass spectrometry was performed on an Agilent Technologies 1100 Series LC/MS ESI-MS (positive mode). Highresolution mass spectrometry was performed on an Ionspec Ultima FTMS or an Agilent Technologies 1100 Series LC/MS-TOF; ESI-MS (positive mode).

Unless otherwise stated, all reactions were conducted in oven- $\left(150{ }^{\circ} \mathrm{C}\right)$ and flame-dried glassware under an inert atmosphere of dry nitrogen. Indicated temperatures refer to those of the reaction bath, while ambient laboratory temperature is noted as $22{ }^{\circ} \mathrm{C}$. Anhydrous solvents were obtained from Aldrich. Amino acid derivatives were obtained from Advanced Chemtech, Novabiochem, or Bachem Bioscience. All amino amides were utilized as their respective free bases; most were prepared obtained through purchase of the corresponding Cbz-protected derivatives and subsequent hydrogenolysis. ${ }^{2}$ Within each experimental are additional footnotes concerning the preparation of specific reagents and starting materials.

The following is a description of reagents which required special handling prior to use; listed in order of appearance. ${ }^{3} N, N^{\prime}$-Dimethylethylenediamine (DMED) was distilled from and stored over $\mathrm{KOH}$. Cuprous iodide was recrystallized from a saturated aqueous solution of sodium iodide. Chlorotrimethylsilane (TMSCl) was distilled from $\mathrm{CaH}_{2}$ immediately prior to use. Butyllithium (Aldrich; solution in hexanes) was titrated using $N$-pivaloyl-o-toluidine according to the method of Suffert. ${ }^{4} \mathrm{PPh}_{3}$ was recrystallized from hexanes. All other reagents were used as obtained from Aldrich, Alfa-Aesar, Fluka, Lancaster, or Strem Chemicals.

\section{Synthesis of enamides}

\section{General Procedure I: Cu-catalyzed coupling in THF}

A solution of the vinyl iodide and DMED in THF $(1.00 \mathrm{~mL})$ was prepared in a flamedried $5 \mathrm{~mL}$ conical flask then set aside. Separately, an oven-dried $10 \mathrm{~mL}$ Schlenk tube fitted with a septum was charged with the amide, $\mathrm{CuI}$ and $\mathrm{Cs}_{2} \mathrm{CO}_{3}$ then evacuated and back-filled with dry nitrogen three times. The vinyl iodide solution was then transferred to the Schlenk tube, the septum rapidly exchanged for a glass stopper and the vessel sealed with Teflon tape. The resulting suspension was then immersed in a preheated oil bath and maintained at $70{ }^{\circ} \mathrm{C}$ for $16 \mathrm{~h}$. After cooling to $22{ }^{\circ} \mathrm{C}$ the reaction mixture was diluted with EtOAc $(2 \mathrm{~mL})$ and placed directly atop a previously prepared silica gel column for purification.

\section{General Procedure II: Cu-catalyzed coupling in DMF}

A solution of the vinyl iodide and DMED in DMF $(1.00 \mathrm{~mL})$ was prepared in a flamedried $5 \mathrm{~mL}$ conical flask then set aside. Separately, an oven-dried $10 \mathrm{~mL}$ Schlenk tube fitted with a septum was charged with the amide, $\mathrm{CuI}$ and $\mathrm{Cs}_{2} \mathrm{CO}_{3}$ then evacuated and back-filled with 
dry nitrogen three times. The vinyl iodide solution was then transferred to the Schlenk tube, the septum rapidly exchanged for a glass stopper and the vessel sealed with Teflon tape. The resulting suspension was then immersed in a preheated oil bath and maintained at $50{ }^{\circ} \mathrm{C}$ for $1 \mathrm{~h}$. After cooling to $22{ }^{\circ} \mathrm{C}$, all volatiles were removed in vacuo and the residue directly purified by preparative HPLC. Alternatively, the crude reaction mixture was diluted with EtOAc $(50 \mathrm{~mL})$ then exhaustively washed with a saturated solution of $\mathrm{NaCl}$. After drying over $\mathrm{Na}_{2} \mathrm{SO}_{4}$, filtration and concentration in vacuo, the crude residue was purified by silica gel chromatography.

Preparation of $\quad N$-((1E)-1-propylpent-1-enyl)(2S)-2-[(tert-butoxy)carbonylamino]-4methylpentanamide (1)

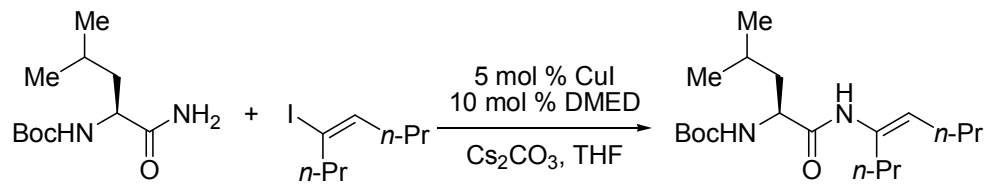

Following General Procedure I, Boc-Leu- $\mathrm{NH}_{2}(0.230 \mathrm{~g}, 1.00 \mathrm{mmol})$, E-4-iodooct-4-ene (119 mg, $0.500 \mathrm{mmol})$, CuI (4.8 mg, $25 \mu \mathrm{mol} ; 5 \mathrm{~mol} \%$ ), DMED (5.4 $\mu \mathrm{L}, 0.05 \mathrm{mmol})$ and $\mathrm{Cs}_{2} \mathrm{CO}_{3}(244 \mathrm{mg}, 0.750 \mathrm{mmol})$ were combined. After $16 \mathrm{~h}$ at $70{ }^{\circ} \mathrm{C}$, the suspension was cooled to $22{ }^{\circ} \mathrm{C}$ then diluted with EtOAc $(2 \mathrm{~mL})$ and purified directly by chromatography on silica $(4: 1$ hexanes/EtOAc) to afford a white powder (158 mg, $0.463 \mathrm{mmol} ; 92.6 \%)$.

${ }^{1}$ H NMR: $\left(300 \mathrm{MHz}, \mathrm{CDCl}_{3}\right)$

$7.23(1 \mathrm{H}$, brs $), 5.82(1 \mathrm{H}$, brt, $J=7.2 \mathrm{~Hz}), 4.94(1 \mathrm{H}$, brd, $J=7.2 \mathrm{~Hz}), 4.05(1 \mathrm{H}$, brs), 2.17 (2H, brt, $J=7.5 \mathrm{~Hz}), 2.00(2 \mathrm{H}, \mathrm{dt}, J=7.5,7.5 \mathrm{~Hz}), 1.70-1.63(2 \mathrm{H}, \mathrm{m})$, $1.49-1.30(5 \mathrm{H}, \mathrm{m}), 1.42(9 \mathrm{H}, \mathrm{s}), 0.92(3 \mathrm{H}, \mathrm{d}, J=6.3 \mathrm{~Hz}), 0.91(3 \mathrm{H}, \mathrm{d}, J=6.1 \mathrm{~Hz})$, $0.89(3 \mathrm{H}, \mathrm{d}, J=7.4 \mathrm{~Hz}), 0.88(3 \mathrm{H}, \mathrm{d}, J=7.3 \mathrm{~Hz})$.

${ }^{13} \underline{\mathrm{C} N M R}:\left(151 \mathrm{MHz}, \mathrm{CDCl}_{3}\right)$

$170.7,156.0,133.7,118.4,80.1,53.6,40.7,31.6,29.2,28.3,24.8,23.1,22.7,22.1$, $21.0,13.8,13.6$

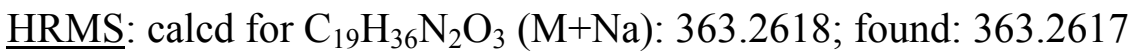

TLC: $R_{f} 0.6$ (silica gel, 4:1 hexanes/EtOAc, ninhydrin)

Preparation of $N$-((1E)-1-propylpent-1-enyl)(2S)-4-methyl-2-[(phenylmethoxy)carbonylamino]pentanamide (2)

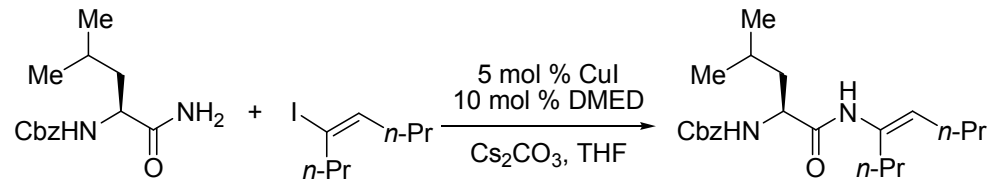

Following General Procedure I, Cbz-Leu-NH $\mathrm{NH}_{2}(0.264 \mathrm{~g}, 1.00 \mathrm{mmol}), E$-4-iodooct-4-ene (119 mg, $0.500 \mathrm{mmol}$ ), CuI (4.8 mg, $25 \mu \mathrm{mol} ; 5 \mathrm{~mol} \%$ ), DMED (5.4 $\mu \mathrm{L}, 0.05 \mathrm{mmol})$ and $\mathrm{Cs}_{2} \mathrm{CO}_{3}(244 \mathrm{mg}, 0.750 \mathrm{mmol})$ were combined. After $16 \mathrm{~h}$ at $70{ }^{\circ} \mathrm{C}$, the suspension was cooled to $22{ }^{\circ} \mathrm{C}$ then diluted with EtOAc $(2 \mathrm{~mL})$ and purified directly by chromatography on silica (step gradient from 4:1 to 3:2 hexanes/EtOAc) to afford the expected product as a white powder (104 $\mathrm{mg}, 0.278 \mathrm{mmol} ; 55.6 \%)$ and the hydantoin also as a white solid (47.5, $0.178 \mathrm{mmol} ; 31.0 \%)$. 
${ }^{1} \underline{\mathrm{H} \mathrm{NMR}}:\left(600 \mathrm{MHz}, \mathrm{CDCl}_{3}\right)$

7.36-7.30 (5H, m), $7.01(1 \mathrm{H}$, brs), $5.82(1 \mathrm{H}$, brs $), 5.20(1 \mathrm{H}$, brd, $J=7.4 \mathrm{~Hz}), 5.11$ $(2 \mathrm{H}, \mathrm{s}), 4.14(1 \mathrm{H}, \mathrm{s}), 2.19\left(2 \mathrm{H}, \mathrm{ABqt}, J_{\mathrm{AB}}=14.2 \mathrm{~Hz}, J_{\mathrm{t}}=7.5 \mathrm{~Hz}\right), 2.02(2 \mathrm{H}, \mathrm{q}, J=$ $7.5 \mathrm{~Hz}), 1.72-1.65(2 \mathrm{H}, \mathrm{m}), 1.54-1.48(1 \mathrm{H}, \mathrm{m}), 1.43-1.36(4 \mathrm{H}, \mathrm{m}), 0.94-0.88(12 \mathrm{H}$, $\mathrm{m})$

${ }^{13} \underline{\mathrm{C} \mathrm{NMR}}:\left(151 \mathrm{MHz}, \mathrm{CDCl}_{3}\right)$

$170.3,156.3,136.1,133.6,128.5,128.2,128.0,118.9,67.1,54.2,41.1,31.6,29.2$, $24.7,23.1,22.9,22.1,21.0,13.9,13.6$

HRMS: calcd for $\mathrm{C}_{22} \mathrm{H}_{34} \mathrm{~N}_{2} \mathrm{O}_{3}(\mathrm{M}+\mathrm{H})$ : 375.2642 ; found: 375.2646

TLC: $R_{f} 0.4$ (silica gel, 4:1 hexanes/EtOAc, CAM)

$R_{f} 0.2$ (silica gel, 4:1 hexanes/EtOAc, CAM)

Preparation of $N$-((1E)-1-propylpent-1-enyl)(2S)-2-amino-4-methylpentanamide (3)

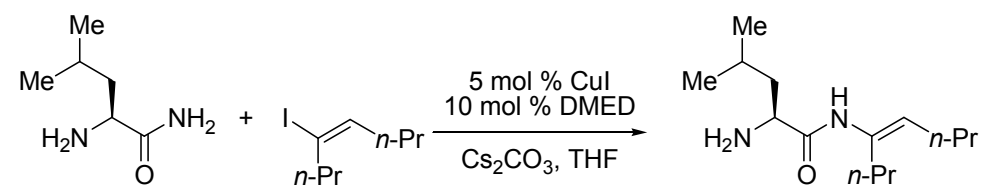

Following General Procedure I, H-Leu- $\mathrm{NH}_{2}(0.130 \mathrm{~g}, 1.00 \mathrm{mmol})$, E-4-iodooct-4-ene (119 mg, $0.500 \mathrm{mmol}), \mathrm{CuI}(4.8 \mathrm{mg}, 25 \mu \mathrm{mol} ; 5 \mathrm{~mol} \%)$, DMED (5.4 $\mu \mathrm{L}, 0.05 \mathrm{mmol})$ and $\mathrm{Cs}_{2} \mathrm{CO}_{3}(244 \mathrm{mg}, 0.750 \mathrm{mmol})$ were combined. After $16 \mathrm{~h}$ at $70{ }^{\circ} \mathrm{C}$, the suspension was cooled to $22{ }^{\circ} \mathrm{C}$ then diluted with EtOAc $(2 \mathrm{~mL})$ and purified directly by chromatography on silica $(9: 1$ $\mathrm{CH}_{2} \mathrm{Cl}_{2} / \mathrm{MeOH}$ ) to afford a colorless oil (49.5 mg, $0.206 \mathrm{mmol} ; 41.2 \%$ ).

${ }^{1} \mathrm{H}$ NMR: $\left(600 \mathrm{MHz}, \mathrm{CDCl}_{3}\right)$

$8.46(1 \mathrm{H}, \mathrm{brs}), 5.94(1 \mathrm{H}, \mathrm{t}, J=7.6 \mathrm{~Hz}), 3.35(1 \mathrm{H}, \mathrm{dd}, J=9.8,3.6 \mathrm{~Hz}), 2.21(2 \mathrm{H}$, $\mathrm{dd}, J=7.7,7.3 \mathrm{~Hz}), 2.02(2 \mathrm{H}, \mathrm{dt}, J=7.5,7.3 \mathrm{~Hz}), 1.75-1.68(2 \mathrm{H}, \mathrm{m}), 1.48-1.31$ $(7 \mathrm{H}, \mathrm{m}), 0.95(3 \mathrm{H}, \mathrm{d}, J=6.4 \mathrm{~Hz}), 0.92-0.86(9 \mathrm{H}, \mathrm{m})$

${ }^{13} \mathrm{C} \mathrm{NMR}:\left(151 \mathrm{MHz}, \mathrm{CDCl}_{3}\right)$

$173.5,133.6,116.6,54.0,44.1,31.7,29.2,25.0,23.4,23.3,21.3,21.2,13.9,13.7$

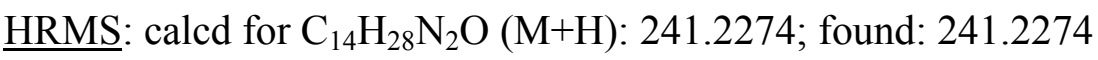

TLC: $R_{f} 0.4$ (silica gel, 9:1 $\mathrm{CH}_{2} \mathrm{Cl}_{2} / \mathrm{MeOH}$, ninhydrin)

\section{Preparation of (2S)- $\mathrm{N}$-((1Z)-1-propylpent-1-enyl)-2-amino-4-methylpentanamide (4)}

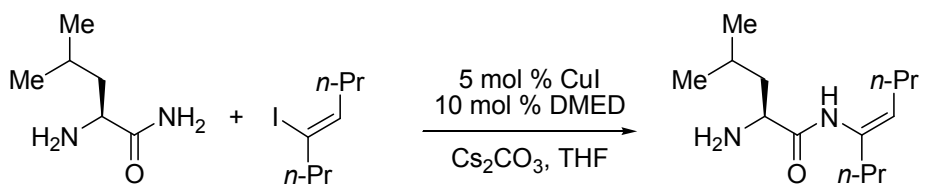

Following General Procedure I, H-Leu-NH $\mathrm{NH}_{2}(0.130 \mathrm{~g}, 1.00 \mathrm{mmol})$, Z-4-iodooct-4-ene (119 mg, $0.500 \mathrm{mmol}), \mathrm{CuI}(4.8 \mathrm{mg}, 25 \mu \mathrm{mol} ; 5 \mathrm{~mol} \%)$, DMED (5.4 $\mu \mathrm{L}, 0.05 \mathrm{mmol})$ and $\mathrm{Cs}_{2} \mathrm{CO}_{3}(244 \mathrm{mg}, 0.750 \mathrm{mmol})$ were combined. After $16 \mathrm{~h}$ at $70{ }^{\circ} \mathrm{C}$, the suspension was cooled 
to $22{ }^{\circ} \mathrm{C}$ then diluted with EtOAc $(2 \mathrm{~mL})$ and purified directly by chromatography on silica $(9: 1$ $\left.\mathrm{CH}_{2} \mathrm{Cl}_{2} / \mathrm{MeOH}\right)$ to afford a colorless oil $(6.4 \mathrm{mg}, 27 \mu \mathrm{mol} ; 5.3 \%)$.

${ }^{1} \mathrm{H}$ NMR: $\left(600 \mathrm{MHz}, \mathrm{CDCl}_{3}\right)$

8.57 (1H, brs), $4.91(1 \mathrm{H}, \mathrm{t}, J=7.0 \mathrm{~Hz}), 3.42(1 \mathrm{H}, \mathrm{dd}, J=9.8,3.6 \mathrm{~Hz}), 2.41-2.32$ $(2 \mathrm{H}, \mathrm{m}), 1.95(2 \mathrm{H}, \mathrm{q}, J=7.3 \mathrm{~Hz}), 1.78-1.71(2 \mathrm{H}, \mathrm{m}), 1.45-1.35(5 \mathrm{H}, \mathrm{m}), 0.98(3 \mathrm{H}$, d, $J=6.3 \mathrm{~Hz}), 0.94(3 \mathrm{H}, \mathrm{d}, J=6.2 \mathrm{~Hz}), 0.90(3 \mathrm{H}, \mathrm{t}, J=7.4 \mathrm{~Hz}), 0.89(3 \mathrm{H}, \mathrm{t}, J=$ $7.4 \mathrm{~Hz})$

${ }^{13} \mathrm{C} \mathrm{NMR}:\left(151 \mathrm{MHz}, \mathrm{CDCl}_{3}\right)$

$173.2,134.8,118.7,54.0,44.2,36.5,28.8,25.0,23.4,22.5,21.3,20.9,13.8,13.5$

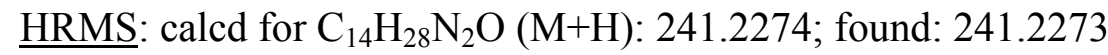

TLC: $R_{f} 0.3$ (silica gel, 9:1 $\mathrm{CH}_{2} \mathrm{Cl}_{2} / \mathrm{MeOH}$, ninhydrin)

Preparation of $N$-((1E)-1-propylpent-1-enyl)(2S)-2-aminopropanamide (5)

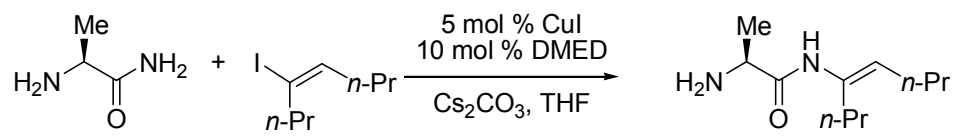

Following General Procedure I, H-Ala- $\mathrm{NH}_{2}(88.1 \mathrm{mg}, 1.00 \mathrm{mmol})$, E-4-iodooct-4-ene (119 mg, $0.500 \mathrm{mmol}$ ), CuI (4.8 mg, $25 \mu \mathrm{mol} ; 5 \mathrm{~mol} \%$ ), DMED (5.4 $\mu \mathrm{L}, 0.05 \mathrm{mmol})$ and $\mathrm{Cs}_{2} \mathrm{CO}_{3}(244 \mathrm{mg}, 0.750 \mathrm{mmol})$ were combined. After $16 \mathrm{~h}$ at $70{ }^{\circ} \mathrm{C}$, the suspension was cooled to $22{ }^{\circ} \mathrm{C}$ then diluted with EtOAc $(2 \mathrm{~mL})$ and purified directly by chromatography on silica $(9: 1$ $\mathrm{CH}_{2} \mathrm{Cl}_{2} / \mathrm{MeOH}$ ) to afford a colorless oil (36.9 mg, $0.186 \mathrm{mmol} ; 37.2 \%$ ).

${ }^{1} \mathrm{H}$ NMR: $\left(600 \mathrm{MHz}, \mathrm{CDCl}_{3}\right)$

8.44 (1H, brs), $5.98(1 \mathrm{H}, \mathrm{t}, J=7.5 \mathrm{~Hz}), 3.49(1 \mathrm{H}, \mathrm{q}, J=6.9 \mathrm{~Hz}), 2.23(2 \mathrm{H}, \mathrm{dd}, J=$ 7.7, $7.4 \mathrm{~Hz}), 2.04(2 \mathrm{H}, \mathrm{q}, J=7.5 \mathrm{~Hz}), 1.50-1.45(2 \mathrm{H}, \mathrm{m}), 1.44-1.37(2 \mathrm{H}, \mathrm{m}), 1.36$ $(3 \mathrm{H}, \mathrm{d}, J=7.0 \mathrm{~Hz}), 0.93(3 \mathrm{H}, \mathrm{t}, J=7.4 \mathrm{~Hz}), 0.92(3 \mathrm{H}, \mathrm{t}, J=7.4 \mathrm{~Hz})$

${ }^{13} \mathrm{C} \mathrm{NMR}:\left(151 \mathrm{MHz}, \mathrm{CDCl}_{3}\right)$

$173.6,133.6,116.8,51.3,31.7,29.2,23.3,21.7,21.2,13.9,13.7$

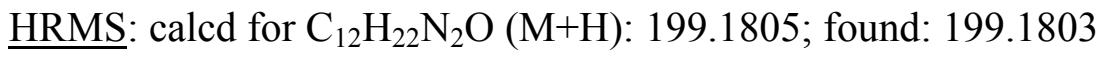

TLC: $R_{f} 0.3$ (silica gel, 9:1 $\mathrm{CH}_{2} \mathrm{Cl}_{2} / \mathrm{MeOH}$, ninhydrin)

Preparation of $N-\{1-[N-((1 E)-1-p r o p y l p e n t-1-e n y l)$ carbamoyl](1S)ethyl $\}(2 S)-2$-amino-4methylpentanamide (7)

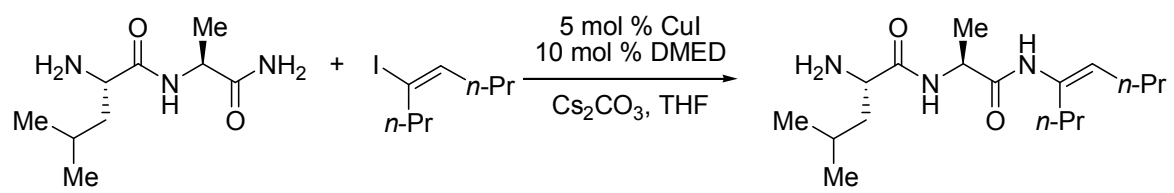

Following General Procedure I, H-Leu-Ala- $\mathrm{NH}_{2}(0.101 \mathrm{~g}, 0.500 \mathrm{mmol}), E$-4-iodooct-4ene (59.5 mg, $0.250 \mathrm{mmol})$, CuI (2.40 mg, $12.5 \mu \mathrm{mol} ; 5 \mathrm{~mol} \%)$, DMED (2.7 $\mu \mathrm{L}, 25 \mu \mathrm{mol})$ and $\mathrm{Cs}_{2} \mathrm{CO}_{3}(122 \mathrm{mg}, 0.375 \mathrm{mmol})$ were combined. After $16 \mathrm{~h}$ at $70{ }^{\circ} \mathrm{C}$, the suspension was cooled 
to $22{ }^{\circ} \mathrm{C}$ then diluted with EtOAc $(2 \mathrm{~mL})$ and purified directly by chromatography on silica (9:1 $\left.\mathrm{CH}_{2} \mathrm{Cl}_{2} / \mathrm{MeOH}\right)$ to afford a colorless oil (40.5 mg, $0.130 \mathrm{mmol} ; 52.0 \%$ ).

${ }^{1} \mathrm{H}$ NMR: $\left(300 \mathrm{MHz}, \mathrm{CDCl}_{3}\right)$

$7.73(1 \mathrm{H}, \mathrm{brd}, J=7.7 \mathrm{~Hz}), 7.49(1 \mathrm{H}, \mathrm{brs}), 5.88(1 \mathrm{H}, \mathrm{t}, J=7.5 \mathrm{~Hz}), 4.42(1 \mathrm{H}, \mathrm{dq}, J$ $=7.2 \mathrm{~Hz}), 3.40(1 \mathrm{H}, \mathrm{dd}, J=9.9,34 \mathrm{~Hz}), 2.19\left(2 \mathrm{H}\right.$, Abqt, $J_{\mathrm{AB}}=14.1 \mathrm{~Hz}, J_{\mathrm{d}}=$ $7.3 \mathrm{~Hz}), 2.02(2 \mathrm{H}, \mathrm{q}, J=7.2 \mathrm{~Hz}), 1.79-1.65(2 \mathrm{H}, \mathrm{m}), 1.48-1.33(5 \mathrm{H}, \mathrm{m}), 1.38(3 \mathrm{H}$, $\mathrm{d}, J=7.0 \mathrm{~Hz}), 0.97(3 \mathrm{H}, \mathrm{d}, J=6.4 \mathrm{~Hz}), 0.94(3 \mathrm{H}, \mathrm{d}, J=6.1 \mathrm{~Hz}), 0.91(3 \mathrm{H}, \mathrm{t}, J=$ $7.5 \mathrm{~Hz}), 0.91(3 \mathrm{H}, \mathrm{t}, J=7.4 \mathrm{~Hz})$

${ }^{13} \mathrm{C} \mathrm{NMR}:\left(151 \mathrm{MHz}, \mathrm{CDCl}_{3}\right)$

$176.1,170.4,133.9,118.1,53.3,49.1,43.9,31.7,29.2,24.8,23.4,23.2,21.3,21.1$, $17.3,13.9,13.6$

HRMS: calcd for $\mathrm{C}_{17} \mathrm{H}_{33} \mathrm{~N}_{3} \mathrm{O}_{2}(\mathrm{M}+\mathrm{H}): 312.2646$; found: 312.2645

TLC: $R_{f} 0.4$ (silica gel, 9:1 $\mathrm{CH}_{2} \mathrm{Cl}_{2} / \mathrm{MeOH}$, ninhydrin)

\section{Preparation of $\mathrm{N}$-((1E)-6-(2-furyl)hex-1-enyl)-2-aminoacetamide (12)}

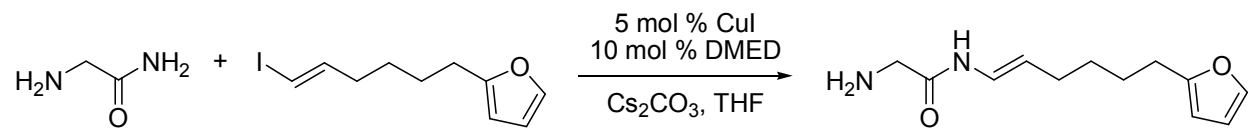

Following General Procedure I, H-Gly- $\mathrm{NH}_{2}(53.7 \mathrm{mg}, 0.724 \mathrm{mmol}), 8(0.100 \mathrm{mg}, 0.362$ mmol), $\mathrm{CuI}(3.4 \mathrm{mg}, 18 \mu \mathrm{mol} ; 5 \mathrm{~mol} \%)$, DMED $(4.0 \mu \mathrm{L}, 36 \mu \mathrm{mol})$ and $\mathrm{Cs}_{2} \mathrm{CO}_{3}(177 \mathrm{mg}, 0.543$ mmol) were combined. After $16 \mathrm{~h}$ at $70{ }^{\circ} \mathrm{C}$, the suspension was cooled to $22{ }^{\circ} \mathrm{C}$ then diluted with EtOAc $(2 \mathrm{~mL})$ and purified directly by chromatography on silica (step gradient from 9:1 to 4:1 $\mathrm{CH}_{2} \mathrm{Cl}_{2} / \mathrm{MeOH}$ ) to afford a white solid (22.6 mg, $0.102 \mathrm{mmol} ; 28.1 \%$ ).

${ }^{1}$ H NMR: $\left(600 \mathrm{MHz}, \mathrm{CDCl}_{3}\right)$

$8.81(1 \mathrm{H}$, brd, $J=8.1 \mathrm{~Hz}), 7.2(1 \mathrm{H}, \mathrm{s}), 6.74(1 \mathrm{H}, \mathrm{brt}, J=12.5 \mathrm{~Hz}), 6.26(1 \mathrm{H}, \mathrm{dd}, J$ $=2.8,1.8 \mathrm{~Hz}), 5.96(1 \mathrm{H}, \mathrm{d}, J=2.5 \mathrm{~Hz}), 5.23(1 \mathrm{H}, \mathrm{dt}, J=14.2,7.0 \mathrm{~Hz}), 3.40(2 \mathrm{H}$, s), $2.61(2 \mathrm{H}, \mathrm{t}, J=7.5 \mathrm{~Hz}), 2.06(2 \mathrm{H}, \mathrm{dt}, J=6.9,6.9 \mathrm{~Hz}), 1.64(2 \mathrm{H}, \mathrm{tt}, J=7.6,7.4$ $\mathrm{Hz}), 1.42(2 \mathrm{H}, \mathrm{tt}, J=7.6,7.4 \mathrm{~Hz})$

${ }^{13} \mathrm{C} \mathrm{NMR}:\left(151 \mathrm{MHz}, \mathrm{CDCl}_{3}\right)$

169.6, 156.3, 140.7, 122.0, 113.5, 110.0, 104.7, 44.4, 29.5, 29.4, 27.8, 27.5

HRMS: calcd for $\mathrm{C}_{12} \mathrm{H}_{18} \mathrm{~N}_{2} \mathrm{O}_{2}(\mathrm{M}+\mathrm{H}): 223.1441$; found: 223.1444

Preparation of $N$-((1E)-6-(2-furyl)hex-1-enyl)(2S)-2-aminopropanamide (13)

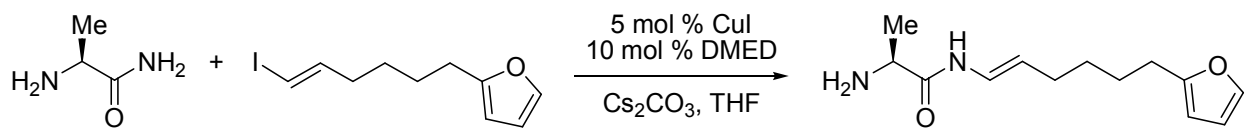

Following General Procedure I, H-Ala-NH $2(95.7 \mathrm{mg}, 1.09 \mathrm{mmol}), 8(0.150 \mathrm{mg}, 0.543$ mmol), $\mathrm{CuI}(5.2 \mathrm{mg}, 27 \mu \mathrm{mol} ; 5 \mathrm{~mol} \%)$, DMED $(6.0 \mu \mathrm{L}, 54 \mu \mathrm{mol})$ and $\mathrm{Cs}_{2} \mathrm{CO}_{3}(265 \mathrm{mg}, 0.815$ mmol) were combined. After $16 \mathrm{~h}$ at $70{ }^{\circ} \mathrm{C}$, the suspension was cooled to $22{ }^{\circ} \mathrm{C}$ then diluted 
with EtOAc $(2 \mathrm{~mL})$ and purified directly by chromatography on silica $\left(9: 1 \mathrm{CH}_{2} \mathrm{Cl}_{2} / \mathrm{MeOH}\right)$ to afford a white solid (103 mg, $0.435 \mathrm{mmol} ; 80.0 \%$ ).

${ }^{1}$ H NMR: $\left(600 \mathrm{MHz}, \mathrm{CDCl}_{3}\right)$

$8.86(1 \mathrm{H}, \mathrm{brd}, J=10.3 \mathrm{~Hz}), 7.28(1 \mathrm{H}, \mathrm{dd}, J=1.6,0.7 \mathrm{~Hz}), 6.69(1 \mathrm{H}, \mathrm{ddt}, J=14.2$, $11.0,1.3 \mathrm{~Hz}), 6.26(1 \mathrm{H}, \mathrm{dd}, J=3.2,1.8 \mathrm{~Hz}), 3.52(1 \mathrm{H}, \mathrm{q}, J=7.1 \mathrm{~Hz}), 2.61(2 \mathrm{H}, \mathrm{t}$, $J=7.6 \mathrm{~Hz}), 2.05(2 \mathrm{H}, \mathrm{dtd}, J=7.3,7.3,1.3 \mathrm{~Hz}), 1.64(2 \mathrm{H}, \mathrm{tt}, J=7.8,7.6 \mathrm{~Hz}), 1.41$ $(2 \mathrm{H}, \mathrm{tt}, J=7.6,7.6 \mathrm{~Hz}), 1.35(3 \mathrm{H}, \mathrm{d}, J=7.1 \mathrm{~Hz})$

${ }^{13} \mathrm{C} \mathrm{NMR}:\left(151 \mathrm{MHz}, \mathrm{CDCl}_{3}\right)$

$172.5,156.2,140.7,122.3,113.5,110.0,104.7,50.4,29.5,29.3,27.8,27.4,21.5$

HRMS: calcd for $\mathrm{C}_{13} \mathrm{H}_{20} \mathrm{~N}_{2} \mathrm{O}_{2}(\mathrm{M}+\mathrm{H}): 237.1598$; found: 237.1594

Preparation of $N$-((1E)-6-(2-furyl)hex-1-enyl)(2S)-2-amino-3-methylbutanamide (14)

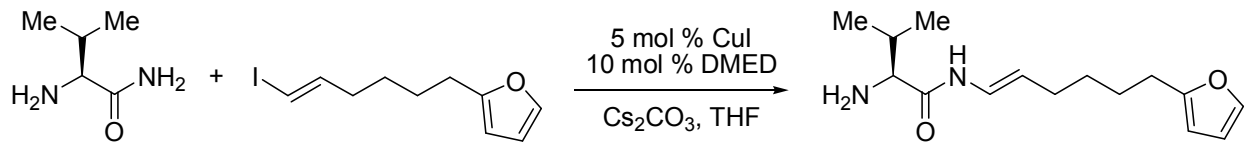

Following General Procedure I, H-Val- $\mathrm{NH}_{2}$ (126 mg, $\left.1.09 \mathrm{mmol}\right), 8$ (0.150 mg, 0.543 mmol), $\mathrm{CuI}(5.2 \mathrm{mg}, 27 \mu \mathrm{mol} ; 5 \mathrm{~mol} \%)$, DMED $(6.0 \mu \mathrm{L}, 54 \mu \mathrm{mol})$ and $\mathrm{Cs}_{2} \mathrm{CO}_{3}(265 \mathrm{mg}, 0.815$ mmol) were combined. After $16 \mathrm{~h}$ at $70{ }^{\circ} \mathrm{C}$, the suspension was cooled to $22{ }^{\circ} \mathrm{C}$ then diluted with EtOAc $(2 \mathrm{~mL})$ and purified directly by chromatography on silica $\left(9: 1 \mathrm{CH}_{2} \mathrm{Cl}_{2} / \mathrm{MeOH}\right)$ to afford a colorless oil (84.0 mg, $0.318 \mathrm{mmol}$; 58.5\%).

${ }^{1}$ H NMR: $\left(300 \mathrm{MHz}, \mathrm{CDCl}_{3}\right)$

$8.89(1 \mathrm{H}, \mathrm{brd}, J=10.4 \mathrm{~Hz}), 7.27(1 \mathrm{H}, \mathrm{dd}, J=1.9,0.8 \mathrm{~Hz}), 6.72(1 \mathrm{H}, \mathrm{ddt}, J=14.2$, 11.0, $1.4 \mathrm{~Hz}), 6.25(1 \mathrm{H}, \mathrm{dd}, J=3.1,1.9 \mathrm{~Hz}), 5.95(1 \mathrm{H}, \mathrm{dq}, J=3.1,0.8 \mathrm{~Hz}), 5.19$ $(1 \mathrm{H}, \mathrm{dt}, J=14.3,7.1 \mathrm{~Hz}), 3.25(1 \mathrm{H}, \mathrm{d}, J=3.7 \mathrm{~Hz}), 2.60(2 \mathrm{H}$, brt, $J=7.5 \mathrm{~Hz}), 2.34$ $(1 \mathrm{H}, \mathrm{qqd}, J=7.9 .6 .9,3.7 \mathrm{~Hz}), 2.04(2 \mathrm{H}, \mathrm{dtd}, J=7.4,7.2,1.3 \mathrm{~Hz}), 1.68-1.58(2 \mathrm{H}$, m), $1.46-1.36(2 \mathrm{H}, \mathrm{m}), 0.98(3 \mathrm{H}, \mathrm{d}, J=7.0 \mathrm{~Hz}), 0.80(3 \mathrm{H}, \mathrm{d}, J=6.9 \mathrm{~Hz})$

${ }^{13}$ C NMR: $\left(75 \mathrm{MHz}, \mathrm{CDCl}_{3}\right)$

$171.5,156.2,140.7,122.2,113.2,110.0,104.7,59.8,30.7,29.5,29.4,27.8,27.5$, $19.7,15.9$

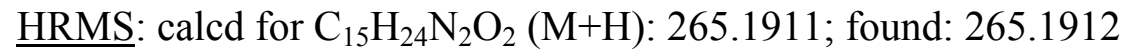

Preparation of $N$-((1E)-6-(2-furyl)hex-1-enyl)(2S)-2-amino-4-methylpentanamide (15)

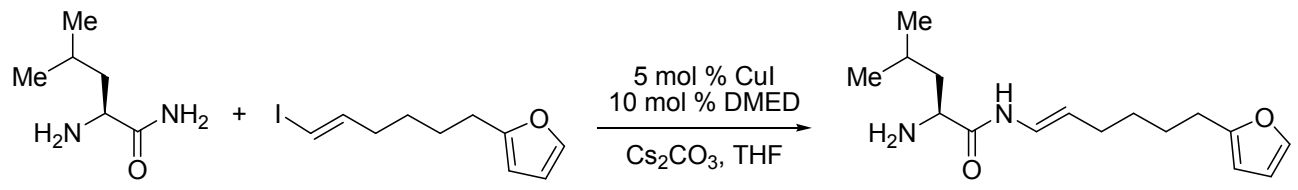

Following General Procedure I, H-Leu-NH $(141 \mathrm{mg}, 1.09 \mathrm{mmol}), 8(0.150 \mathrm{mg}, 0.543$ mmol), $\mathrm{CuI}(5.2 \mathrm{mg}, 27 \mu \mathrm{mol} ; 5 \mathrm{~mol} \%)$, DMED $(6.0 \mu \mathrm{L}, 54 \mu \mathrm{mol})$ and $\mathrm{Cs}_{2} \mathrm{CO}_{3}(265 \mathrm{mg}, 0.815$ mmol) were combined. After $16 \mathrm{~h}$ at $70{ }^{\circ} \mathrm{C}$, the suspension was cooled to $22^{\circ} \mathrm{C}$ then diluted 
with EtOAc $(2 \mathrm{~mL})$ and purified directly by chromatography on silica $\left(9: 1 \mathrm{CH}_{2} \mathrm{Cl}_{2} / \mathrm{MeOH}\right)$ to afford a colorless oil (139 mg, $0.498 \mathrm{mmol}$; 91.7\%).

${ }^{1}$ H NMR: $\left(300 \mathrm{MHz}, \mathrm{CDCl}_{3}\right)$

$8.89(1 \mathrm{H}, \mathrm{brd}, J=9.7 \mathrm{~Hz}), 7.28(1 \mathrm{H}, \mathrm{dd}, J=1.9,0.8 \mathrm{~Hz}), 6.71(1 \mathrm{H}, \mathrm{ddt}, J=14.0$, 11.0, $1.4 \mathrm{~Hz}), 6.26(1 \mathrm{H}, \mathrm{dd}, J=3.1,1.9 \mathrm{~Hz}), 5.96(1 \mathrm{H}, \mathrm{ddq}, J=3.1,1.7,0.9 \mathrm{~Hz})$, $5.20(1 \mathrm{H}, \mathrm{dt}, J=14.3,7.2 \mathrm{~Hz}), 3.41(1 \mathrm{H}, \mathrm{dd}, J=9.9,3.6 \mathrm{~Hz}), 2.61(2 \mathrm{H}, \mathrm{t}, J=7.4$ $\mathrm{Hz}), 2.06(2 \mathrm{H}, \mathrm{qd}, J=7.3,1.4 \mathrm{~Hz}), 1.78-1.59(4 \mathrm{H}, \mathrm{m}), 1.47-1.28(5 \mathrm{H}, \mathrm{m}), 0.96$ $(3 \mathrm{H}, \mathrm{d}, J=6.4 \mathrm{~Hz}), 0.93(3 \mathrm{H}, \mathrm{d}, J=6.2 \mathrm{~Hz})$

${ }^{13} \mathrm{C} \mathrm{NMR}:\left(151 \mathrm{MHz}, \mathrm{CDCl}_{3}\right)$

$172.6,156.3,140.7,122.4,113.2,110.0,104.7,53.2,43.9,29.5,29.4,27.8,27.5$, $24.9,23.4,21.3$

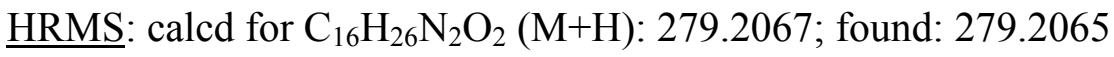

Preparation of $\mathrm{N}$-((1E)-6-(2-furyl)hex-1-enyl)(2S,3S)-2-amino-3-methylpentanamide (16)

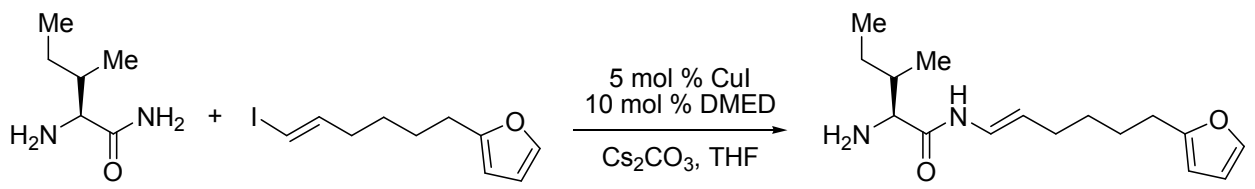

Following General Procedure I, H-Ile- $\mathrm{NH}_{2}(141 \mathrm{mg}, 1.09 \mathrm{mmol}), 8(0.150 \mathrm{mg}, 0.543$ $\mathrm{mmol}), \mathrm{CuI}(5.2 \mathrm{mg}, 27 \mu \mathrm{mol} ; 5 \mathrm{~mol} \%)$, DMED $(6.0 \mu \mathrm{L}, 54 \mu \mathrm{mol})$ and $\mathrm{Cs}_{2} \mathrm{CO}_{3}(265 \mathrm{mg}, 0.815$ mmol) were combined. After $16 \mathrm{~h}$ at $70{ }^{\circ} \mathrm{C}$, the suspension was cooled to $22{ }^{\circ} \mathrm{C}$ then diluted with EtOAc $(2 \mathrm{~mL})$ and purified directly by chromatography on silica $\left(9: 1 \mathrm{CH}_{2} \mathrm{Cl}_{2} / \mathrm{MeOH}\right)$ to afford a colorless oil (139 mg, $0.344 \mathrm{mmol} ; 63.4 \%$ ).

${ }^{1} \mathrm{H}$ NMR: $\left(300 \mathrm{MHz}, \mathrm{CDCl}_{3}\right)$

$8.92(1 \mathrm{H}, \mathrm{brd}, J=10.8 \mathrm{~Hz}), 7.29(1 \mathrm{H}, \mathrm{dd}, J=1.9,0.9 \mathrm{~Hz}), 6.71(1 \mathrm{H}, \mathrm{ddt}, J=14.3$, 11.0, $1.4 \mathrm{~Hz}), 6.25(1 \mathrm{H}, \mathrm{dd}, J=3.1,1.9 \mathrm{~Hz}), 5.95(1 \mathrm{H}, \mathrm{dq}, J=3.1,0.9 \mathrm{~Hz}), 5.18$ $(1 \mathrm{H}, \mathrm{dt}, J=14.3,7.2 \mathrm{~Hz}), 3.29(1 \mathrm{H}, \mathrm{d}, J=3.6 \mathrm{~Hz}), 2.60(2 \mathrm{H}$, brt, $J=7.5 \mathrm{~Hz})$, 2.08-1.98 (3H, m), 1.68-1.58 (2H, m), 1.46-1.27 (5H, m), 1.12-1.00 (1H, m), 0.96 $(3 \mathrm{H}, \mathrm{d}, J=7.0 \mathrm{~Hz}), 0.88(3 \mathrm{H}, \mathrm{dd}, J=7.4,7.2 \mathrm{~Hz})$

${ }^{13} \mathrm{C} \mathrm{NMR}:\left(75 \mathrm{MHz}, \mathrm{CDCl}_{3}\right)$

$171.5,156.2,140.7,122.2,113.1,110.0,104.6,59.6,37.8,29.5,29.4,27.8,27.4$, $23.6,16.2,11.9$

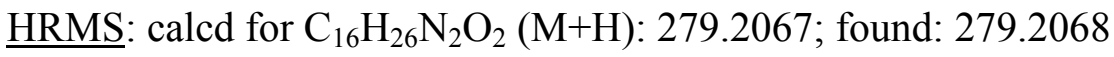

Preparation of $N$-((1E)-6-(2-furyl)hex-1-enyl)(2S)-2-amino-4-methylthiobutanamide (17)

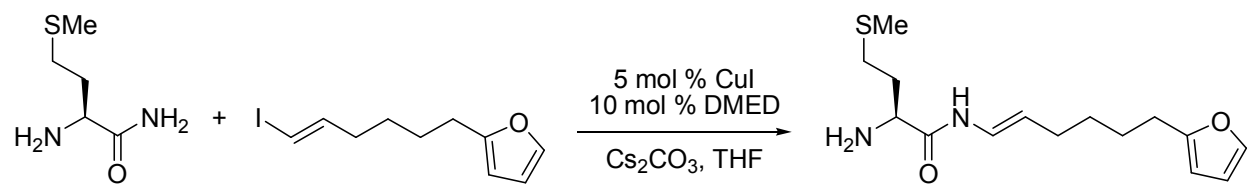

Following General Procedure I, H-Met-NH $\mathrm{NH}_{2}(107 \mathrm{mg}, 0.724 \mathrm{mmol}), 8$ (0.100 mg, 0.362 $\mathrm{mmol}), \mathrm{CuI}(3.4 \mathrm{mg}, 18 \mu \mathrm{mol} ; 5 \mathrm{~mol} \%)$, DMED $(4.0 \mu \mathrm{L}, 36 \mu \mathrm{mol})$ and $\mathrm{Cs}_{2} \mathrm{CO}_{3}(177 \mathrm{mg}, 0.543$ 
mmol) were combined. After $16 \mathrm{~h}$ at $70{ }^{\circ} \mathrm{C}$, the suspension was cooled to $22{ }^{\circ} \mathrm{C}$ then diluted with EtOAc $(2 \mathrm{~mL})$ and purified directly by chromatography on silica $\left(9: 1 \mathrm{CH}_{2} \mathrm{Cl}_{2} / \mathrm{MeOH}\right)$ to afford a white solid (78.9 $\mathrm{mg}, 0.266 \mathrm{mmol} ; 73.5 \%)$.

${ }^{1}$ H NMR: $\left(600 \mathrm{MHz}, \mathrm{CDCl}_{3}\right)$

$8.84(1 \mathrm{H}$, brd, $J=10.5 \mathrm{~Hz}), 7.28(1 \mathrm{H}, \mathrm{dd}, J=1.7,0.8 \mathrm{~Hz}), 6.70(1 \mathrm{H}, \mathrm{ddt}, J=14.2$, 11.0, $1.3 \mathrm{~Hz}), 6.26(1 \mathrm{H}, \mathrm{dd}, J=3.0,1.9 \mathrm{~Hz}), 5.95(1 \mathrm{H}, \mathrm{dd}, J=3.2,0.9 \mathrm{~Hz}), 5.21$ $(1 \mathrm{H}, \mathrm{dt}, J=14.2,7.1 \mathrm{~Hz}), 3.52(1 \mathrm{H}, \mathrm{dd}, J=8.4,4.4 \mathrm{~Hz}), 2.64-2.57(4 \mathrm{H}, \mathrm{m}), 2.21$ $(1 \mathrm{H}, \mathrm{dtd}, J=14.0,8.1,4.6 \mathrm{~Hz}), 2.10(3 \mathrm{H}, \mathrm{s}), 2.06(2 \mathrm{H}, \mathrm{dtd}, J=7.2,7.2,1.2 \mathrm{~Hz})$, $1.79-1.73(1 \mathrm{H}, \mathrm{m}), 1.64(2 \mathrm{H}, \mathrm{tt}, J=7.7,7.5 \mathrm{~Hz}), 1.42(2 \mathrm{H}, \mathrm{tt}, J=7.7,7.5 \mathrm{~Hz})$

${ }^{13} \underline{\mathrm{C} N M R}:\left(75 \mathrm{MHz}, \mathrm{CDCl}_{3}\right)$

$171.5,156.2,140.7,122.0,113.6,110.0,104.7,54.0,33.9,30.7,29.5,29.3,27.8$, $27.5,15.3$

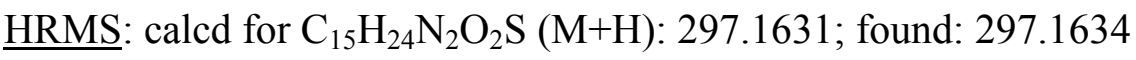

Preparation of $N$-((1E)-6-(2-furyl)hex-1-enyl)(2S)-2-amino-4-carbamoylbutanamide (18)

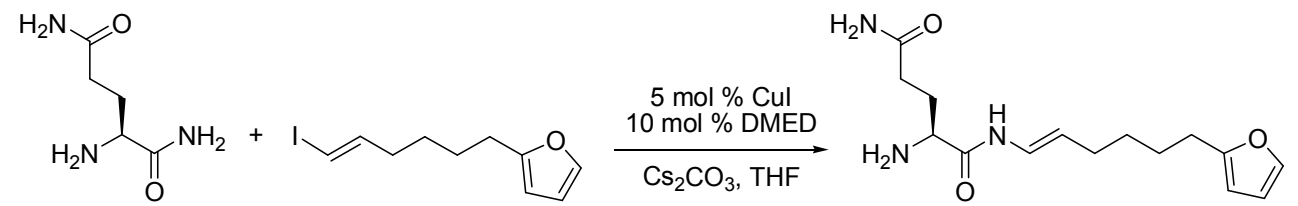

Following General Procedure II, H-Gln- $\mathrm{NH}_{2}$ (145 mg, $\left.1.00 \mathrm{mmol}\right), 8$ (138 mg, 0.500 mmol), $\mathrm{CuI}(4.8 \mathrm{mg}, 25 \mu \mathrm{mol} ; 5 \mathrm{~mol} \%)$, DMED $(5.4 \mu \mathrm{L}, 0.05 \mathrm{mmol})$ and $\mathrm{Cs}_{2} \mathrm{CO}_{3}(244 \mathrm{mg}$, $0.750 \mathrm{mmol}$ ) were combined. After $1 \mathrm{~h}$ at $50{ }^{\circ} \mathrm{C}$, the suspension was cooled to $22{ }^{\circ} \mathrm{C}$, all volatiles removed in vacuo and the residue redissolved in 1:1 $\mathrm{MeCN} / \mathrm{H}_{2} \mathrm{O}(\sim 10 \mathrm{~mL})$. After lyophilization, the crude product mixture was purified by HPLC on a Phenomenex Luca C18 column $(21.2 \times 250 \mathrm{~mm})$ using a $1 \% / \mathrm{min}$ gradient from $5-90 \% \mathrm{MeCN}$ containing $10 \% \mathrm{H}_{2} \mathrm{O}$ and $0.1 \% \mathrm{HCO}_{2} \mathrm{H}$ at $20 \mathrm{~mL} / \mathrm{min}$. The expected product eluting at $18 \mathrm{~min}$ was collected and lyophilized to a white solid $(55.3 \mathrm{mg}, 0.162 \mathrm{mmol} ; 32.6 \%)$. The derived lactam, eluting at 40 min, was also collected and lyophilized to a white solid (7.9 $\mathrm{mg}, 0.029 \mathrm{mmol} ; 5.7 \%)$.

${ }^{1}$ H NMR: (600 MHz, DMSO- $d_{6}$ )

9.90 (1H, brs), 8.33 (1H, brs), $7.47(1 \mathrm{H}, \mathrm{dd}, J=1.8,0.7 \mathrm{~Hz}), 7.33(1 \mathrm{H}, \mathrm{s}), 6.76$ $(1 \mathrm{H}, \mathrm{s}), 6.58(1 \mathrm{H}, \mathrm{d}, J=14.3 \mathrm{~Hz}), 6.32(1 \mathrm{H}, \mathrm{dd}, J=3.1,1.9 \mathrm{~Hz}), 6.06(1 \mathrm{H}, \mathrm{dd}, J=$ 3.1, $0.7 \mathrm{~Hz}), 5.36(3 \mathrm{H}$, brs), $5.26(1 \mathrm{H}, \mathrm{dt}, J=14.3,7.2 \mathrm{~Hz}), 3.38$ (1H, brs), 2.59 $(2 \mathrm{H}, \mathrm{t}, J=7.5 \mathrm{~Hz}), 2.11(2 \mathrm{H}, \mathrm{t}, J=7.8 \mathrm{~Hz}), 2.00(2 \mathrm{H}, \mathrm{q}, J=7.0 \mathrm{~Hz}), 1.86-1.81$ $(1 \mathrm{H}, \mathrm{m}), 1.74-1.68(1 \mathrm{H}, \mathrm{m}), 1.57(2 \mathrm{H}, \mathrm{tt}, J=7.6,7.5 \mathrm{~Hz}), 1.37-1.32(2 \mathrm{H}, \mathrm{m})$

${ }^{13}$ C NMR: (151 MHz, DMSO- $d_{6}$ )

$173.7,170.0,164.8,155.6,141.1,122.8,112.6,110.2,104.9,53.5,31.1,29.2$, $28.9,28.9,27.0$

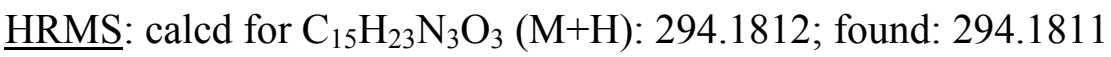




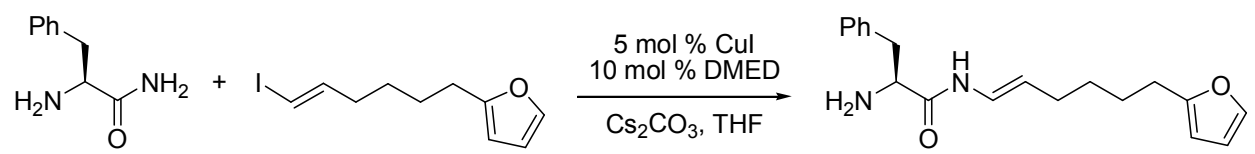

Following General Procedure I, H-Phe- $\mathrm{NH}_{2}(178 \mathrm{mg}, 1.09 \mathrm{mmol}), 8(0.150 \mathrm{mg}, 0.543$ mmol), $\mathrm{CuI}(5.2 \mathrm{mg}, 27 \mu \mathrm{mol} ; 5 \mathrm{~mol} \%)$, DMED $(6.0 \mu \mathrm{L}, 54 \mu \mathrm{mol})$ and $\mathrm{Cs}_{2} \mathrm{CO}_{3}(265 \mathrm{mg}, 0.815$ mmol) were combined. After $16 \mathrm{~h}$ at $70{ }^{\circ} \mathrm{C}$, the suspension was cooled to $22{ }^{\circ} \mathrm{C}$ then diluted with EtOAc $(2 \mathrm{~mL})$ and purified directly by chromatography on silica $\left(9: 1 \mathrm{CH}_{2} \mathrm{Cl}_{2} / \mathrm{MeOH}\right)$ to afford a colorless oil (153 mg, $0.488 \mathrm{mmol} ; 89.9 \%$ ).

${ }^{1} \mathrm{H}$ NMR: $\left(600 \mathrm{MHz}, \mathrm{CDCl}_{3}\right)$

$8.84(1 \mathrm{H}$, brd, $J-10.6 \mathrm{~Hz}), 7.31(2 \mathrm{H}, \mathrm{dd}, J=7.4,7.2 \mathrm{~Hz}), 7.28(1 \mathrm{H}, \mathrm{dd}, J=1.8$, $0.9 \mathrm{~Hz}), 7.26-7.23(1 \mathrm{H}, \mathrm{m}), 7.21(2 \mathrm{H}, \mathrm{brd}, J=7.0 \mathrm{~Hz}), 6.73(1 \mathrm{H}$, ddt, $J=14.3$, $10.9,1.4 \mathrm{~Hz}), 6.26(1 \mathrm{H}, \mathrm{dd}, J=3.0,1.9 \mathrm{~Hz}), 5.96(1 \mathrm{H}, \mathrm{dd}, J=3.2,0.9 \mathrm{~Hz}), 5.18$ $(1 \mathrm{H}, \mathrm{dt}, J=14.4,7.2 \mathrm{~Hz}), 3.62(1 \mathrm{H}, \mathrm{dd}, J=9.7,3.8 \mathrm{~Hz}), 3.30\left(1 \mathrm{H}, \mathbf{A B X}, J_{\mathrm{AB}}=\right.$ $\left.14.0 \mathrm{~Hz}, J_{\mathrm{AX}}=3.8 \mathrm{~Hz}\right), 2.67\left(1 \mathrm{H}, \mathrm{ABX}, J_{\mathrm{AB}}=14.0 \mathrm{~Hz}, J_{\mathrm{BX}}=9.7 \mathrm{~Hz}\right), 2.61(2 \mathrm{H}, \mathrm{t}$, $J=7.5 \mathrm{~Hz}), 2.06(2 \mathrm{H}, \mathrm{dtd}, J=7.2,7.2,1.1 \mathrm{~Hz}), 1.64(2 \mathrm{H}, \mathrm{tt}, J=7.7,7.7 \mathrm{~Hz}), 1.42$ $(2 \mathrm{H}, \mathrm{tt}, J=7.7,7.4 \mathrm{~Hz})$

${ }^{13} \mathrm{C} \mathrm{NMR}:\left(151 \mathrm{MHz}, \mathrm{CDCl}_{3}\right)$

$171.3,156.2,140.7,137.7,129.2,128.7,126.9,122.2,113.7,110.0,104.7,56.1$, $40.8,29.4,29.3,27.8,27.4$

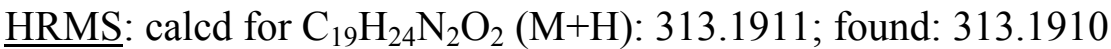

\section{Preparation of $N$-((1E)-6-(2-furyl)hex-1-enyl)(2S)-2-amino-3-(4-hydroxyphenyl)propan- amide (20)}

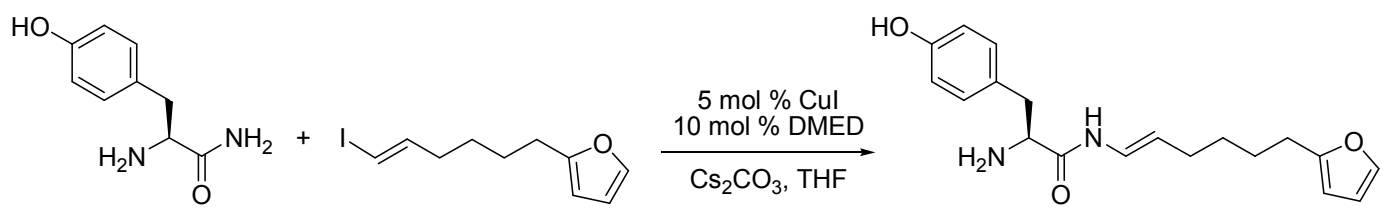

Following General Procedure II, H-Tyr- $\mathrm{NH}_{2}(0.180 \mathrm{~g}, 1.00 \mathrm{mmol}), 8$ (138 mg, 0.500 mmol), $\mathrm{CuI}(4.8 \mathrm{mg}, 25 \mu \mathrm{mol} ; 5 \mathrm{~mol} \%)$, DMED $(5.4 \mu \mathrm{L}, 0.05 \mathrm{mmol})$ and $\mathrm{Cs}_{2} \mathrm{CO}_{3}(244 \mathrm{mg}$, $0.750 \mathrm{mmol}$ ) were combined. After $1 \mathrm{~h}$ at $50{ }^{\circ} \mathrm{C}$, the suspension was cooled to $22{ }^{\circ} \mathrm{C}$ then diluted with EtOAc $(50 \mathrm{~mL})$, washed with saturated aqueous $\mathrm{NaCl}(5 \times 10 \mathrm{~mL})$, dried over $\mathrm{Na}_{2} \mathrm{SO}_{4}$, filtered and concentrated in vacuo. Purification by chromatography on silica (step gradient from 1:1 hexanes/EtOAc to 19:1 $\mathrm{CH}_{2} \mathrm{Cl}_{2} / \mathrm{MeOH}$ to 9:1 $\mathrm{CH}_{2} \mathrm{Cl}_{2} / \mathrm{MeOH}$ ) afforded the expected product $(52.1 \mathrm{mg}, 0.159 \mathrm{mmol} ; 31.7 \%)$ and the individual imidazolidinone diastereomers resulting from condensation with the liberated aldehyde (4.6 mg, $9.7 \mu \mathrm{mol} ; 3.9 \%$ ) and $(8.6 \mathrm{mg}, 18 \mu \mathrm{mol} ; 7.2 \%)$ respectively, all as colorless oils.

${ }^{1} \mathrm{H}$ NMR: $\left(300 \mathrm{MHz}, \mathrm{CDCl}_{3}\right)$

$8.84(1 \mathrm{H}$, brs, $J=11.0 \mathrm{~Hz}), 7.29(1 \mathrm{H}, \mathrm{dd}, J=1.9,0.9 \mathrm{~Hz}), 7.04\left(2 \mathrm{H}, \mathbf{A A}^{\prime}{ }^{\prime} \mathrm{BB} ', J_{\mathrm{AB}}\right.$ $\left.=8.5 \mathrm{~Hz}, J_{\mathrm{AA}}{ }^{\prime}=2.4 \mathrm{~Hz}\right), 6.79\left(2 \mathrm{H}, \mathrm{AA}^{\prime} \mathbf{B B}^{\prime}, J_{\mathrm{AB}}=8.6 \mathrm{~Hz}, J_{\mathrm{BB}}=2.5 \mathrm{~Hz}\right), 6.72$ $(1 \mathrm{H}, \mathrm{ddt}, J=13.8,10.9,1.3 \mathrm{~Hz}), 6.27(1 \mathrm{H}, \mathrm{dd}, J=3.1,1.9 \mathrm{~Hz}), 5.97(1 \mathrm{H}, \mathrm{dq}, J=$ $3.1,0.8 \mathrm{~Hz}), 5.20(1 \mathrm{H}, \mathrm{dt}, J=14.3,7.2 \mathrm{~Hz}), 3.59\left(1 \mathrm{H}, \mathrm{ABX}, J_{\mathrm{AX}}=4.1 \mathrm{~Hz}, J_{\mathrm{BX}}=\right.$ 
$9.3 \mathrm{~Hz}), 3.17\left(1 \mathrm{H}, \mathrm{ABX}, J_{\mathrm{AB}}=13.9 \mathrm{~Hz}, J_{\mathrm{AX}}=4.0 \mathrm{~Hz}\right), 2.67-2.49(3 \mathrm{H}, \mathrm{m}), 2.07$ $(2 \mathrm{H}, \mathrm{dq}, J=7.3,1.3 \mathrm{~Hz}), 1.69-1.59(2 \mathrm{H}, \mathrm{m}), 1.47-1.37(2 \mathrm{H}, \mathrm{m})$

${ }^{13}$ C NMR: $\left(75 \mathrm{MHz}, \mathrm{CDCl}_{3}\right)$

$171.8,156.2,155.1,140.7,130.4,129.0,122.0,115.7,114.3,110.0,104.7,56.2$, $39.9,29.4,29.3,27.8,27.4$

HRMS: calcd for $\mathrm{C}_{19} \mathrm{H}_{24} \mathrm{~N}_{2} \mathrm{O}_{3}(\mathrm{M}+\mathrm{H}): 329.1860$; found: 329.1865

TLC: $R_{f} 0.3$ (silica gel, 9:1 $\mathrm{CH}_{2} \mathrm{Cl}_{2} / \mathrm{MeOH}$, ninhydrin)

$R_{f} 0.5$ (silica gel, 1:1 hexanes/EtOAc, ninhydrin)

$R_{f} 0.4$ (silica gel, 1:1 hexanes/EtOAc, ninhydrin)

Preparation of $\mathrm{N}$-((1E)-6-(2-furyl)hex-1-enyl)(2S)-2-amino-3-indol-3-ylpropanamide (21)
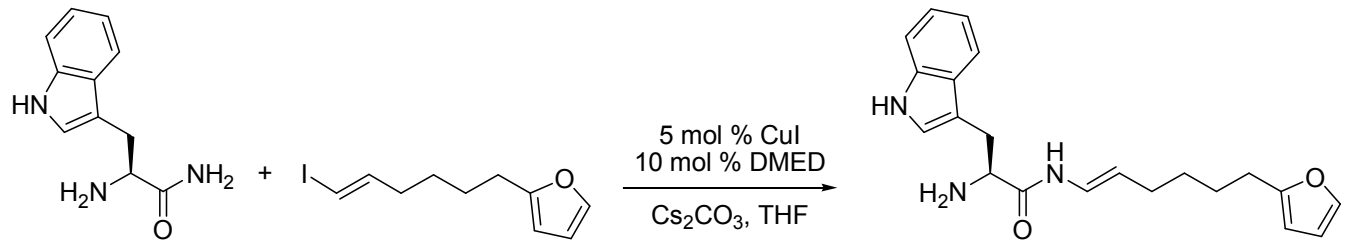

Following General Procedure I, H-Trp- $\mathrm{NH}_{2}$ (147 mg, $\left.0.724 \mathrm{mmol}\right), 8$ (0.100 mg, 0.362 mmol), $\mathrm{CuI}(3.4 \mathrm{mg}, 18 \mu \mathrm{mol} ; 5 \mathrm{~mol} \%)$, DMED $(4.0 \mu \mathrm{L}, 36 \mu \mathrm{mol})$ and $\mathrm{Cs}_{2} \mathrm{CO}_{3}(177 \mathrm{mg}, 0.543$ mmol) were combined. After $16 \mathrm{~h}$ at $70{ }^{\circ} \mathrm{C}$, the suspension was cooled to $22{ }^{\circ} \mathrm{C}$ then diluted with EtOAc $(2 \mathrm{~mL})$ and purified directly by chromatography on silica $\left(9: 1 \mathrm{CH}_{2} \mathrm{Cl}_{2} / \mathrm{MeOH}\right)$ to afford the expected product as a colorless oil $(72.3 \mathrm{mg}, 0.206 \mathrm{mmol} ; 56.8 \%)$ and the dimeric product as a pale yellow oil (20.0 $\mathrm{mg}, 0.040 \mathrm{mmol} ; 22.1 \%)$.

${ }^{1} \mathrm{H}$ NMR: $\left(600 \mathrm{MHz}, \mathrm{CDCl}_{3}\right)$

$8.86(1 \mathrm{H}, \mathrm{brd}, J=10.5 \mathrm{~Hz}), 8.09(1 \mathrm{H}, \mathrm{brs}), 7.67(1 \mathrm{H}, \mathrm{d}, J=7.8 \mathrm{~Hz}), 7.37(1 \mathrm{H}, \mathrm{d}, J$ $=8.3 \mathrm{~Hz}), 729(1 \mathrm{H}, \mathrm{dd}, J=1.8,0.9 \mathrm{~Hz}), 7.22-7.19(1 \mathrm{H}, \mathrm{m}), 7.14-7.12(1 \mathrm{H}, \mathrm{m})$, $7.06(1 \mathrm{H}$, brd, $J=2.0 \mathrm{~Hz}), 6.74(1 \mathrm{H}, \mathrm{ddt}, J=14.3,11.0,1.2 \mathrm{~Hz}), 6.27(1 \mathrm{H}, \mathrm{dd}, J=$ 3.1, $2.0 \mathrm{~Hz}), 5.97(1 \mathrm{H}, \mathrm{dd}, J=3.1,0.9 \mathrm{~Hz}), 5.16(1 \mathrm{H}, \mathrm{dt}, J=14.2,7.2 \mathrm{~Hz}), 3.74$ $(1 \mathrm{H}, \mathrm{dd}, J=9.2,4.0 \mathrm{~Hz}), 3.41\left(1 \mathrm{H}, \mathbf{A B X}, J_{\mathrm{AB}}=14.7 \mathrm{~Hz}, J_{\mathrm{AX}}=4.0 \mathrm{~Hz}\right), 2.92(1 \mathrm{H}$, $\left.\mathrm{ABX}, J_{\mathrm{AB}}=14.6 \mathrm{~Hz} 0, J_{\mathrm{BX}}=9.0 \mathrm{~Hz}\right), 2.61(2 \mathrm{H}, \mathrm{t}, J=7.5 \mathrm{~Hz}), 2.06(2 \mathrm{H}, \mathrm{qd}, J=$ $7.2,1.2 \mathrm{~Hz}), 1.64(2 \mathrm{H}, \mathrm{tt}, J=7.8,7.4 \mathrm{~Hz}), 1.42(2 \mathrm{H}, \mathrm{tt}, J=7.8,7.4 \mathrm{~Hz})$

${ }^{13} \underline{\mathrm{C} \mathrm{NMR}}:\left(151 \mathrm{MHz}, \mathrm{CDCl}_{3}\right)$

$171.8,156.3,140.7,136.4,127.5,123.0,122.4,122.3,119.7,118.9,113.5,111.7$, $111.2,111.0,104.7,55.4,30.5,29.5,29.4,27.8,27.4$

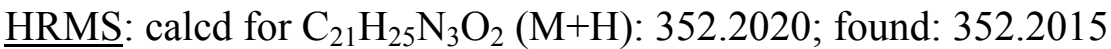

Preparation of (2S)-N-((1Z)-6-(2-furyl)hex-1-enyl)-2-amino-4-methylpentanamide (22)<smiles>CC(C)CC(N)C(N)=O</smiles> 
Following General Procedure I, H-Leu-NH $2(0.130 \mathrm{~g}, 1.00 \mathrm{mmol}), 9$ (138 mg, 0.500 mmol), $\mathrm{CuI}(4.8 \mathrm{mg}, 25 \mu \mathrm{mol} ; 5 \mathrm{~mol} \%)$, DMED $(5.4 \mu \mathrm{L}, 0.05 \mathrm{mmol})$ and $\mathrm{Cs}_{2} \mathrm{CO}_{3}(244 \mathrm{mg}$, $0.750 \mathrm{mmol}$ ) were combined. After $16 \mathrm{~h}$ at $70{ }^{\circ} \mathrm{C}$, the suspension was cooled to $22{ }^{\circ} \mathrm{C}$ then diluted with EtOAc $(2 \mathrm{~mL})$ and purified directly by chromatography on silica (9:1 $\left.\mathrm{CH}_{2} \mathrm{Cl}_{2} / \mathrm{MeOH}\right)$ to afford a colorless oil (70.4 mg, $0.253 \mathrm{mmol} ; 50.6 \%$ ).

${ }^{1} \mathrm{H} \mathrm{NMR}:\left(300 \mathrm{MHz}, \mathrm{CDCl}_{3}\right)$

$9.18(1 \mathrm{H}, \mathrm{brd}, \mathrm{J}=11.1 \mathrm{~Hz}), 7.27(1 \mathrm{H}, \mathrm{dd}, J=1.9,0.9 \mathrm{~Hz}), 6.65(1 \mathrm{H}, \mathrm{ddt}, J=11.4$, 8.9, $1.6 \mathrm{~Hz}), 6.25(1 \mathrm{H}, \mathrm{dd}, J=3.1,1.8 \mathrm{~Hz}), 5.95(1 \mathrm{H}, \mathrm{dq}, J=3.1,0.9 \mathrm{~Hz}), 4.74$ $(1 \mathrm{H}, \mathrm{dt}, J=9.0,7.3 \mathrm{~Hz}), 3.42(1 \mathrm{H}, \mathrm{dd}, J=10.0,3.5 \mathrm{~Hz}), 2.62(2 \mathrm{H}$, brt, $J=7.5 \mathrm{~Hz})$, $2.05(2 \mathrm{H}, \mathrm{dtd}, J=7.3,7.3,1.6 \mathrm{~Hz}), 1.78-1.61(4 \mathrm{H}, \mathrm{m}), 1.50-1.30(5 \mathrm{H}, \mathrm{m}), 0.95$ $(3 \mathrm{H}, \mathrm{d}, J=6.3 \mathrm{~Hz}), 0.92(3 \mathrm{H}, \mathrm{d}, J=6.2 \mathrm{~Hz})$

${ }^{13}$ C NMR: $\left(75 \mathrm{MHz}, \mathrm{CDCl}_{3}\right)$

$172.7,156.1,140.7,120.8,111.2,110.0,104.7,53.3,43.8,28.7,27.7,27.5,25.4$, $24.9,23.4,21.2$

HRMS: calcd for $\mathrm{C}_{16} \mathrm{H}_{26} \mathrm{~N}_{2} \mathrm{O}_{2}(\mathrm{M}+\mathrm{H}): 279.2067$; found: 279.2067

TLC: $R_{f} 0.6$ (silica gel, 9:1 $\mathrm{CH}_{2} \mathrm{Cl}_{2} / \mathrm{MeOH}$, ninhydrin)

Preparation of (2S)-2-amino- $N$-[1-(4-(2-furyl)butyl)vinyl]-4-methylpentanamide (23)

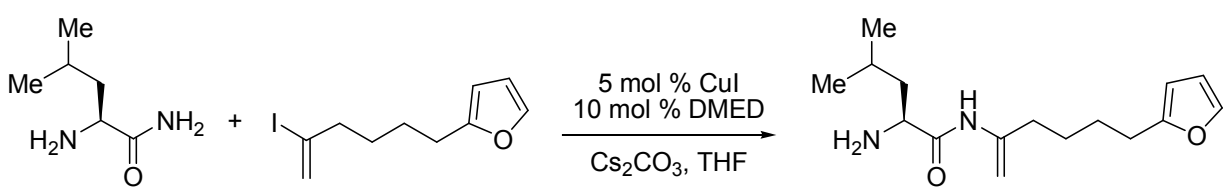

Following General Procedure I, H-Leu-NH 2 (76.4 mg, $0.587 \mathrm{mmol}), 10$ (81.0 mg, 0.293 mmol), $\mathrm{CuI}(2.8 \mathrm{mg}, 15 \mu \mathrm{mol} ; 5 \mathrm{~mol} \%)$, DMED $(3.2 \mu \mathrm{L}, 0.03 \mathrm{mmol})$ and $\mathrm{Cs}_{2} \mathrm{CO}_{3}(143 \mathrm{mg}$, $0.440 \mathrm{mmol})$ were combined in THF $(587 \mu \mathrm{L})$. After $16 \mathrm{~h}$ at $70{ }^{\circ} \mathrm{C}$, the suspension was cooled to $22{ }^{\circ} \mathrm{C}$ then diluted with EtOAc $(2 \mathrm{~mL})$ and purified directly by chromatography on silica (EtOAc) to afford the expected product $(19.5 \mathrm{mg}, 0.070 \mathrm{mmol} ; 19.5 \%)$ and the individual imidazolidinone diastereomers (10.9 $\mathrm{mg}, 0.039 \mathrm{mmol} ; 13.3 \%)$ and $(12.0 \mathrm{mg}, 0.043 \mathrm{mmol}$; $14.7 \%)$ respectively, all as colorless oils.

${ }^{1} \mathrm{H}$ NMR: $\left(600 \mathrm{MHz}, \mathrm{CDCl}_{3}\right)$

$8.73(1 \mathrm{H}, \mathrm{brs}), 7.29$ (1H, dd, $J=1.8,0.8 \mathrm{~Hz}), 6.27(1 \mathrm{H}, \mathrm{dd}, J=3.1,1.9 \mathrm{~Hz}), 5.98$ $(1 \mathrm{H}, \mathrm{dd}, J=3.1,0.8 \mathrm{~Hz}), 5.59(1 \mathrm{H}, \mathrm{s}), 4.49(1 \mathrm{H}, \mathrm{s}), 3.39(1 \mathrm{H}, \mathrm{dd}, J=9.9,3.6 \mathrm{~Hz})$, $2.65(2 \mathrm{H}, \mathrm{t}, J=7.4 \mathrm{~Hz}), 2.20(2 \mathrm{H}, \mathrm{dd}, J=7.6,7.5 \mathrm{~Hz}), 1.78-1.72(2 \mathrm{H}, \mathrm{m}), 1.71-$ $1.66(2 \mathrm{H}, \mathrm{m}), 1.57-1.52(2 \mathrm{H}, \mathrm{m}), 1.39-1.32(1 \mathrm{H}, \mathrm{m}), 0.98(3 \mathrm{H}, \mathrm{d}, J=6.4 \mathrm{~Hz}), 0.94$ $(3 \mathrm{H}, \mathrm{d}, J=6.2 \mathrm{~Hz})$

${ }^{13} \mathrm{C} \mathrm{NMR}:\left(151 \mathrm{MHz}, \mathrm{CDCl}_{3}\right)$

$174.0,156.0,140.7,140.6,110.1,105.7,98.1,54.0,43.9,35.5,27.7,27.3,27.0$, $25.0,23.4,21.3$

HRMS: calcd for $\mathrm{C}_{16} \mathrm{H}_{26} \mathrm{~N}_{2} \mathrm{O}_{2}(\mathrm{M}+\mathrm{H}): 279.2067$; found: 279.2067

TLC: $R_{f} 0.4$ (silica gel, 9:1 $\mathrm{CH}_{2} \mathrm{Cl}_{2} / \mathrm{MeOH}$, ninhydrin) 
$R_{f} 0.4$ (silica gel, EtOAc, ninhydrin)

$R_{f} 0.2$ (silica gel, EtOAc, ninhydrin)

Preparation of (2S)- $\mathrm{N}$-((1Z)-6-(2-furyl)-1-methylhex-1-enyl)-2-amino-4-methylpentanamide (24)

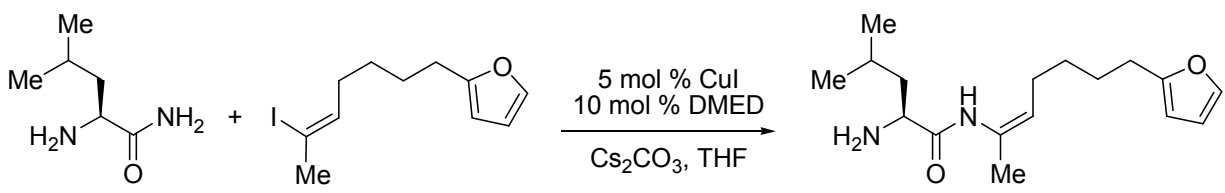

Following General Procedure I, H-Leu-NH $\mathrm{NH}_{2}(0.100 \mathrm{~g}, 0.772 \mathrm{mmol}), 11$ (112 mg, 0.386 $\mathrm{mmol})$, $\mathrm{CuI}(3.7 \mathrm{mg}, 19 \mu \mathrm{mol} ; 5 \mathrm{~mol} \%)$, DMED $(4.2 \mu \mathrm{L}, 0.04 \mathrm{mmol})$ and $\mathrm{Cs}_{2} \mathrm{CO}_{3}(189 \mathrm{mg}$, $0.579 \mathrm{mmol})$ were combined in THF $(770 \mu \mathrm{L})$. After $16 \mathrm{~h}$ at $70{ }^{\circ} \mathrm{C}$, the suspension was cooled to $22{ }^{\circ} \mathrm{C}$ then diluted with EtOAc $(2 \mathrm{~mL})$ and purified directly by chromatography on silica $(9: 1$ $\mathrm{CH}_{2} \mathrm{Cl}_{2} / \mathrm{MeOH}$ ) to afford a colorless oil (47.7 mg, $0.163 \mathrm{mmol} ; 42.3 \%$ ).

${ }^{1}$ H NMR: $\left(300 \mathrm{MHz}, \mathrm{CDCl}_{3}\right)$

8.79 (1H, brs), $7.27(1 \mathrm{H}, \mathrm{dd}, J=1.9,0.9 \mathrm{~Hz}), 6.25(1 \mathrm{H}, \mathrm{dd}, J=3.1,1.9 \mathrm{~Hz}), 5.95$ $(1 \mathrm{H}, \mathrm{dq}, J=3.1,0.9 \mathrm{~Hz}), 4.76(1 \mathrm{H}, \mathrm{brs}, J=7.1 \mathrm{~Hz}), 3.38(1 \mathrm{H}, \mathrm{dd}, J=9.8,3.6 \mathrm{~Hz})$, $2.60(2 \mathrm{H}$, brt, $J=7.3 \mathrm{~Hz}), 2.05(3 \mathrm{H}, \mathrm{q}, J=1.3 \mathrm{~Hz}), 1.98(2 \mathrm{H}$, brq, $J=7.4 \mathrm{~Hz})$, $1.75-1.58(4 \mathrm{H}, \mathrm{m}), 1.46-1.32(4 \mathrm{H}, \mathrm{m}), 0.96(3 \mathrm{H}, \mathrm{d}, J=6.4 \mathrm{~Hz}), 0.93(3 \mathrm{H}, \mathrm{d}, J=6.2$ $\mathrm{Hz}$ )

${ }^{13}$ C NMR: $\left(75 \mathrm{MHz}, \mathrm{CDCl}_{3}\right)$

$173.3,156.2,140.6,131.5,116.8,110.0,104.6,54.0,44.1,28.7,27.7,27.6,26.2$, $25.0,23.4,21.3,21.0$

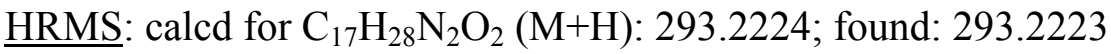

TLC: $R_{f} 0.5$ (silica gel, 9:1 $\mathrm{CH}_{2} \mathrm{Cl}_{2} / \mathrm{MeOH}$, ninhydrin)

\section{Synthesis of vinyl iodides}

\section{Preparation of $E-4$-iodooct-4-ene ${ }^{5}$}

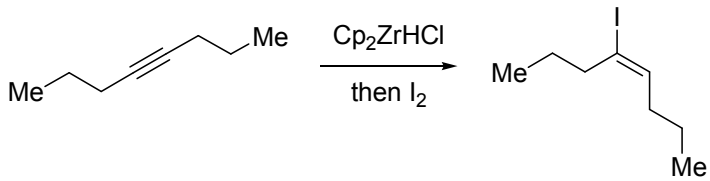

A suspension of $\mathrm{Cp}_{2} \mathrm{ZrHCl}(15.5 \mathrm{~g}, 60.0 \mathrm{mmol})$ in $\mathrm{CH}_{2} \mathrm{Cl}_{2}(250 \mathrm{~mL})$ was treated with 4octyne $(7.34 \mathrm{~mL}, 50.0 \mathrm{mmol})$ dropwise over $5 \mathrm{~min}$ at $22^{\circ} \mathrm{C}$. During the next several hours, the suspension became homogeneous and red-orange in color. After $13.5 \mathrm{~h}$, the now pale yellow solution was cooled to $0{ }^{\circ} \mathrm{C}$ and treated with $\mathrm{I}_{2}(14.0 \mathrm{~g}, 55.0 \mathrm{mmol})$ in one portion. Upon complete dissolution, the ice bath was removed and the solution warmed to $22^{\circ} \mathrm{C}$. After $1 \mathrm{~h}$, the solution was poured into $1 \mathrm{M} \mathrm{HCl}(200 \mathrm{~mL})$ containing $\sim 50 \mathrm{~g}$ ice and the resulting biphase vigorously stirred $0.5 \mathrm{~h}$. The layers were then separated and the aqueous layer washed with $\mathrm{CH}_{2} \mathrm{Cl}_{2}(3 \times 75 \mathrm{~mL})$. The combined $\mathrm{CH}_{2} \mathrm{Cl}_{2}$ layers were washed with saturated aqueous $\mathrm{Na}_{2} \mathrm{~S}_{2} \mathrm{O}_{3}$ and $\mathrm{NaCl}\left(200 \mathrm{~mL}\right.$ each), then dried over $\mathrm{MgSO}_{4}$, filtered and concentrated in vacuo. The crude 
product was purified by chromatography on silica (hexanes) to obtain a pale yellow oil (6.57 $\mathrm{g}$, $27.6 \mathrm{mmol} ; 55.2 \%)$.

${ }^{1} \mathrm{H}$ NMR: $\left(600 \mathrm{MHz}, \mathrm{CDCl}_{3}\right)$

$6.20(1 \mathrm{H}, \mathrm{t}, J=7.5 \mathrm{~Hz}), 2.35(2 \mathrm{H}, \mathrm{t}, J=7.2 \mathrm{~Hz}), 2.03(2 \mathrm{H}, \mathrm{q}, J=7.4 \mathrm{~Hz}), 1.56-$ $1.49(2 \mathrm{H}, \mathrm{m}), 1.42-1.36(2 \mathrm{H}, \mathrm{m}), 0.91(3 \mathrm{H}, \mathrm{t}, J=7.4 \mathrm{~Hz}), 0.91(3 \mathrm{H}, \mathrm{t}, J=7.4 \mathrm{~Hz})$

${ }^{13} \underline{\mathrm{C} \mathrm{NMR}}:\left(151 \mathrm{MHz}, \mathrm{CDCl}_{3}\right)$

$141.5,103.4,40.3,32.9,22.4,22.3,13.6,12.8$

TLC: $R_{f} 0.8$ (silica gel, pentane, uv)

Preparation of $Z$-4-iodooct-4-ene ${ }^{6}$

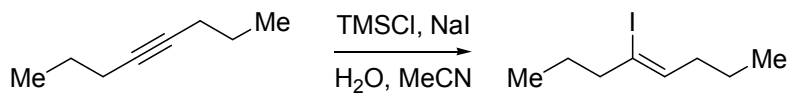

TMSI was prepared in situ through the addition of TMSCl $(3.04 \mathrm{~mL}, 24.0 \mathrm{mmol})$ to a solution of $\mathrm{NaI}(3.60 \mathrm{~g}, 24.0 \mathrm{mmol})$ in $\mathrm{MeCN}(40.0 \mathrm{~mL})$ at $22{ }^{\circ} \mathrm{C}$. The resulting suspension was then treated with $\mathrm{H}_{2} \mathrm{O}(216 \mu \mathrm{L}, 12.0 \mathrm{mmol})$ and, after $10 \mathrm{~min}$, 4-octyne $(2.93 \mathrm{~mL}, 20.0 \mathrm{mmol})$ at a rate of $0.5 \mathrm{~mL} / \mathrm{min}$. The reaction mixture became homogeneous and dark yellow in color during the addition. After $1 \mathrm{~h}$, the solution was diluted with $\mathrm{H}_{2} \mathrm{O}(20 \mathrm{~mL})$, and the resulting redorange biphase washed with $\mathrm{Et}_{2} \mathrm{O}(3 \times 60 \mathrm{~mL})$. The combined $\mathrm{Et}_{2} \mathrm{O}$ layers were washed with saturated aqueous $\mathrm{Na}_{2} \mathrm{~S}_{2} \mathrm{O}_{3}(3 \times 30 \mathrm{~mL})$, then dried over $\mathrm{MgSO}_{4}$, filtered and concentrated in vacuo. Purification by chromatography on silica (hexanes) afforded a colorless oil (2.50 g, 10.5 mmol; 52.5\%).

${ }^{1} \mathrm{H}$ NMR: $\left(300 \mathrm{MHz}, \mathrm{CDCl}_{3}\right)$

$5.47(1 \mathrm{H}, \mathrm{tt}, J=6.7,1.2 \mathrm{~Hz}), 2.46-2.41(2 \mathrm{H}, \mathrm{m}), 2.13-2.06(2 \mathrm{H}, \mathrm{m}), 1.60-1.49(2 \mathrm{H}$, m), $1.47-1.37(2 \mathrm{H}, \mathrm{m}), 0.93(3 \mathrm{H}, \mathrm{t}, J=7.4 \mathrm{~Hz}), 0.88(3 \mathrm{H}, \mathrm{t}, J=7.4 \mathrm{~Hz})$

${ }^{13} \underline{\mathrm{C} \mathrm{NMR}}:\left(75 \mathrm{MHz}, \mathrm{CDCl}_{3}\right)$

$134.8,109.6,47.1,38.4,22.5,21.7,13.7,12.6$

TLC: $R_{f} 0.8$ (silica gel, pentane, uv)

Preparation of 5-(2-furyl)pentan-1-ol

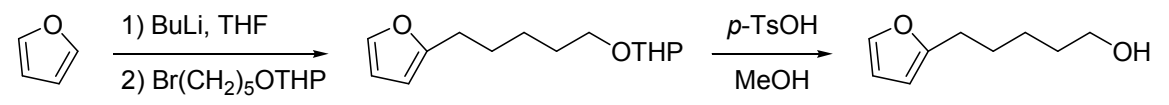

BuLi (302 mmol; $121 \mathrm{~mL}$ of a $2.50 \mathrm{M}$ solution in hexanes) was added dropwise over 0.5 $\mathrm{h}$ to a solution of furan $(27.0 \mathrm{~mL}, 371 \mathrm{mmol})$ in THF $(530 \mathrm{~mL})$ at $0{ }^{\circ} \mathrm{C}$. After $1 \mathrm{~h}$, the pale yellow solution was treated with 2-(5-bromopentyloxy)tetrahydro- $2 \mathrm{H}$-pyran ${ }^{7}$ (25.3 g, $\left.101 \mathrm{mmol}\right)$ at a rate of $1 \mathrm{~mL} / \mathrm{min}$ and the resulting mixture warmed slowly to $22{ }^{\circ} \mathrm{C}$ as the ice bath melted overnight. After $16 \mathrm{~h}$ the solution was treated with saturated aqueous $\mathrm{NH}_{4} \mathrm{Cl}(300 \mathrm{~mL})$ with transfer to a separatory funnel and the layers separated. The aqueous layer was then washed with $\mathrm{Et}_{2} \mathrm{O}(3 \times 250 \mathrm{~mL})$ and the combined $\mathrm{THF}$ and $\mathrm{Et}_{2} \mathrm{O}$ layers dried over $\mathrm{MgSO}_{4}$, filtered and concentrated in vacuo. Purification by chromatography on silica using a gradient from 19:1 to 
4:1 pentane/ $\mathrm{Et}_{2} \mathrm{O}\left(R_{f}=0.5\right.$ in $9: 1$ pentane/ $\left.\mathrm{Et}_{2} \mathrm{O}\right)$ afforded a colorless oil $(21.6 \mathrm{~g}, 90.6 \mathrm{mmol}$; $90.0 \%$ ) that was used directly in the subsequent deprotection step.

A solution of the THP ether $(20.0 \mathrm{~g}, 83.9 \mathrm{mmol})$ in wet $\mathrm{MeOH}(168 \mathrm{~mL})$ was treated with p-TsOH (1.60 g, $8.39 \mathrm{mmol} ; 10 \mathrm{~mol} \%)$ in one portion at $22{ }^{\circ} \mathrm{C}$. After $5 \mathrm{~h}$, all volatiles were removed in vacuo and the residue loaded directly onto a silica gel column previously prepared in 4:1 pentane/ $\mathrm{Et}_{2} \mathrm{O}$. A 4:1 to $1: 4$ pentane $/ \mathrm{Et}_{2} \mathrm{O}$ step gradient was then utilized to elute the product as a colorless oil $(10.2 \mathrm{~g}, 66.1 \mathrm{mmol} ; 78.8 \%)$. Spectroscopic data were consistent with a published report. ${ }^{8}$

\section{Preparation of 5-(2-furyl)pentanal}

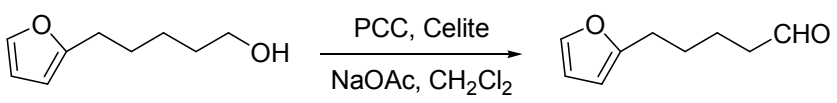

A suspension of PCC (25.9 g, $0.120 \mathrm{~mol}), \mathrm{NaOAc}(984 \mathrm{mg}, 12.0 \mathrm{mmol})$ and Celite $(5 \mathrm{~g})$ in $\mathrm{CH}_{2} \mathrm{Cl}_{2}(280.0 \mathrm{~mL})$ at $22{ }^{\circ} \mathrm{C}$ was treated with 5-(2-furyl)pentan-1-ol $(60.0 \mathrm{mmol} ; 15.0 \mathrm{~mL}$ of a $4.00 \mathrm{M}$ solution in $\left.\mathrm{CH}_{2} \mathrm{Cl}_{2}\right)$ at a rate of $1 \mathrm{~mL} / \mathrm{min}$. Additional $\mathrm{CH}_{2} \mathrm{Cl}_{2}(5 \mathrm{x} 1 \mathrm{~mL})$ was used to quantitate the transfer and the resulting brown slurry stirred $1.5 \mathrm{~h}$. The suspension was diluted with $\mathrm{Et}_{2} \mathrm{O}(300 \mathrm{~mL})$, vigorously stirred $0.5 \mathrm{~h}$ then filtered through Florisil. The filter cake was exhaustively washed with $\mathrm{Et}_{2} \mathrm{O}$ and the combined filtrates concentrated in vacuo. Purification by chromatography on silica (9:1 to $4: 1$ pentane/ $\mathrm{Et}_{2} \mathrm{O}$ gradient) afforded a foul-smelling, colorless oil (6.07 g, 39.9 mmol; 66.5\%).

${ }^{1}$ H NMR: $\left(600 \mathrm{MHz}, \mathrm{CDCl}_{3}\right)$

$9.74(1 \mathrm{H}, \mathrm{t}, J=1.8 \mathrm{~Hz}), 7.28(1 \mathrm{H}, \mathrm{dd}, J=1.8,0.8 \mathrm{~Hz}), 6.26(1 \mathrm{H}, \mathrm{dd}, J=3.1,1.8$ $\mathrm{Hz}), 5.97(1 \mathrm{H}, \mathrm{dd}, J=3.1,0.8 \mathrm{~Hz}), 2.65-2.63(2 \mathrm{H}, \mathrm{m}), 2.45-2.42(2 \mathrm{H}, \mathrm{m}), 1.68-$ $1.66(4 \mathrm{H}, \mathrm{m})$

${ }^{13}$ C NMR: (151 MHz, $\left.\mathrm{CDCl}_{3}\right)$

202.2, 155.5, 140.8, 110.1, 104.9, 43.5, 27.6, 27.5, 21.5

TLC: $R_{f} 0.4$ (silica gel, 4:1 pentane $/ \mathrm{Et}_{2} \mathrm{O}, \mathrm{KMnO}_{4}$ )

Preparation of 2-(6,6-dibromohex-5-enyl)furan

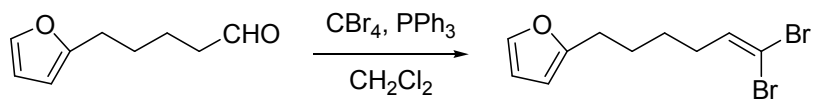

A solution of $\mathrm{PPh}_{3}(34.5 \mathrm{~g}, 131 \mathrm{mmol})$ in $\mathrm{CH}_{2} \mathrm{Cl}_{2}(200.0 \mathrm{~mL})$ was cooled to $0{ }^{\circ} \mathrm{C}$ and treated with $\mathrm{CBr}_{4}(21.8 \mathrm{~g}, 65.7 \mathrm{mmol})$ in one portion. Using a cannula, a solution of 5-(2furyl)pentanal $(5.00 \mathrm{~g}, 32.9 \mathrm{mmol})$ in $\mathrm{CH}_{2} \mathrm{Cl}_{2}(100.0 \mathrm{~mL})$ was then added over $0.75 \mathrm{~h}$ with additional $\mathrm{CH}_{2} \mathrm{Cl}_{2}(3 \times 10 \mathrm{~mL})$ used to quantitate the transfer. Complete conversion was noted within $5 \mathrm{~min}$. The red-orange solution was then poured into pentane $(300 \mathrm{~mL})$ with vigorous stirring and the resulting suspension filtered through Celite. The filter cake was washed with pentane $(3 \times 150 \mathrm{~mL})$ and the combined filtrates concentrated in vacuo. Purification by chromatography on silica (pentane) afforded a colorless oil $(9.24 \mathrm{~g}, 30.0 \mathrm{mmol} ; 91.3 \%)$.

${ }^{1} \mathrm{H} \mathrm{NMR}:\left(300 \mathrm{MHz}, \mathrm{CDCl}_{3}\right)$ 
$7.29(1 \mathrm{H}, \mathrm{dd}, J=1.9,0.9 \mathrm{~Hz}), 6.37(1 \mathrm{H}, \mathrm{t}, J=7.3 \mathrm{~Hz}), 6.27(1 \mathrm{H}, \mathrm{ddt}, J=3.2,1.9$, $0.3 \mathrm{~Hz}), 5.98(1 \mathrm{H}, \mathrm{dq}, J=3.2,0.9 \mathrm{~Hz}), 2.63(2 \mathrm{H}, \mathrm{brt}, J=7.3 \mathrm{~Hz}), 2.12(2 \mathrm{H}, \mathrm{dt}, J=$ 7.3, $7.3 \mathrm{~Hz}), 1.72-1.62(2 \mathrm{H}, \mathrm{m}), 1.52-1.42(2 \mathrm{H}, \mathrm{m})$

${ }^{13}$ C NMR: $\left(75 \mathrm{MHz}, \mathrm{CDCl}_{3}\right)$

$155.8,140.8,138.4,110.1,104.9,88.9,32.7,27.6,27.4,27.2$

TLC: $R_{f} 0.8$ (silica gel, 4:1 pentane $/ \mathrm{Et}_{2} \mathrm{O}, \mathrm{KMnO}_{4}$ )

\section{Preparation of 2-hex-5-ynylfuran}

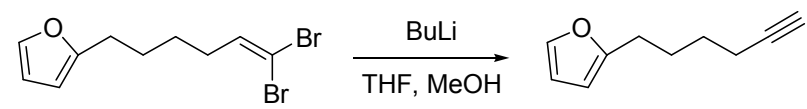

2-(6,6-dibromohex-5-enyl)furan (6.88 g, $22.3 \mathrm{mmol})$ was dissolved in THF (112 $\mathrm{mL})$, cooled to $-78^{\circ} \mathrm{C}$ and treated with BuLi $(46.9 \mathrm{mmol} ; 22.3 \mathrm{~mL}$ of a $2.10 \mathrm{M}$ solution in hexanes) at a rate of $1 \mathrm{~mL} / \mathrm{min}$. Upon completion of the addition, the solution was warmed to $-20{ }^{\circ} \mathrm{C}$, maintained $0.75 \mathrm{~h}$, then cooled back to $-78^{\circ} \mathrm{C}$ and treated with $\mathrm{MeOH}(1.81 \mathrm{~mL}, 44.7 \mathrm{mmol})$. The resulting solution was warmed immediately back to $22{ }^{\circ} \mathrm{C}$, stirred $0.75 \mathrm{~h}$, then poured into saturated aqueous $\mathrm{NH}_{4} \mathrm{Cl}(300 \mathrm{~mL})$. The layers were separated and the aqueous layers washed with $\mathrm{Et}_{2} \mathrm{O}(4 \mathrm{x} 150 \mathrm{~mL})$. The combined $\mathrm{THF}$ and $\mathrm{Et}_{2} \mathrm{O}$ layers were dried over $\mathrm{MgSO}_{4}$, filtered and concentrated to a pale yellow oil. NOTE: compound is volatile and care should be taken during solvent removal operations. Subsequent purification by chromatography on silica (pentane) afforded a colorless oil (3.30 g, $22.3 \mathrm{mmol} ;>98 \%)$.

${ }^{1}$ H NMR: $\left(600 \mathrm{MHz}, \mathrm{CDCl}_{3}\right)$

$7.29(1 \mathrm{H}, \mathrm{dd}, J=1.8,0.8 \mathrm{~Hz}), 6.27(1 \mathrm{H}, \mathrm{dd}, J=3.1,1.8 \mathrm{~Hz}), 5.98(1 \mathrm{H}, \mathrm{dd}, J=3.1$, $0.8 \mathrm{~Hz}), 2.64(2 \mathrm{H}, \mathrm{t}, J=7.6 \mathrm{~Hz}), 2.21(2 \mathrm{H}, \mathrm{td}, J=7.0,2.6 \mathrm{~Hz}), 1.94(1 \mathrm{H}, \mathrm{t}, J=2.7$ $\mathrm{Hz}), 1.79-1.73$ (2H, m), 1.60-1.55 (2H, m)

${ }^{13} \underline{\mathrm{C} \mathrm{NMR}}:\left(151 \mathrm{MHz}, \mathrm{CDCl}_{3}\right)$

$155.9,140.8,110.0,104.8,84.2,68.4,27.9,27.4,27.1,18.2$

\section{Alternative preparation of 2-hex-5-ynylfuran}

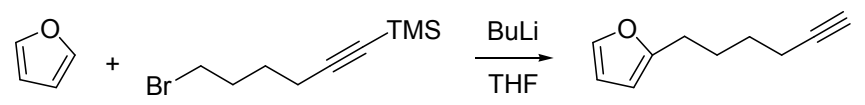

BuLi (75.0 mmol; $31.2 \mathrm{~mL}$ of a $2.40 \mathrm{M}$ solution in hexanes) was added dropwise at 1 $\mathrm{mL} / \mathrm{min}$ to a solution of furan $(6.36 \mathrm{~mL}, 87.5 \mathrm{mmol})$ in THF $(125 \mathrm{~mL})$ at $0{ }^{\circ} \mathrm{C}$. After $1 \mathrm{~h}$, the pale yellow solution was treated with 8-bromo-2,2-dimethyl-2-silaoct-3-yne ${ }^{9}$ (5.83 g, $25.0 \mathrm{mmol}$ ) at a rate of $0.5 \mathrm{~mL} / \mathrm{min}$ and the resulting mixture warmed slowly to $22{ }^{\circ} \mathrm{C}$ as the ice bath melted overnight. After $18 \mathrm{~h}$ the yellow-orange solution was treated with saturated aqueous $\mathrm{NH}_{4} \mathrm{Cl}(100$ $\mathrm{mL}$ ) with transfer to a separatory funnel and the layers separated. The aqueous layer was then washed with $\mathrm{Et}_{2} \mathrm{O}(3 \times 100 \mathrm{~mL})$ and the combined $\mathrm{THF}$ and $\mathrm{Et}_{2} \mathrm{O}$ layers washed with saturated aqueous $\mathrm{NaCl}(100 \mathrm{~mL})$, then dried over $\mathrm{MgSO}_{4}$, filtered and concentrated in vacuo. Purification by chromatography on silica (pentane) afforded a colorless oil (2.57 g, $17.3 \mathrm{mmol} ; 69.4 \%)$.

Preparation of 2-((5E)-6-iodohex-5-enyl)furan (8) 


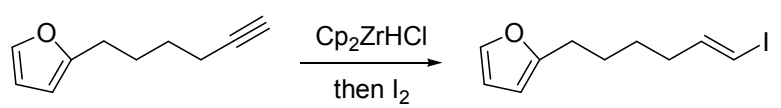

2-Hex-5-ynylfuran (1.96 g, $13.2 \mathrm{mmol})$ was dissolved in $\mathrm{CH}_{2} \mathrm{Cl}_{2}(53.0 \mathrm{~mL})$, cooled to 0 ${ }^{\circ} \mathrm{C}$, then treated with $\mathrm{Cp}_{2} \mathrm{ZrHCl}(5.12 \mathrm{~g}, 19.8 \mathrm{mmol})$ in one portion. The resulting suspension was warmed to $22{ }^{\circ} \mathrm{C}$, maintained $0.75 \mathrm{~h}$, then cooled back to $0{ }^{\circ} \mathrm{C}$ and treated with $\mathrm{I}_{2}(19.8$ $\mathrm{mmol} ; 5.00 \mathrm{M}$ solution in THF) at a rate of $1 \mathrm{~mL} / \mathrm{min}$. The red-orange reaction mixture was stirred $0.25 \mathrm{~h}$ then treated with $5 \%$ aqueous $\mathrm{NaHCO}_{3}$ until gas evolution was complete $(\sim 10 \mathrm{~mL})$. The $\mathrm{CH}_{2} \mathrm{Cl}_{2}$ solution was then transferred to a separatory funnel and washed with saturated aqueous $\mathrm{NaHCO}_{3}(3 \times 10 \mathrm{~mL})$; any solids which form can be removed by filtration through Celite. The combined aqueous layers were further washed with pentane $(3 \mathrm{x} 10 \mathrm{~mL})$ then discarded. The $\mathrm{CH}_{2} \mathrm{Cl}_{2}$ and pentane solutions were combined, dried over $\mathrm{MgSO}_{4}$, filtered and concentrated in vacuo to an orange oil. Purification by chromatography on silica (pentane) afforded a pale pink oil that was decolorized by passage through a short pad of Florisil to yield a colorless oil (2.23 g, $8.08 \mathrm{mmol} ; 61.1 \%)$.

${ }^{1} \mathrm{H}$ NMR: $\left(600 \mathrm{MHz}, \mathrm{CDCl}_{3}\right)$

$7.29(1 \mathrm{H}, \mathrm{dd}, J=1.8,0.8 \mathrm{~Hz}), 6.50(1 \mathrm{H}, \mathrm{dt}, J=14.3,7.3 \mathrm{~Hz}), 6.27(1 \mathrm{H}, \mathrm{dd}, J=$ $3.1,1.9 \mathrm{~Hz}), 5.99(1 \mathrm{H}, \mathrm{dt}, J=14.3,1.4 \mathrm{~Hz}), 5.96(1 \mathrm{H}, \mathrm{dd}, J=3.1,0.7 \mathrm{~Hz}), 2.61$ $(2 \mathrm{H}, \mathrm{t}, J=7.4 \mathrm{~Hz}), 2.08(2 \mathrm{H}, \mathrm{dtd}, J=7.4,7.3,1.3 \mathrm{~Hz}), 1.64(2 \mathrm{H}, \mathrm{tt}, J=7.6,7.6$ $\mathrm{Hz}), 1.44(2 \mathrm{H}, \mathrm{tt}, J=7.6,7.4 \mathrm{~Hz})$

${ }^{13} \mathrm{C} \mathrm{NMR}:\left(151 \mathrm{MHz}, \mathrm{CDCl}_{3}\right)$

$155.9,146.3,140.8,110.0,104.8,74.6,35.7,27.8,27.7,27.3$

TLC: $R_{f} 0.4$ (silica gel, pentane, $\mathrm{KMnO}_{4}$ )

\section{Preparation of 2-((5Z)-6-iodohex-5-enyl)furan (9) ${ }^{10}$}

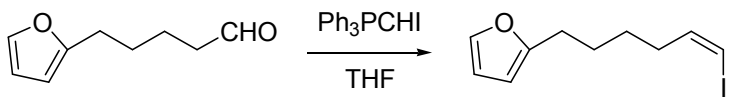

A suspension of $\left[\mathrm{Ph}_{3} \mathrm{PCH}_{2} \mathrm{I}\right] \mathrm{I}^{11}(1.99 \mathrm{~g}, 3.75 \mathrm{mmol})$ in THF $(15.0 \mathrm{~mL})$ was treated with NaHMDS (3.50 mmol; $3.50 \mathrm{~mL}$ of a $1.00 \mathrm{M}$ solution in THF) at $22{ }^{\circ} \mathrm{C}$. After nearly complete dissolution, the orange reaction mixture was cooled to $-78{ }^{\circ} \mathrm{C}$ and treated with DMPU $(2.26 \mathrm{~mL}$, $18.7 \mathrm{mmol})$. After $10 \mathrm{~min}$, a solution of 5-(2-furyl)pentanal $(381 \mathrm{mg}, 2.50 \mathrm{mmol})$ in THF $(7.00$ $\mathrm{mL}$ ) was added over $0.25 \mathrm{~h}$ using a cannula. Additional THF $(3 \times 1.00 \mathrm{~mL})$ was used to quantitate the transfer and the resulting suspension maintained at $-78{ }^{\circ} \mathrm{C}$ for $0.5 \mathrm{~h}$. The cooling bath was then removed and the reaction mixture warmed to $22{ }^{\circ} \mathrm{C}$ during the next $0.5 \mathrm{~h}$. The suspension was poured into hexanes $(150 \mathrm{~mL})$, stirred vigorously for $5 \mathrm{~min}$ then filtered through Celite. The filter cake was washed with hexanes $(3 \times 25 \mathrm{~mL})$, and the combined filtrates transferred to a separatory funnel and washed with saturated aqueous $\mathrm{NH}_{4} \mathrm{Cl}(2 \times 25 \mathrm{~mL})$ followed by saturated aqueous $\mathrm{NaCl}(25 \mathrm{~mL})$, then dried over $\mathrm{MgSO}_{4}$, filtered and concentrated in vacuo. Purification by chromatography on silica (pentane) afforded a colorless oil (466 mg, $1.69 \mathrm{mmol} 67.5 \%)$. The $Z: E$ ratio was determined by ${ }^{1} \mathrm{H}$ NMR to be $13: 1$.

${ }^{1} \mathrm{H}$ NMR: $\left(600 \mathrm{MHz}, \mathrm{CDCl}_{3}\right)$ 
7.29 (1H, brs), $6.27(1 \mathrm{H}, \mathrm{dd}, J=3.1,1.8 \mathrm{~Hz}), 6.20(1 \mathrm{H}, \mathrm{dt}, J=7.2,1.0 \mathrm{~Hz}), 6.16$ $(1 \mathrm{H}, \mathrm{td}, J=6.9,6.7 \mathrm{~Hz}), 5.98(1 \mathrm{H}, \mathrm{dd}, J=3.1,0.8 \mathrm{~Hz}), 2.64(2 \mathrm{H}, \mathrm{t}, J=7.6 \mathrm{~Hz})$, $2.17(2 \mathrm{H}, \mathrm{dtd}, J=7.4,7.4,1.0 \mathrm{~Hz}), 1.68(2 \mathrm{H}, \mathrm{tt}, J=7.7,7.7 \mathrm{~Hz}), 1.48(2 \mathrm{H}, \mathrm{tt}, J=$ $7.7,7.4 \mathrm{~Hz})$

${ }^{13} \mathrm{C} \mathrm{NMR}:\left(151 \mathrm{MHz}, \mathrm{CDCl}_{3}\right)$

$156.1,141.0,140.7,110.0,104.8,82.5,34.4,27.8,27.5,27.4$

TLC: $R_{f} 0.9$ (silica gel, $4: 1$ pentane $/ \mathrm{Et}_{2} \mathrm{O}, \mathrm{CAM}$ )

Preparation of 2-(5-iodohex-5-enyl)furan (10) ${ }^{12}$

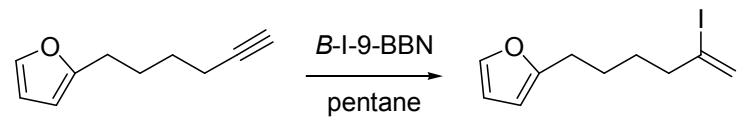

$B$-I-9-BBN (10.8 mmol; $10.8 \mathrm{~mL}$ of a $1.0 \mathrm{M}$ solution in hexanes) was diluted with pentane $(60.0 \mathrm{~mL})$, cooled to $0{ }^{\circ} \mathrm{C}$ then treated with 2-hex-5-ynylfuran $(1.33 \mathrm{~g}, 9.00 \mathrm{mmol})$ dropwise over $5 \mathrm{~min}$. The purple solution became red-brown in color during the addition. After $1 \mathrm{~h}$, the mixture was treated with glacial $\mathrm{AcOH}(6.00 \mathrm{~mL})$, maintained at $0{ }^{\circ} \mathrm{C}$ for $0.5 \mathrm{~h}$, then treated with $\mathrm{H}_{2} \mathrm{O}(84 \mathrm{~mL})$. The resulting biphase was warmed to $22{ }^{\circ} \mathrm{C}$, stirred vigorously for 0.5 $\mathrm{h}$ then separated. The aqueous layer was then washed with hexanes $(3 \times 50 \mathrm{~mL})$. The combined hexanes washes were further washed with $\mathrm{H}_{2} \mathrm{O}$, saturated aqueous $\mathrm{NaHCO}_{3}$ and $\mathrm{Na}_{2} \mathrm{~S}_{2} \mathrm{O}_{3}$ and finally $\mathrm{H}_{2} \mathrm{O}\left(50 \mathrm{~mL}\right.$ each), then dried over $\mathrm{MgSO}_{4}$, filtered and concentrated in vacuo. Purification by chromatography on silica (hexanes) afforded a colorless oil (764 mg, $2.77 \mathrm{mmol}$; $30.7 \%)$.

${ }^{1}$ H NMR: $\left(600 \mathrm{MHz}, \mathrm{CDCl}_{3}\right)$

$7.30(1 \mathrm{H}, \mathrm{dd}, J=1.8,0.8 \mathrm{~Hz}), 6.28(1 \mathrm{H}, \mathrm{dd}, J=3.1,1.9 \mathrm{~Hz}), 6.02(1 \mathrm{H}, \mathrm{q}, J=1.4$ $\mathrm{Hz}), 5.99(1 \mathrm{H}, \mathrm{dq}, J=3.1,0.9 \mathrm{~Hz}), 5.69(1 \mathrm{H}, \mathrm{dt}, J=1.4,0.6 \mathrm{~Hz}), 2.65(2 \mathrm{H}, \mathrm{t}, J=$ $7.4 \mathrm{~Hz}), 2.41(2 \mathrm{H}, \mathrm{td}, J=7.4,1.2 \mathrm{~Hz}), 1.68-1.62(2 \mathrm{H}, \mathrm{m}), 1.60-1.54(2 \mathrm{H}, \mathrm{m})$

${ }^{13} \underline{\mathrm{C} \mathrm{NMR}}:\left(151 \mathrm{MHz}, \mathrm{CDCl}_{3}\right)$

$156.0,140.8,125.5,112.1,110.1,104.8,45.0,28.5,27.7,26.6$

TLC: $R_{f} 0.3$ (silica gel, hexanes, $\mathrm{KMnO}_{4}$ )

\section{Preparation of 2-((5Z)-6-iodohept-5-enyl)furan (11) ${ }^{13}$}

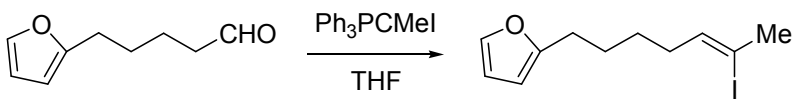

A solution of $\mathrm{I}_{2}(673 \mathrm{mg}, 2.65 \mathrm{mmol})$ in $\mathrm{THF}(22.0 \mathrm{~mL})$ was cooled to $-78{ }^{\circ} \mathrm{C}$ then set aside. A suspension of [ $\left.\mathrm{Ph}_{3} \mathrm{PEt}\right] \mathrm{I}(1.25 \mathrm{~g}, 3.00 \mathrm{mmol})$ in THF $(15.0 \mathrm{~mL})$ was treated with BuLi (3.00 mmol; $2.12 \mathrm{~mL}$ of a $1.42 \mathrm{M}$ solution in THF) at $22{ }^{\circ} \mathrm{C}$. Following complete dissolution, the red-orange reaction mixture was then transferred to the iodine solution over 25 min using a cannula. The now light yellow solution was stirred $5 \mathrm{~min}$, then warmed to $-20{ }^{\circ} \mathrm{C}$ and treated with NaHMDS (2.55 mmol; $2.55 \mathrm{~mL}$ of a $1.00 \mathrm{M}$ solution in THF). The now homogeneous redorange solution was then treated with 5-(2-furyl)pentanal $(381 \mathrm{mg}, 2.50 \mathrm{mmol})$ dropwise over 5

min; the solution became heterogeneous during the addition with formation of a yellow-brown 
precipitate. After $10 \mathrm{~min}$, the suspension was poured into pentane $(150 \mathrm{~mL})$, stirred vigorously for $5 \mathrm{~min}$ then filtered through Celite. The filter cake was washed with hexanes $(5 \times 10 \mathrm{~mL})$, and the combined filtrates transferred to a separatory funnel and washed with saturated aqueous $\mathrm{NH}_{4} \mathrm{Cl}$ and $\mathrm{NaCl}$ (25 mL each), then dried over $\mathrm{MgSO}_{4}$, filtered and concentrated in vacuo. Purification by chromatography on silica (pentane) afforded a colorless oil (256 mg, $0.882 \mathrm{mmol}$ $35.3 \%$ ). The $Z: E$ ratio was determined by ${ }^{1} \mathrm{H}$ NMR to be $>25: 1$.

${ }^{1}$ H NMR: $\left(600 \mathrm{MHz}, \mathrm{CDCl}_{3}\right)$

$7.29(1 \mathrm{H}, \mathrm{dd}, J=1.9,0.9 \mathrm{~Hz}), 6.27(1 \mathrm{H}, \mathrm{dd}, J=3.3,2.1 \mathrm{~Hz}), 5.98(1 \mathrm{H}, \mathrm{dq}, J=3.1$, $0.8 \mathrm{~Hz}), 5.39(1 \mathrm{H}, \mathrm{tq}, J=6.8,1.5 \mathrm{~Hz}), 2.63(2 \mathrm{H}, \mathrm{brt}, J=7.6 \mathrm{~Hz}), 2.48(3 \mathrm{H}, \mathrm{q}, J=$ $1.4 \mathrm{~Hz}), 2.13-2.09(2 \mathrm{H}, \mathrm{m}), 1.67(2 \mathrm{H}, \mathrm{tt}, J=7.4,7.4 \mathrm{~Hz}), 1.44(2 \mathrm{H}, \mathrm{tt}, J=7.4,7.4$ $\mathrm{Hz})$

${ }^{13} \underline{\mathrm{C} N M R}:\left(151 \mathrm{MHz}, \mathrm{CDCl}_{3}\right)$

$156.2,140.7,135.1,110.0,104.7,101.1,36.3,33.5,27.8,27.8,27.5$

TLC: $R_{f} 0.8$ (silica gel, 9:1 pentane/Et ${ }_{2} \mathrm{O}, \mathrm{CAM}$ )

\section{Determination of HI addition stereochemistry}

In order to establish the stereochemistry of HI addition to acetylenes in the method of Kamiya, we performed a series of labeling experiments with 1-octyne. Our benchmark reaction was the haloboronation method of Suzuki, ${ }^{11}$ who reported similar labeling studies to establish the addition stereochemistry. For purposes of comparison, each labeling experiment was run alongside the protio variant such that a direct overlay of spectroscopic data could be performed; see stacked spectra at the end of the supporting information. The levels of incorporation we obtained were consistent with related studies reported in the literature. ${ }^{14}$ It should also be noted that ${ }^{1} \mathrm{H}$ NMR analysis of the crude material was consistent with the purified products shown; spectroscopic data was also consistent with published reports. ${ }^{15}$ Based on these results, we reason the discrepancy in stereochemical assignment derives from the fact that in terminal vinyl iodides, the proton cis to the iodine atom resides upfield of the corresponding trans proton; a phenomenon opposite to that observed for internal derivatives.

\section{Preparation of $Z$-1-deuterio-2-iodooct-1-ene ${ }^{11}$}

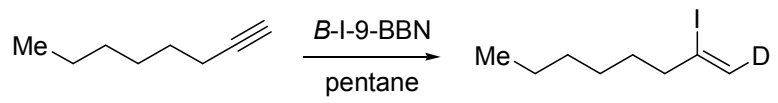

$B$-I-9-BBN (1.80 mmol; $1.80 \mathrm{~mL}$ of a $1.0 \mathrm{M}$ solution in hexanes) was diluted with pentane $(10.0 \mathrm{~mL})$, cooled to $0{ }^{\circ} \mathrm{C}$ then treated with 1-octyne $(222 \mu \mathrm{L}, 1.50 \mathrm{mmol})$ dropwise over 5 min. The purple solution became yellow-orange and cloudy during the addition; within 20 min, the solution cleared After $1 \mathrm{~h}$, the mixture was treated with glacial $\mathrm{CD}_{3} \mathrm{CO}_{2} \mathrm{D}(1.00 \mathrm{~mL})$, maintained at $0{ }^{\circ} \mathrm{C}$ for $0.5 \mathrm{~h}$, then treated $3 \mathrm{M} \mathrm{NaOH}(12 \mathrm{~mL})$ and $30 \% \mathrm{H}_{2} \mathrm{O}_{2}(2 \mathrm{~mL})$. The resulting biphase was warmed to $22{ }^{\circ} \mathrm{C}$, stirred vigorously for $0.5 \mathrm{~h}$ then separated. The aqueous layer was then washed with hexanes $(3 \times 30 \mathrm{~mL})$. The combined hexanes washes were further washed with $\mathrm{H}_{2} \mathrm{O}$, saturated aqueous $\mathrm{NaHCO}_{3}$ and $\mathrm{H}_{2} \mathrm{O}\left(30 \mathrm{~mL}\right.$ each), then dried over $\mathrm{MgSO}_{4}$, filtered and concentrated in vacuo. Purification by distillation under reduced pressure and chromatography on silica ( $R_{f} 0.8$ in hexanes) afforded a colorless oil $(0.190 \mathrm{~g}, 0.793 \mathrm{mmol}$; $52.9 \%)$. 
Preparation of $E$-1-deuterio-2-iodooct-1-ene ${ }^{5}$

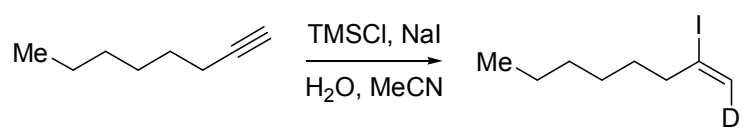

TMSI was prepared in situ through the addition of TMSCl $(759 \mu \mathrm{L}, 6.00 \mathrm{mmol})$ to a solution of $\mathrm{NaI}(899 \mathrm{mg}, 6.00 \mathrm{mmol})$ in $\mathrm{MeCN}-d_{3}(10.0 \mathrm{~mL})$ at $22{ }^{\circ} \mathrm{C}$. The resulting opaque solution was then treated with $\mathrm{D}_{2} \mathrm{O}(54 \mu \mathrm{L}, 3.00 \mathrm{mmol})$ and, after $10 \mathrm{~min}, 1$-octyne $(739 \mu \mathrm{L}, 5.00$ $\mathrm{mmol}$ ) at a rate of $0.5 \mathrm{~mL} / \mathrm{min}$. The reaction mixture became homogeneous and dark yellow in color during the addition. After $1 \mathrm{~h}$, the solution was diluted with $\mathrm{H}_{2} \mathrm{O}(5 \mathrm{~mL})$, and the resulting red-orange biphase washed with pentane $(3 \times 15 \mathrm{~mL})$. The combined pentane layers were washed with saturated aqueous $\mathrm{Na}_{2} \mathrm{~S}_{2} \mathrm{O}_{3}$ and $\mathrm{NaCl}\left(15 \mathrm{~mL}\right.$ each), then dried over $\mathrm{MgSO}_{4}$, filtered and concentrated in vacuo. Purification by chromatography on silica (hexanes) afforded a colorless oil (442 mg, $1.85 \mathrm{mmol} ; 37.0 \%$ ).

\section{Determination of aminopeptidase activity}

Test substrates $(0.0376 \mu \mathrm{mol} ; 8.0 \mathrm{mM}$ solution in DMSO) were diluted into $0.5 \mathrm{~mL}$ micro-centrifuge tubes containing buffer (50 mM Hepes/pH 7.5, $10 \mathrm{mM} \mathrm{CaCl}_{2}, 1 \%$ Brij), then treated with APM $(0.2 \mathrm{U} / \mathrm{mL}$ buffer; Roche Applied Science) to a final reaction volume of 75 $\mu \mathrm{L}$. The solution was mixed, and immediately $30 \mu \mathrm{L}$ transferred to an HPLC vial containing 15 $\mu \mathrm{L}$ of $\mathrm{MeCN}$ for $\mathrm{t}=0$ measurement. The remaining reaction solution was incubated at $37^{\circ} \mathrm{C}$ for $25 \mathrm{~min} ; 30 \mu \mathrm{L}$ was again transferred to an HPLC vial containing $15 \mu \mathrm{L}$ of $\mathrm{MeCN}$ for $\mathrm{t}=25$ measurement. This process was repeated for $0,6.5 \times 10^{-4}$ and $1.5 \times 10^{-3} \mathrm{U}$ enzyme respectively; each run was performed in duplicate. The test substrates and products were analyzed by reverse phase HPLC on a Phenomenex Luna C18 column (4.6 x $150 \mathrm{~mm}, 5 \mu \mathrm{m})$ using $0.1 \%$ $\mathrm{HCO}_{2} \mathrm{H} / \mathrm{MeCN}$ gradient with UV detection at $220 \mathrm{~nm}$. The change in substrate peak area was used to determine rate constant $\mathrm{k}$ from the following equation:

$$
\mathrm{k}=\{(\% \text { hydrolyzed } / 100) *[\mathrm{~S}]\} /[\mathrm{E}] *[\text { time }]
$$

Where: $\mathrm{S}=$ test substrate concentration in $\mu \mathrm{mol}$

$\mathrm{E}=\mathrm{APN}$ concentration in $\mathrm{U} / \mathrm{mL}$

$\mathrm{k}=\mu \mathrm{mol}$ substrate hydrolyzed/minute $/ \mathrm{U}$ 


\section{References}

1. Substrates (and standards) were prepared for chiral analysis using a three-step digestion $\left(\mathrm{DCl} / \mathrm{D}_{2} \mathrm{O}, 110{ }^{\circ} \mathrm{C}, 16-18 \mathrm{~h}\right)$, esterification $\left(\mathrm{DCl} / \mathrm{MeOH}, 90{ }^{\circ} \mathrm{C}, 0.5 \mathrm{~h}\right)$ and protection $\left(\left(\mathrm{CF}_{3} \mathrm{CO}\right)_{2} \mathrm{O} / \mathrm{CF}_{3} \mathrm{CO}_{2} \mathrm{Et}, 130{ }^{\circ} \mathrm{C}, 10 \mathrm{~min}\right)$ sequence.

2. For a convenient preparation of protected amino amide derivatives, see: Pozdnev, A. F. Tetrahedron Lett. 1995, 36, 7115

3. A general text covering the techniques described herein is available: Armarego, W. L. F.; Perrin, D. D. Purification of Laboratory Chemicals, 4th ed.; Butterworth-Heinemann: Oxford, U. K., 1998.

4. Suffert, J. J. Org. Chem. 1989, 54, 509

5. Heffron, T. P.; Trenkle, J. D.; Jamison, T. D. Tetrahedron, 2003, 59, 8913

6. Kamiya, N.; Chikami, Y.; Ishii, Y. Synlett, 1990, 11, 675

7. (a) Bestmann, H. J.; Gunawardena, N. E. Synthesis, 1992, 12, 1239 (b) Baldwin, S. W.; Wilson, J. D.; Aube, J. J. Org. Chem. 1985, 50, 4432

8. Foehlisch, B.; Herter, R. Chem Ber, 1984, 117, 2580

9. Schaus, S. E.; Branalt, J.; Jocobsen, E. N. J. Org. Chem. 1998, 63, 4875

10. Adapted from the method of Stork and Zhao: Tetrahedron Lett. 1989, 30, 2173

11. Conway, J. C.; Qualye, P.; Regan, A. C.; Urch, C. J. Tetrahedron, 2005, 61, 11910

12. Hara, S.; Dojo, H.; Takinami, S.; Suzuki, A. Tetrahedron Lett. 1983, 24, 731

13. Chen, J.; Wang, T.; Zhao, K. Tetrahedron Lett. 1994, 35, 2827

14. Kurosu, M.; Lin, M. -H.; Kishi, Y. J. Am. Chem. Soc. 2004, 126, 12248

15. (a) Hudrlick, P. F.; Kulkarni, A. K.; Jain, S.; Kudrlick, A. M. Tetrahedron 1983, 39, 877.

(b) Kropp, P. J.; Crawford, S. D. J. Org. Chem. 1994, 59, 3102 and references therein. 


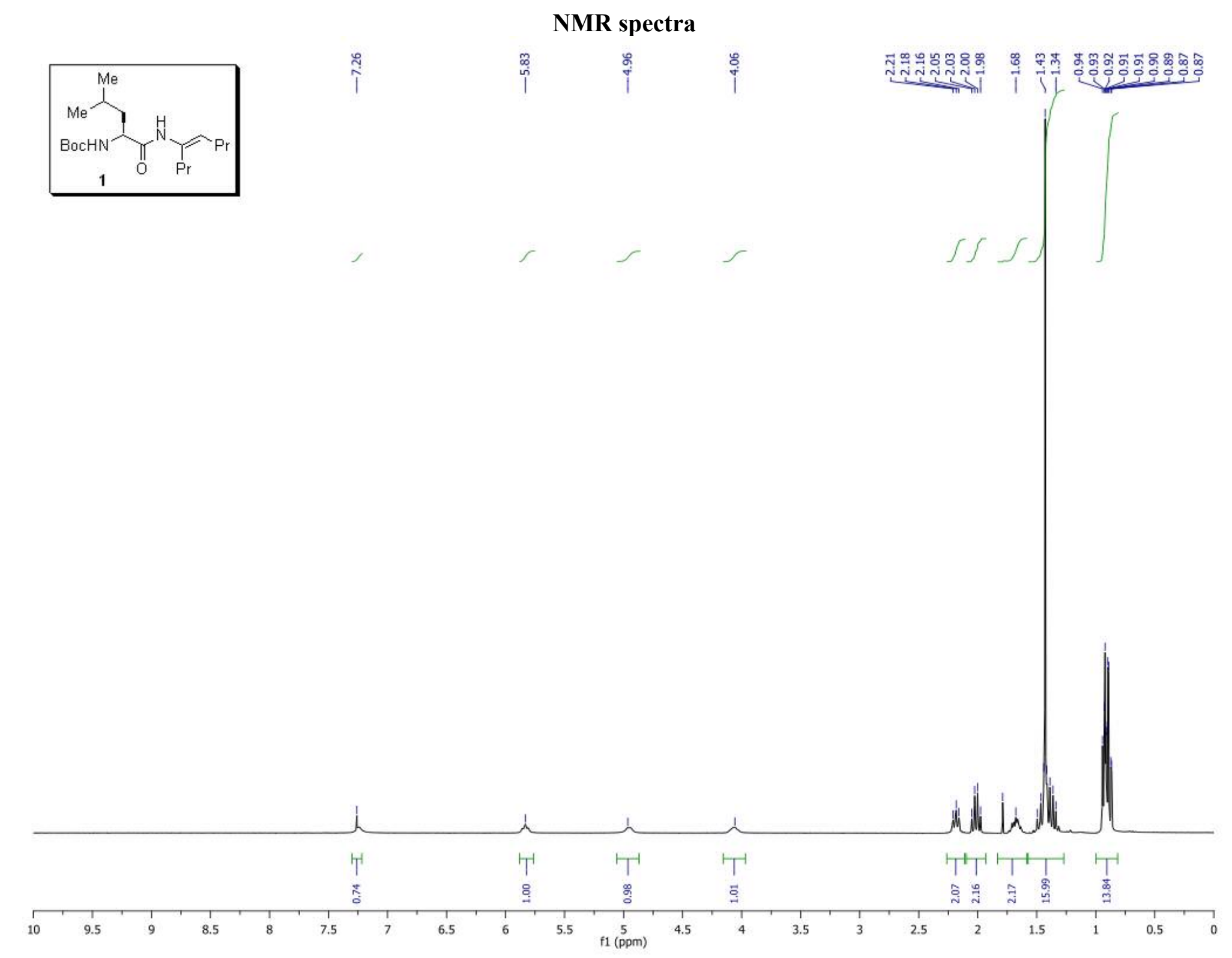




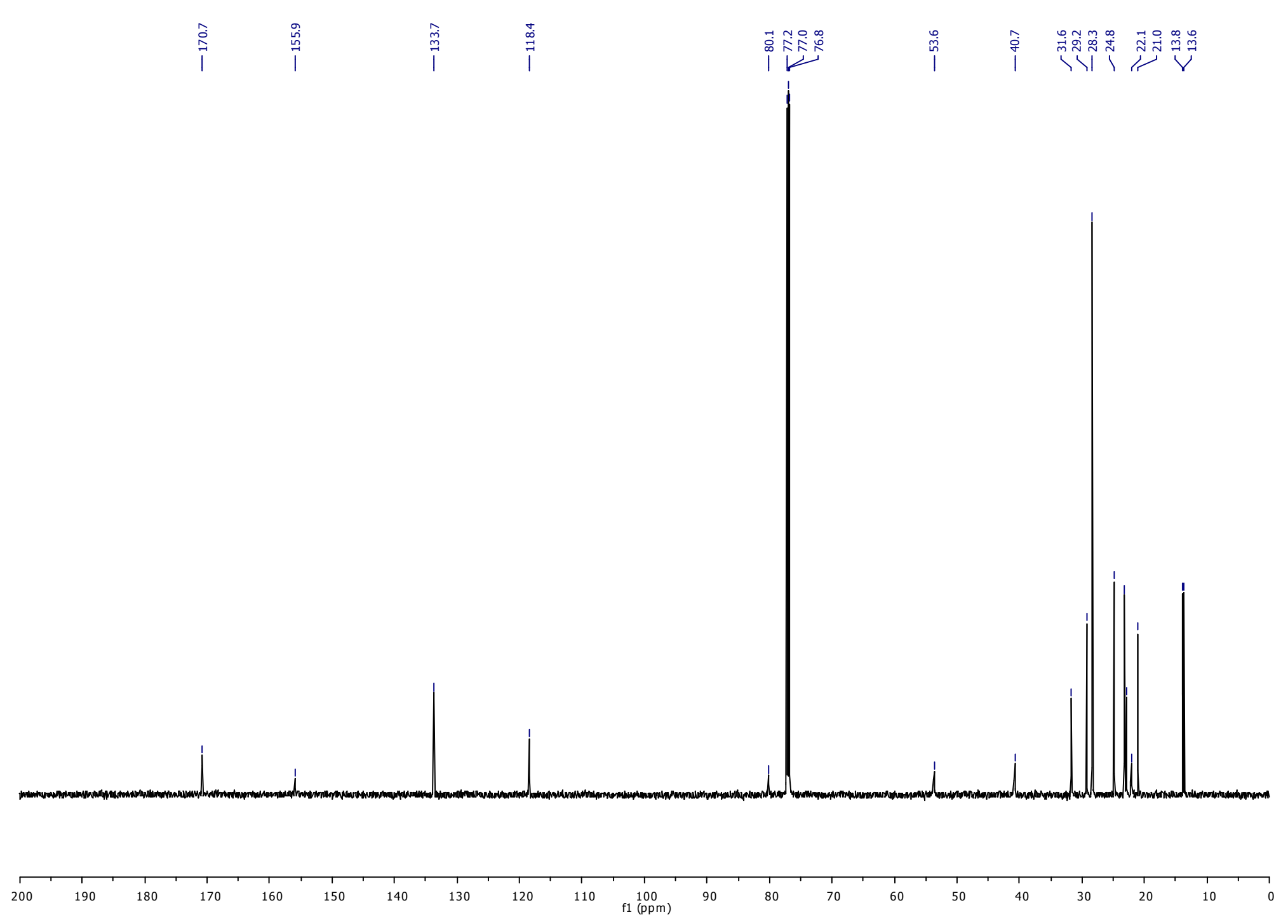




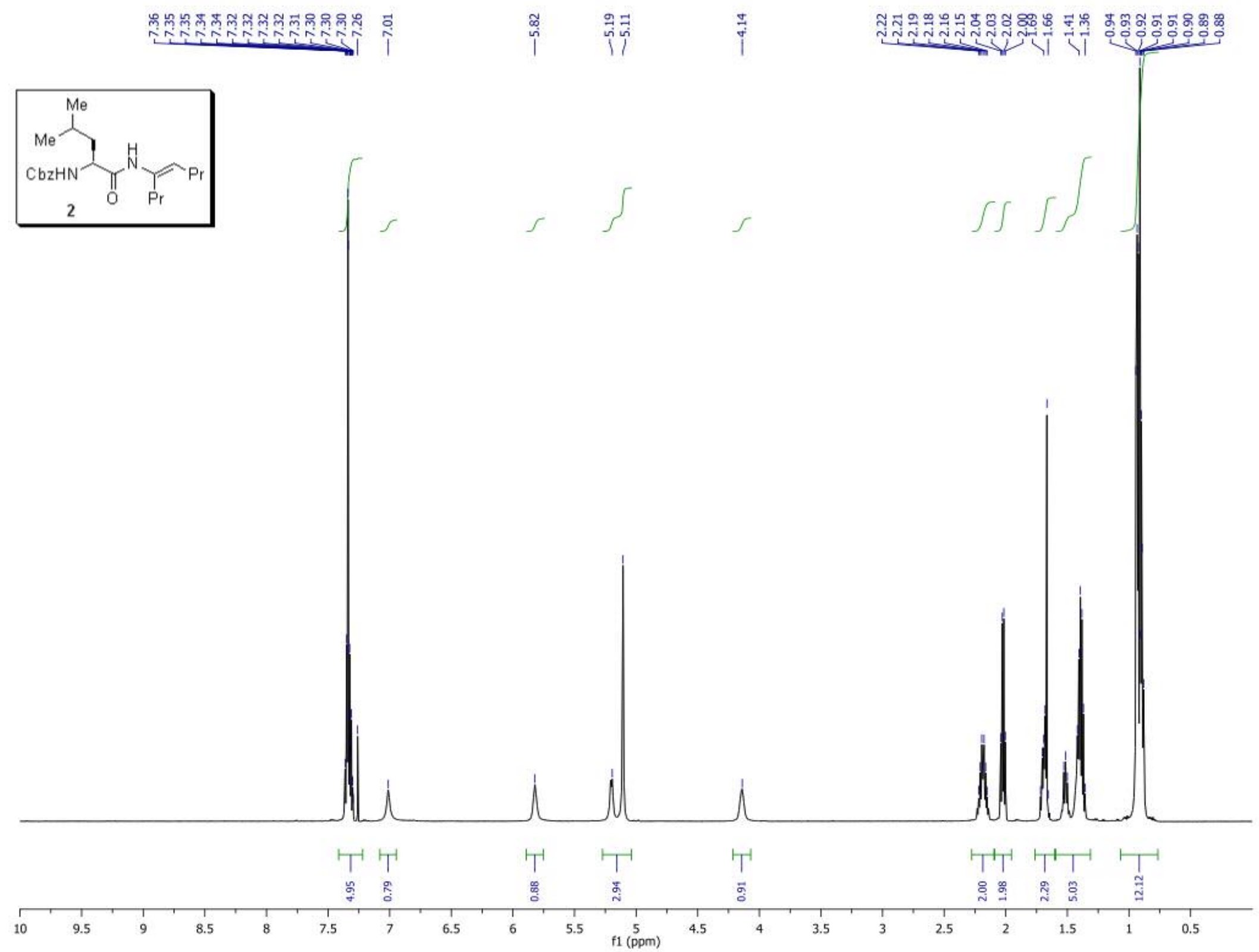




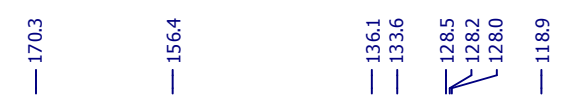

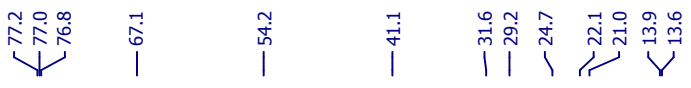
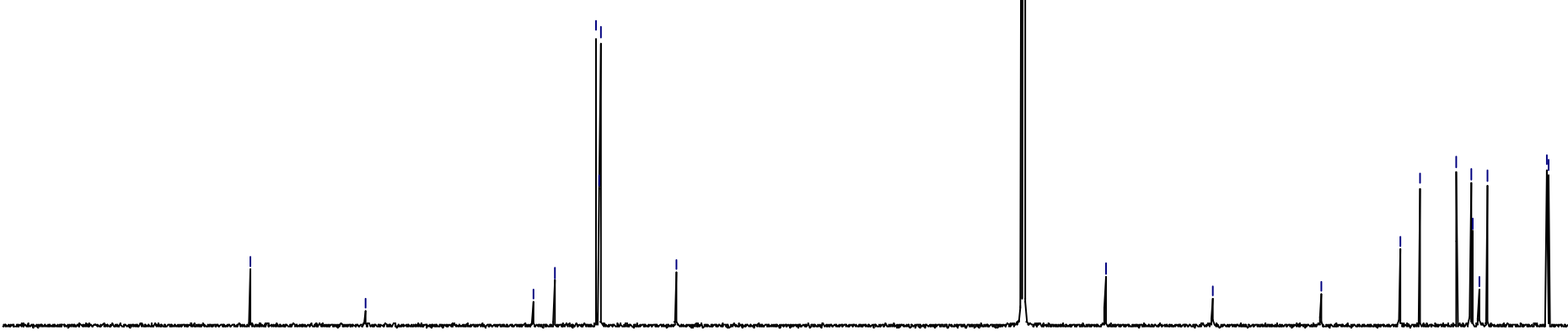

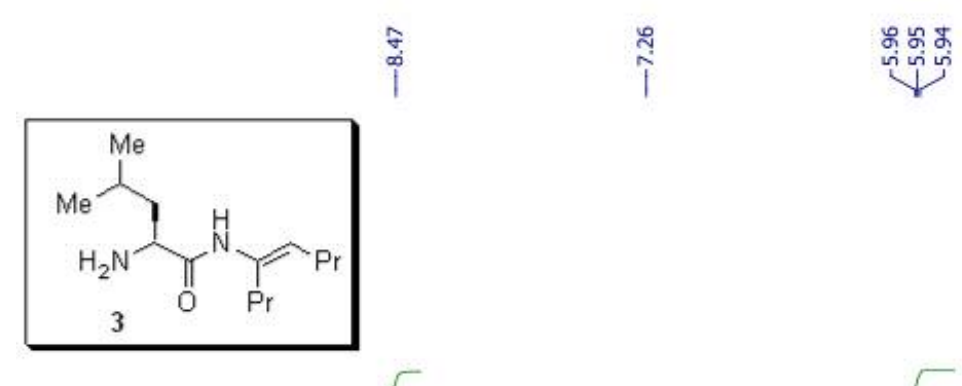

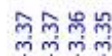

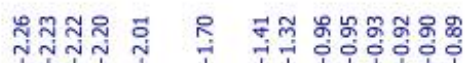

$\stackrel{2}{\uparrow}$

ขึ

ำกำ

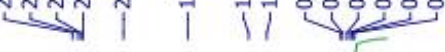

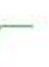

$r$
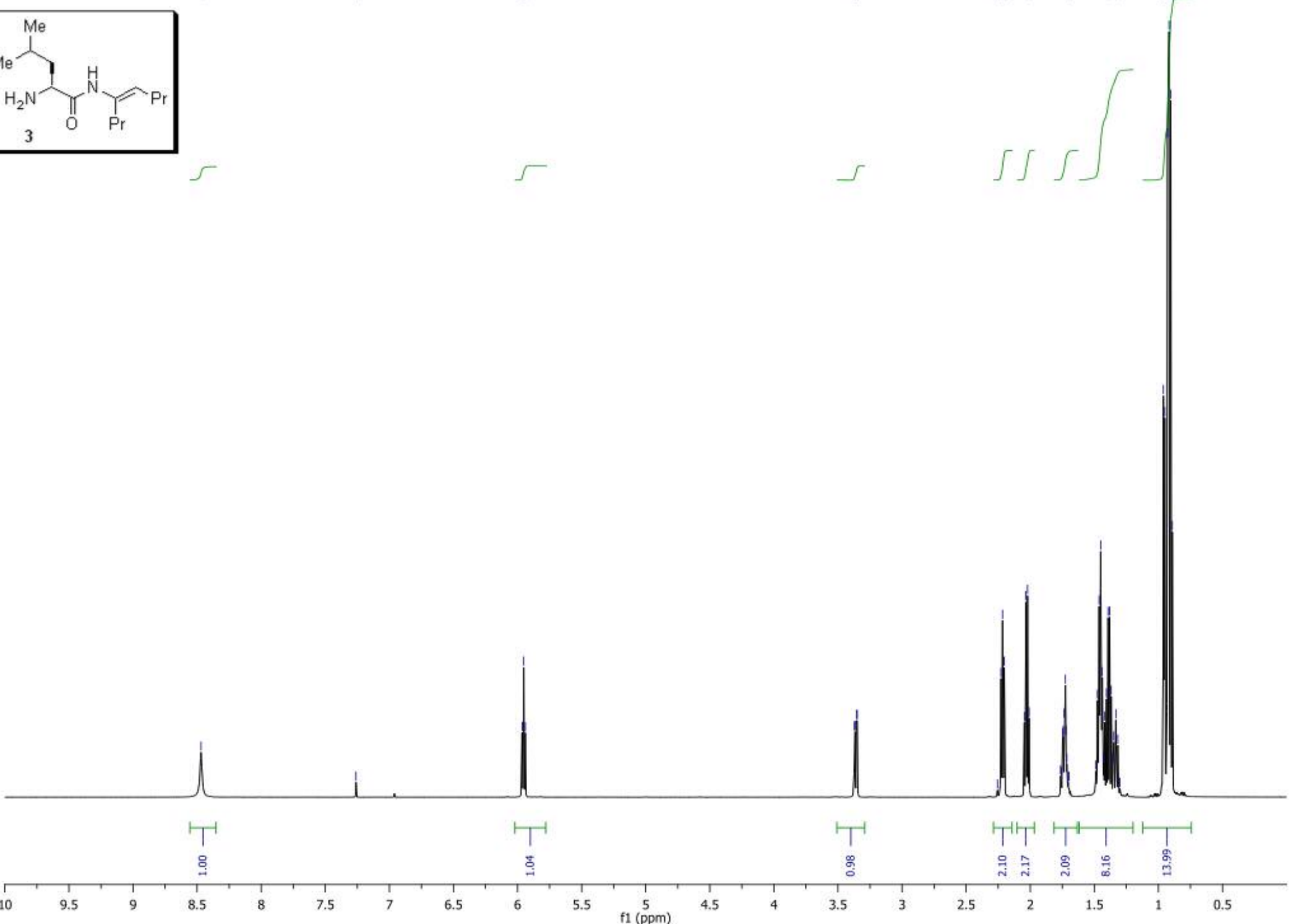

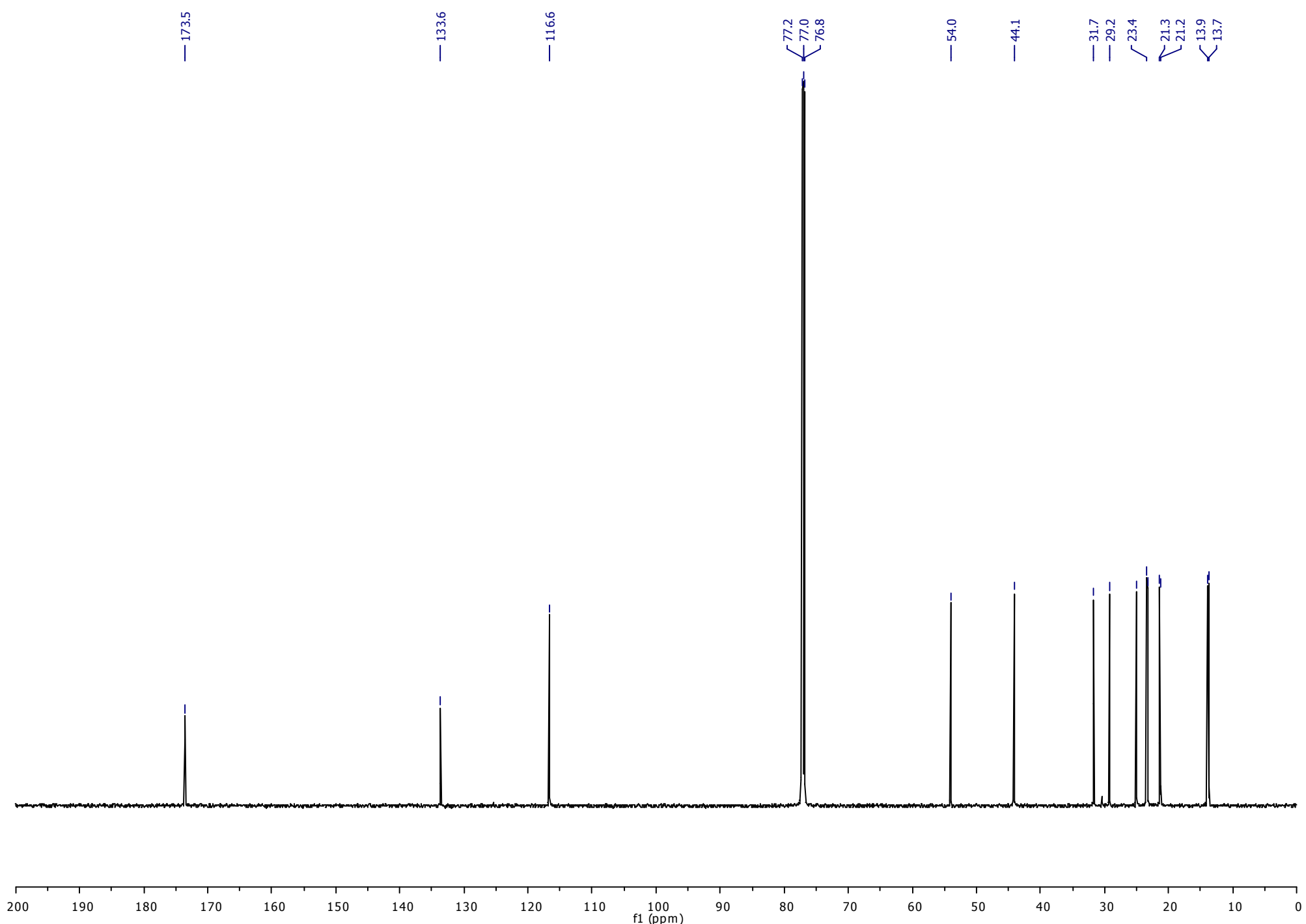

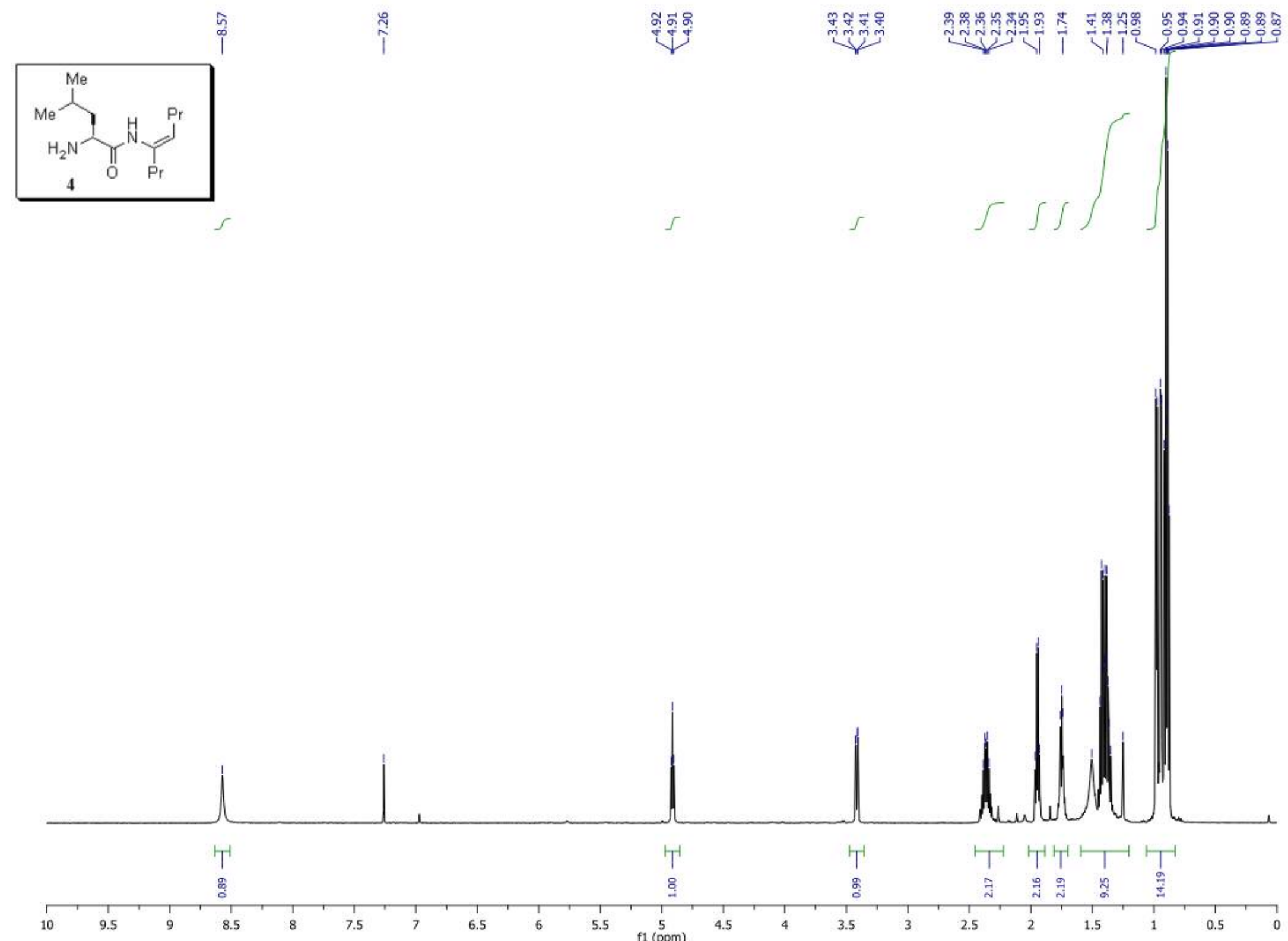


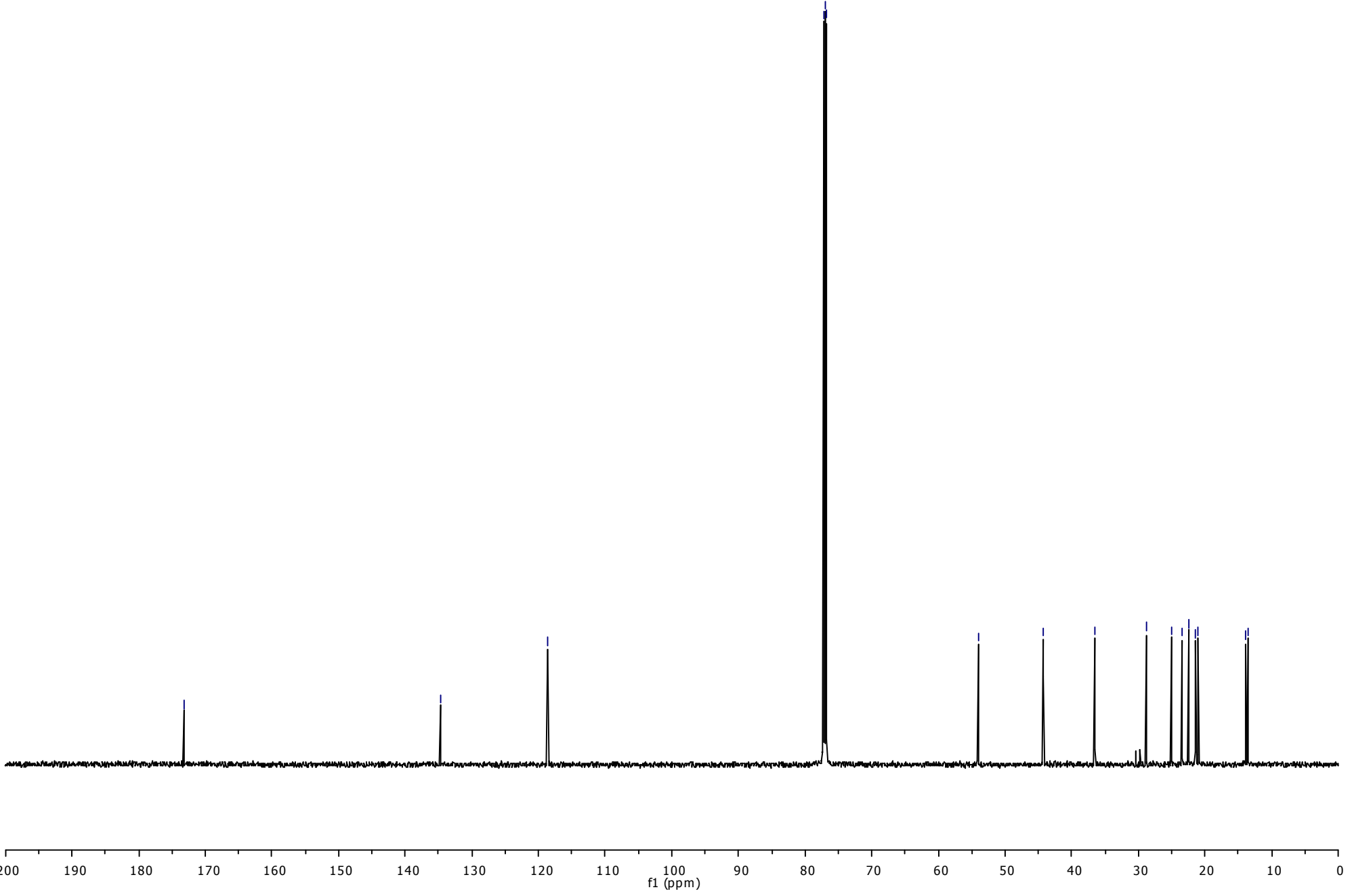



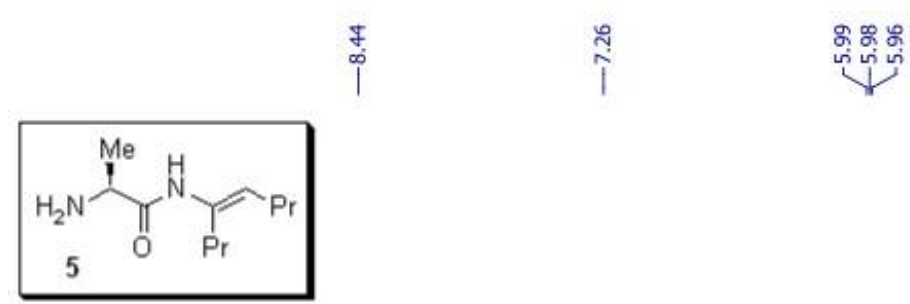

ขึำ

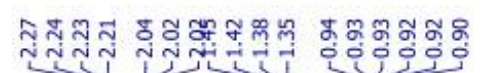

$\underset{\substack{q \\ \infty}}{\substack{q \\ i}}$

望

$\rightarrow$
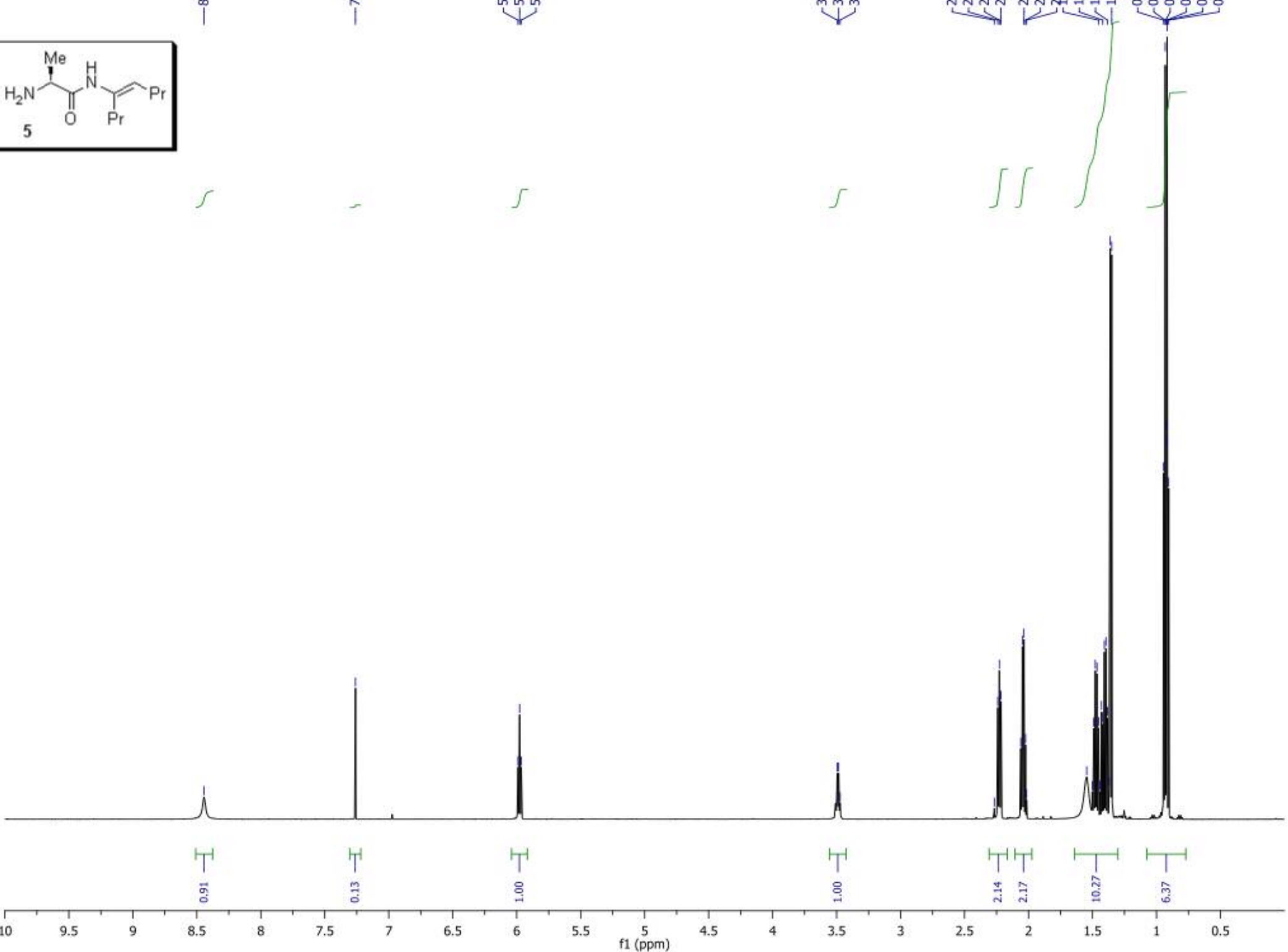

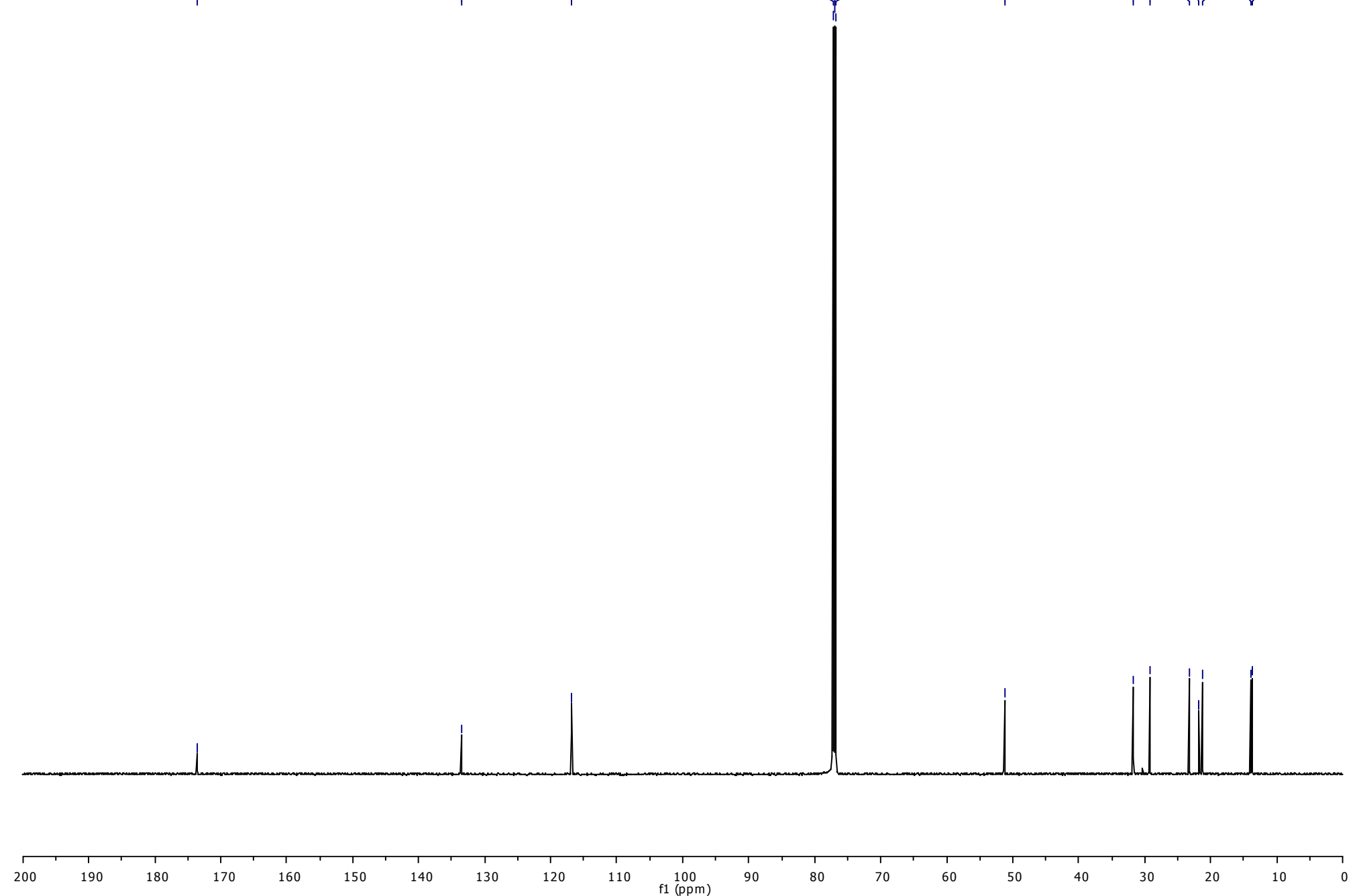


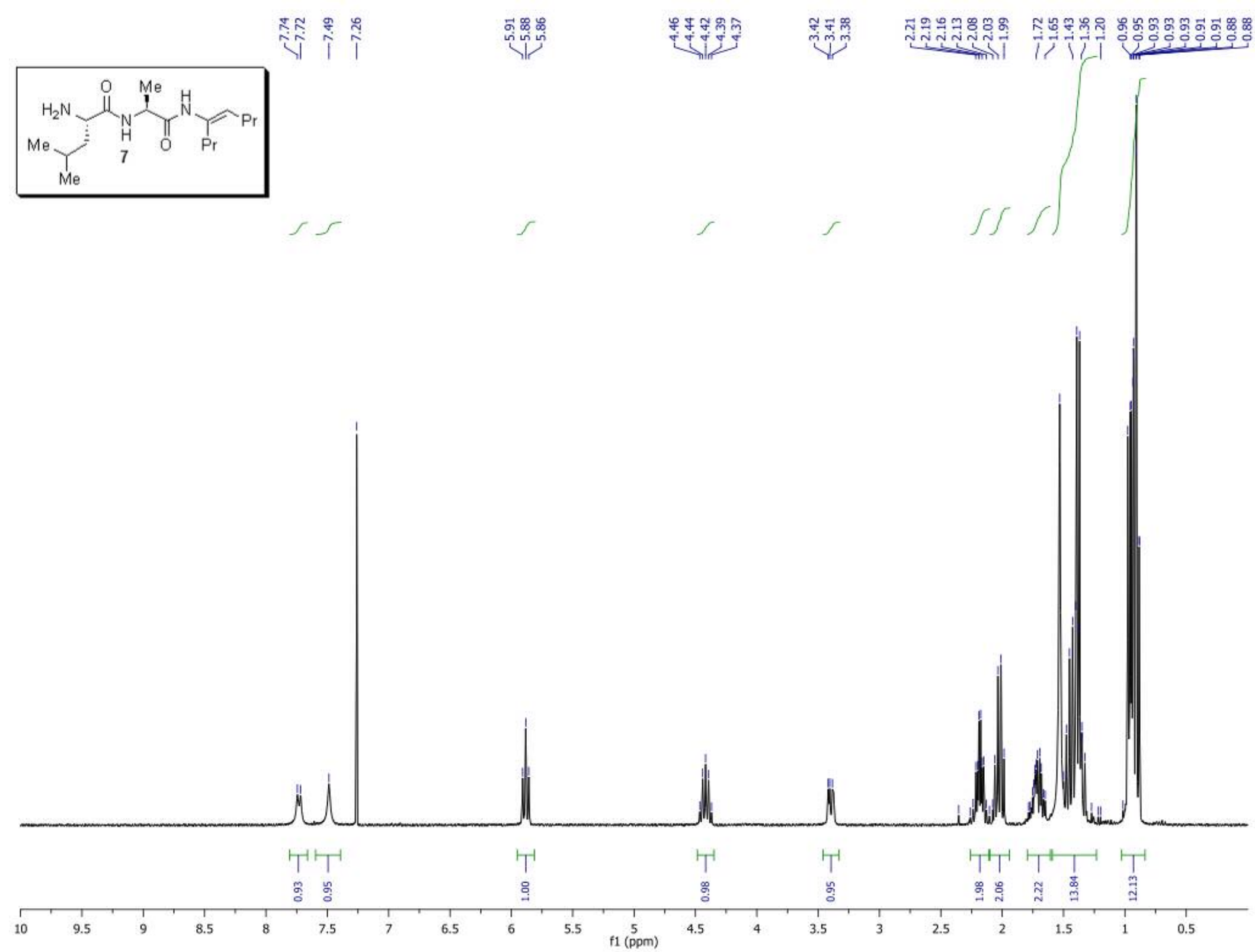




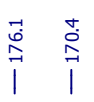

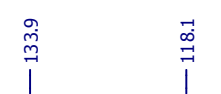

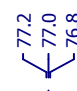

|

ำ ํำ
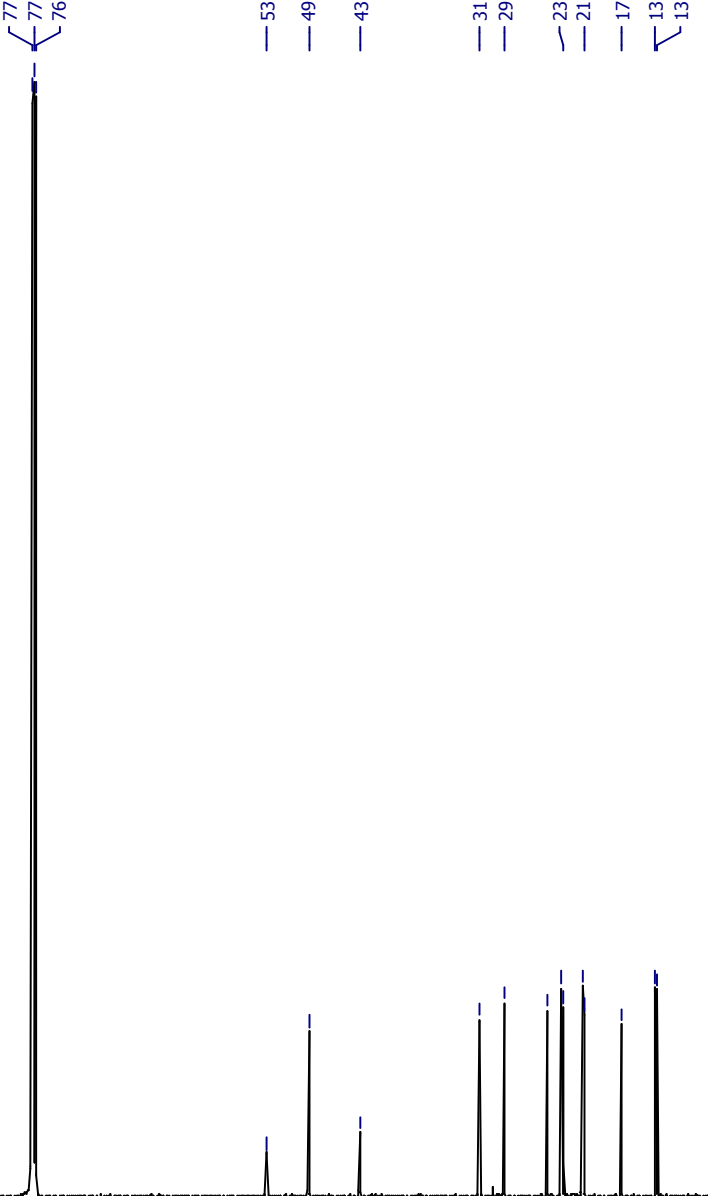


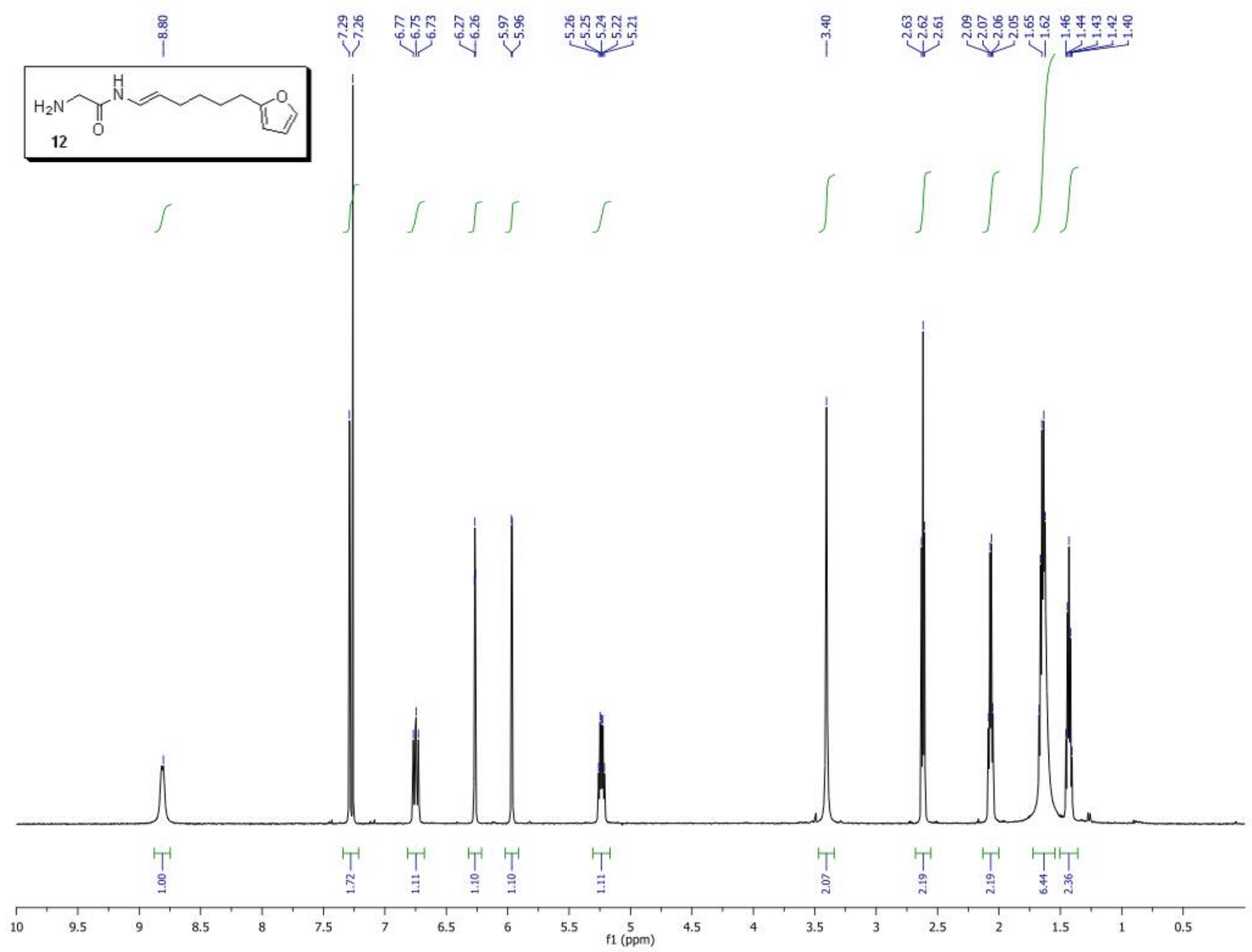



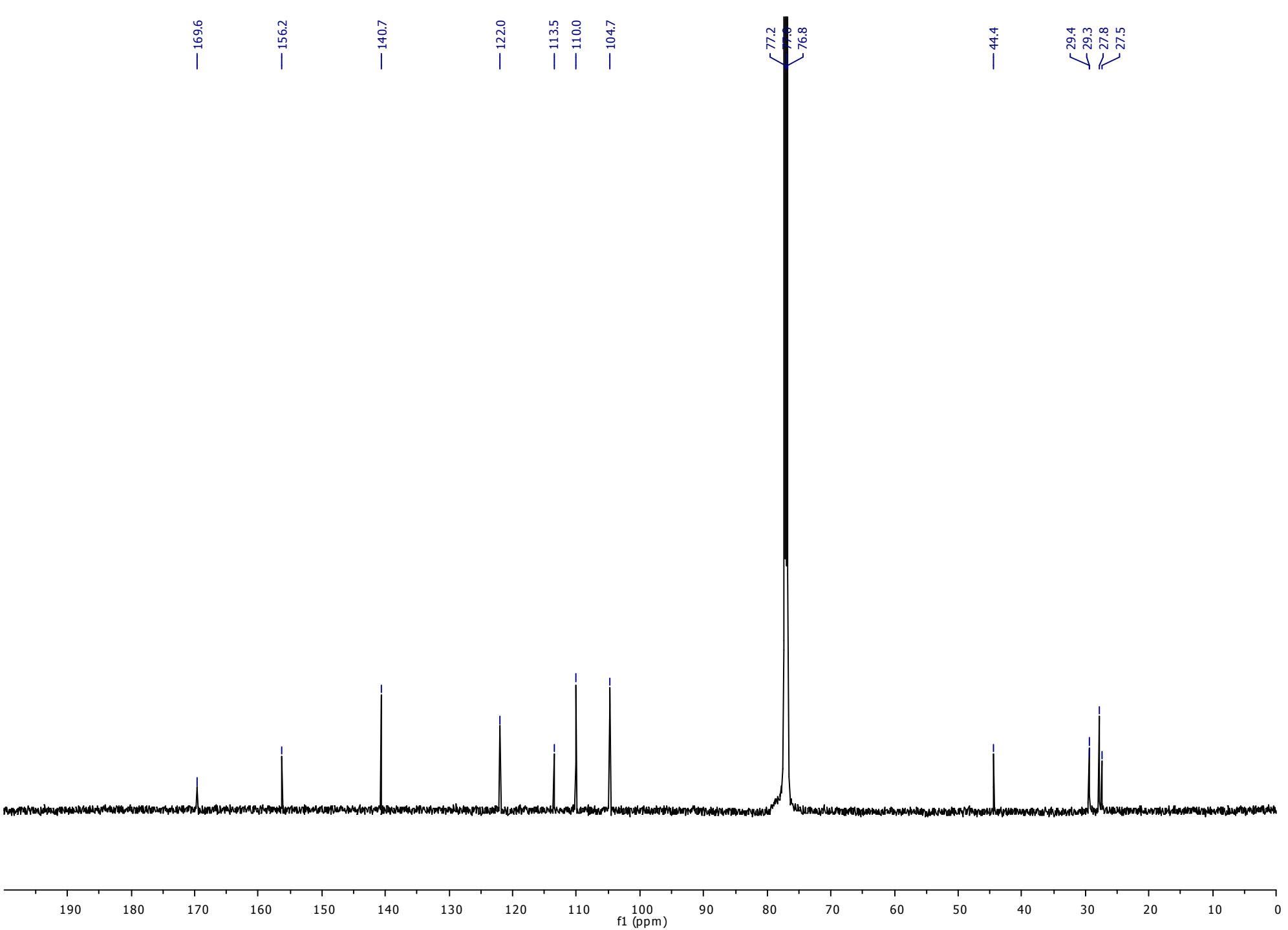


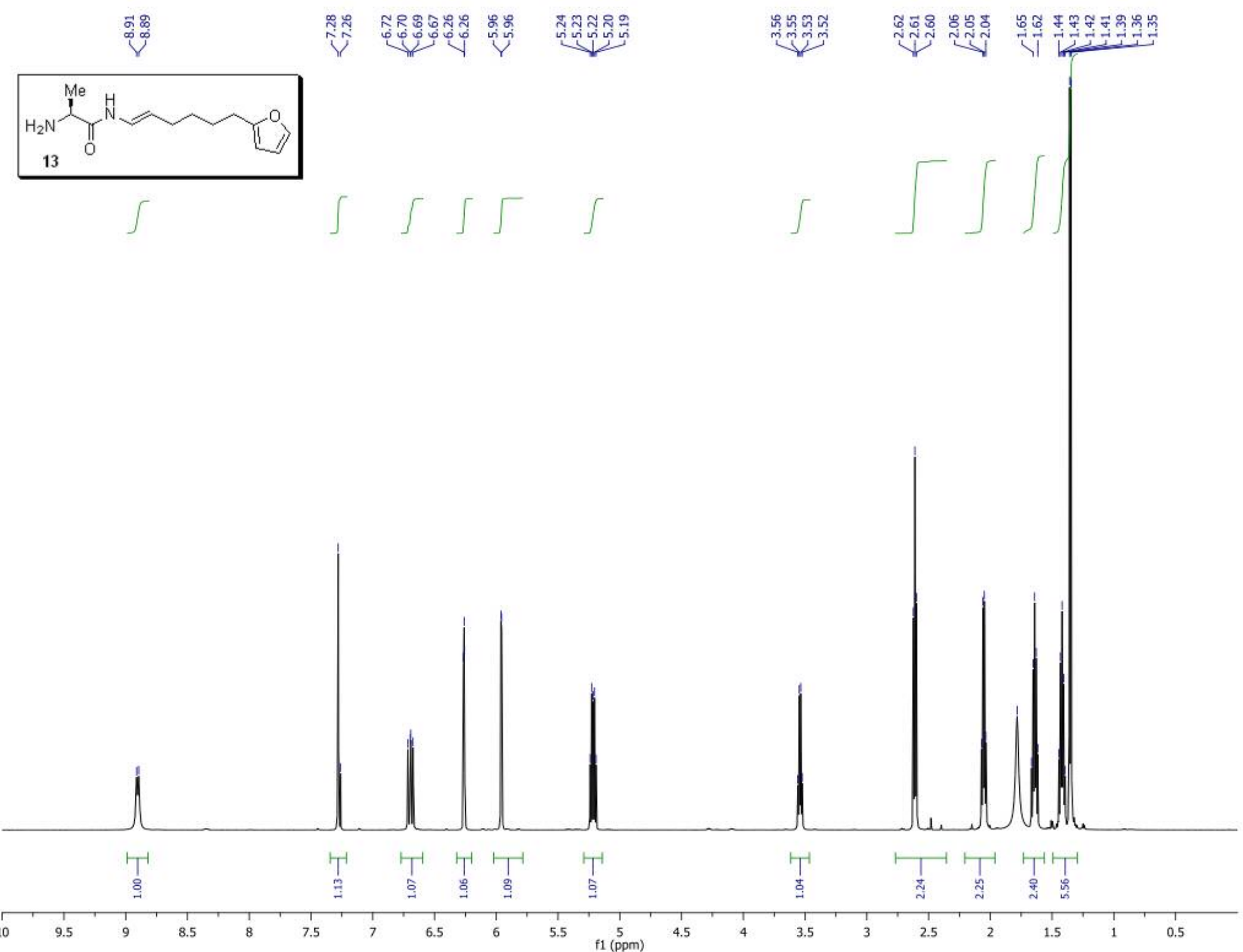



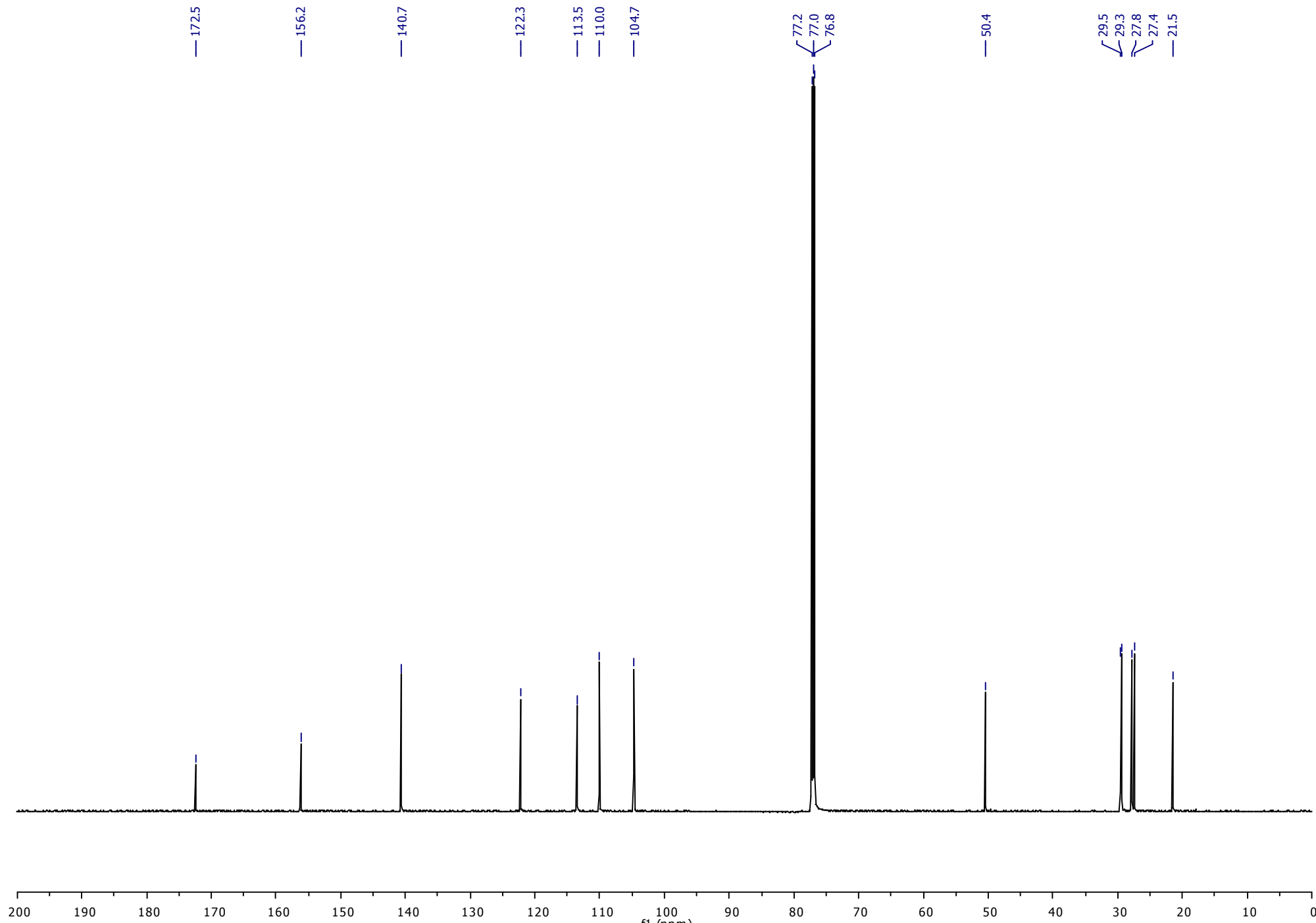


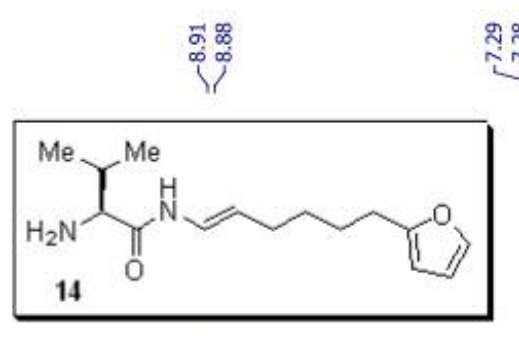

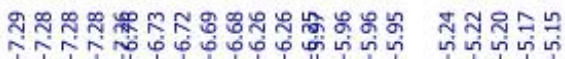

inioni y

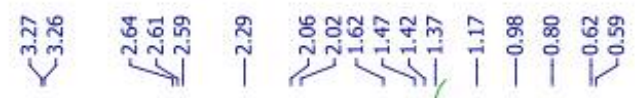
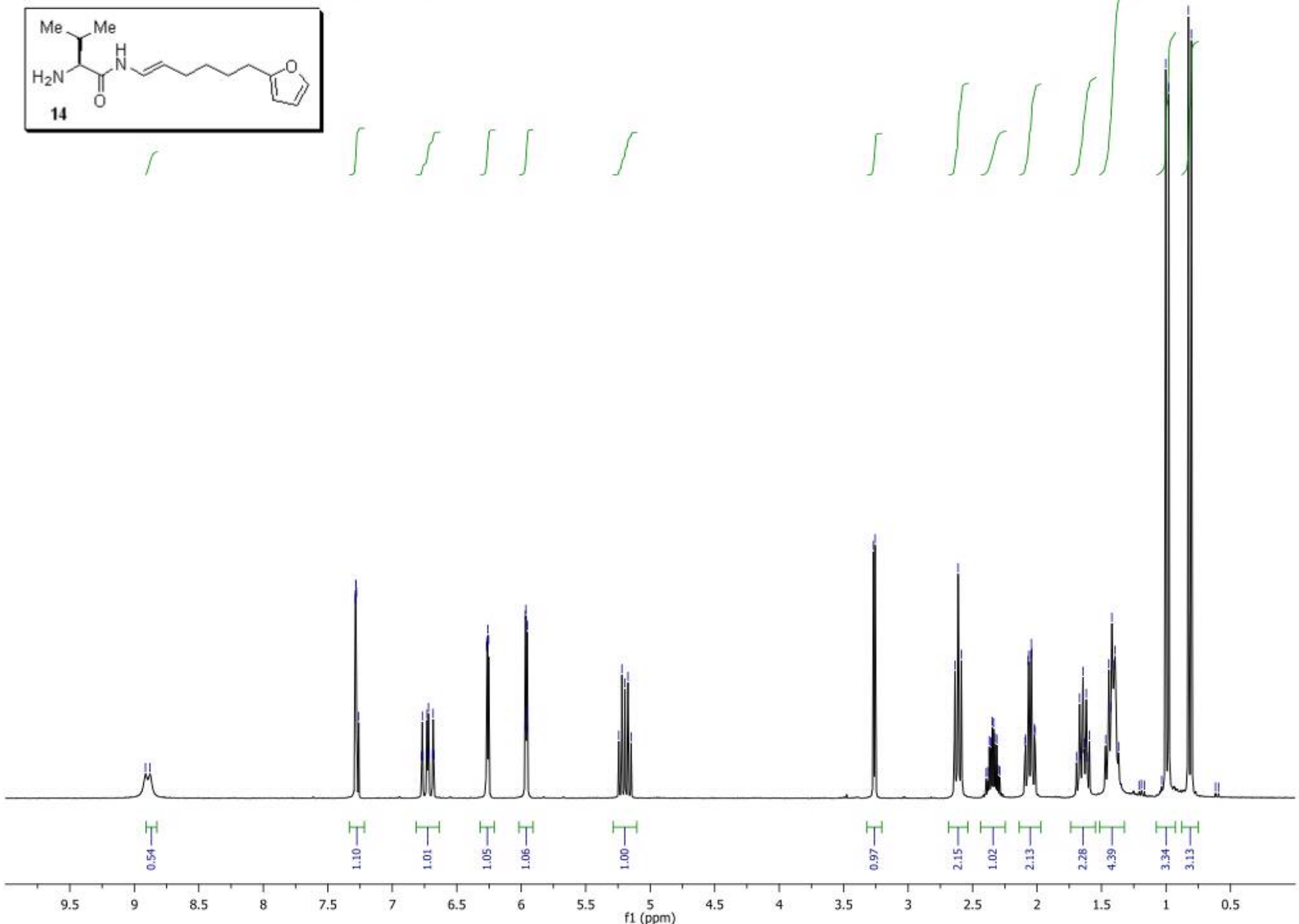

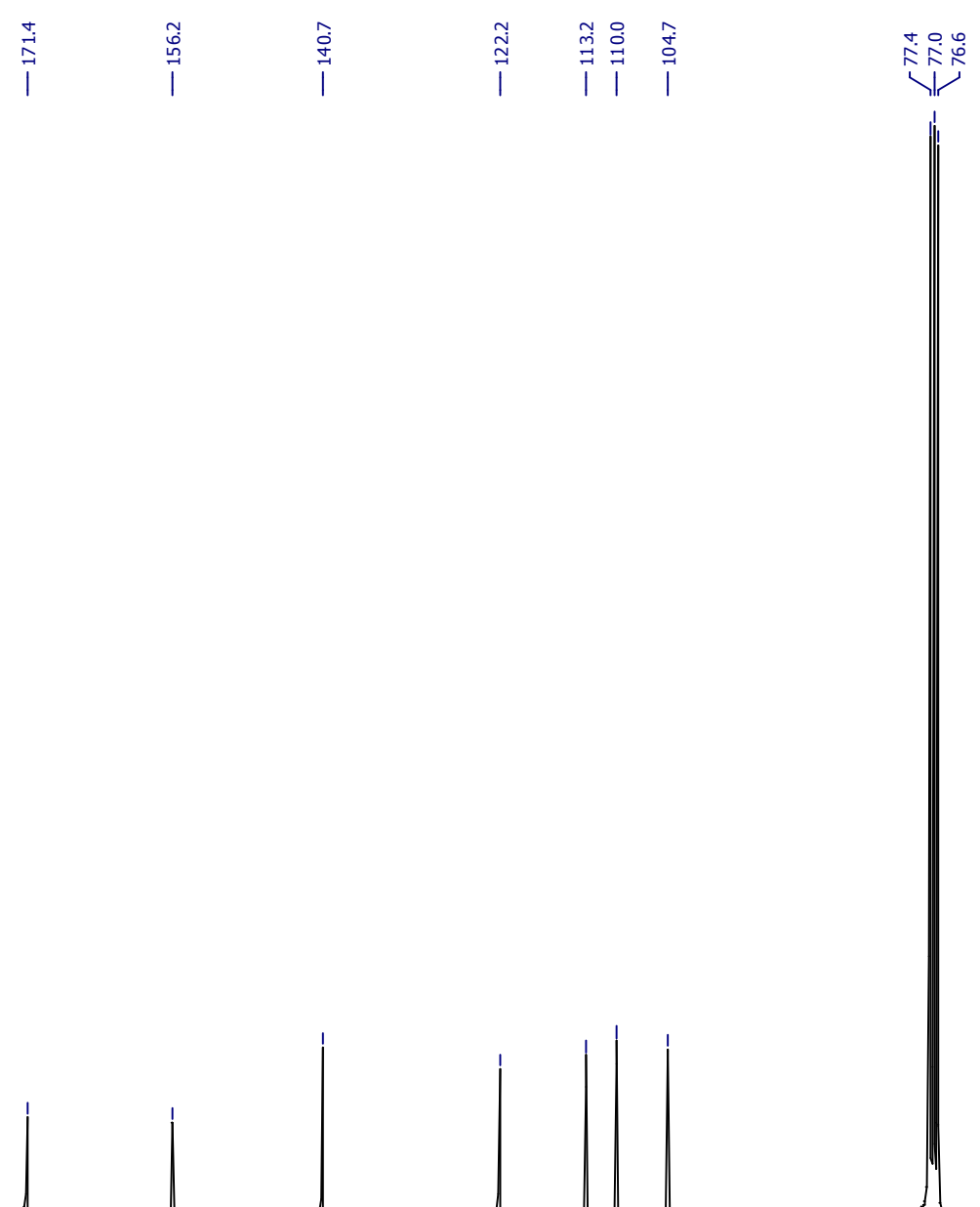

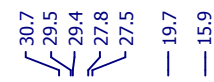

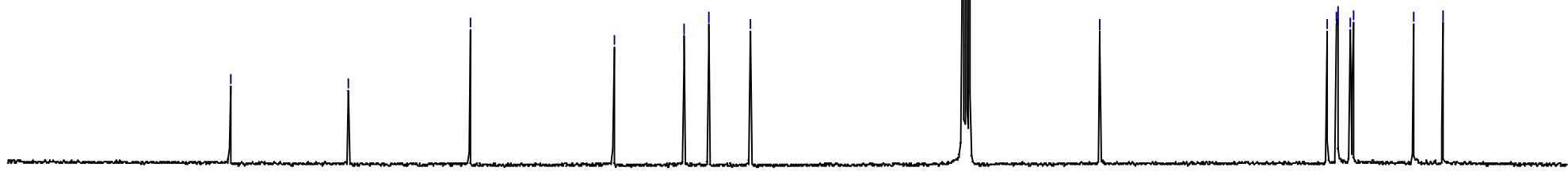

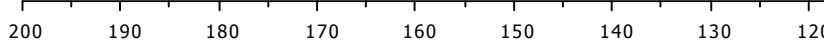

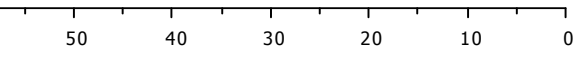




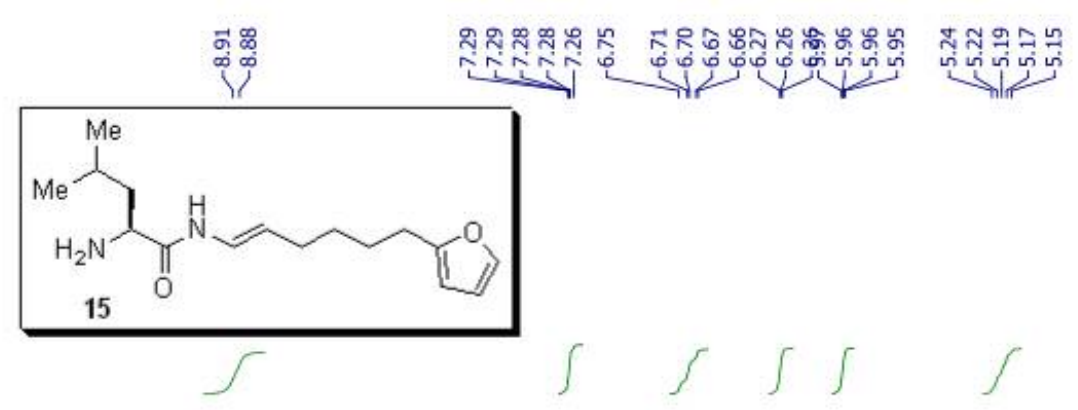

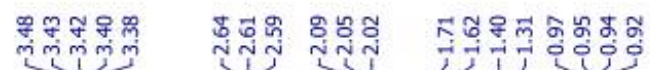

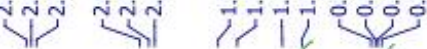

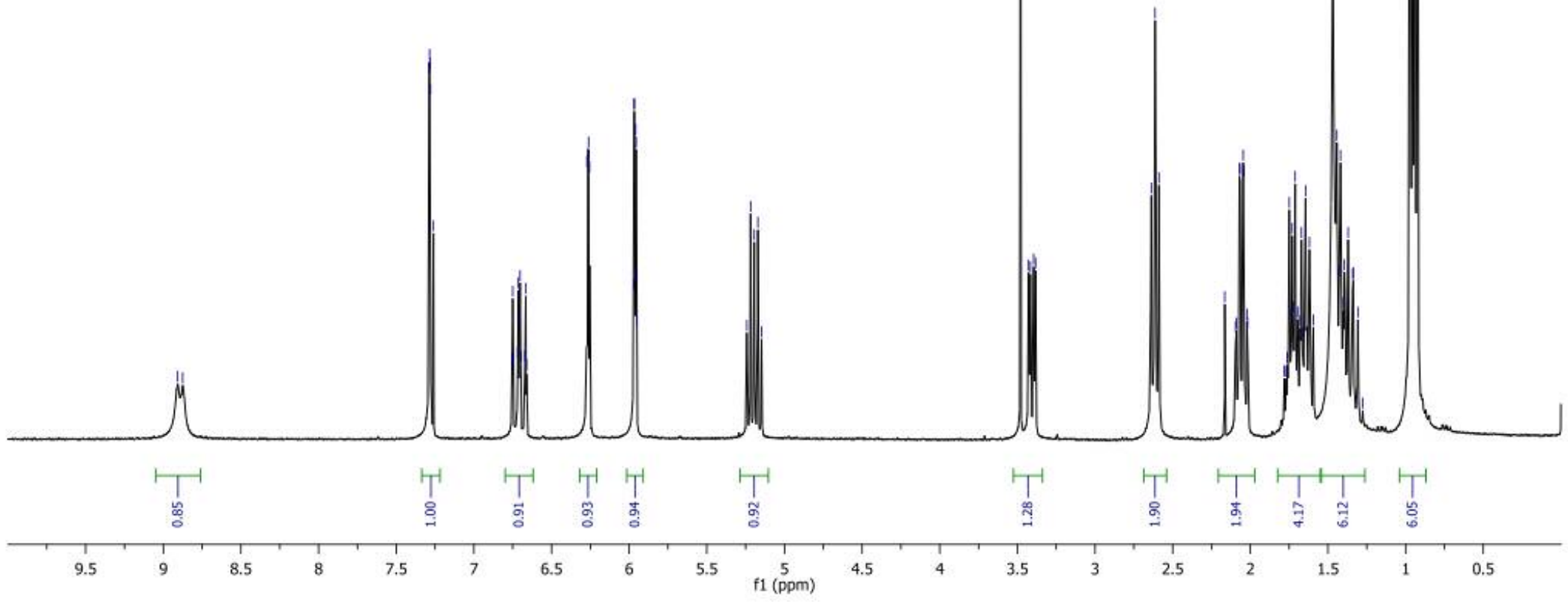




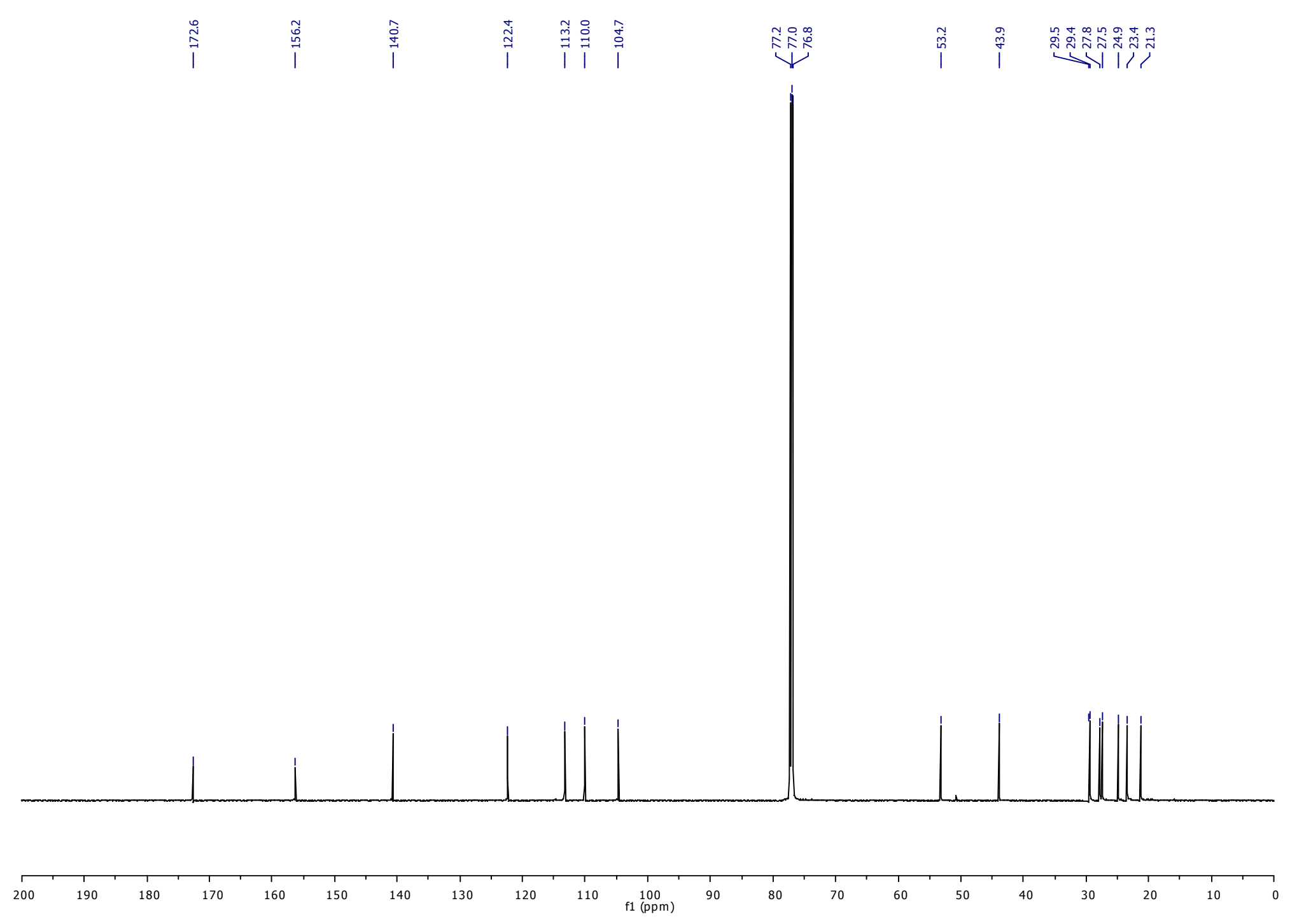



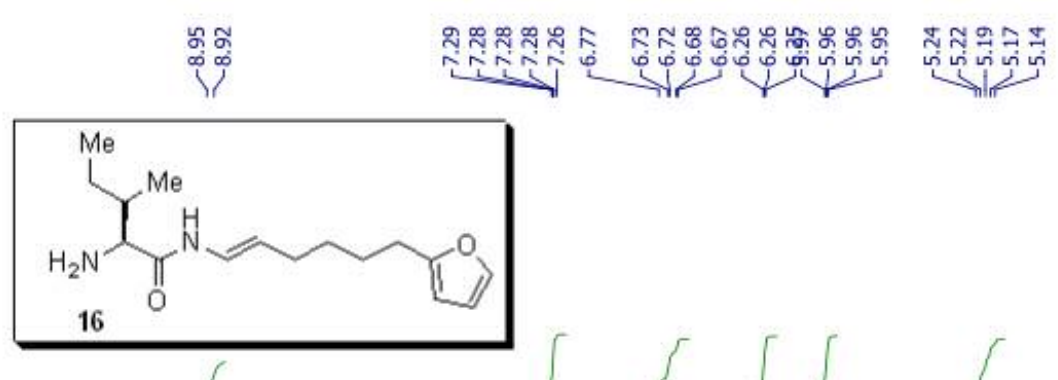

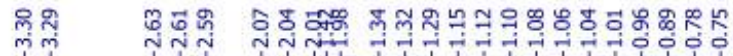
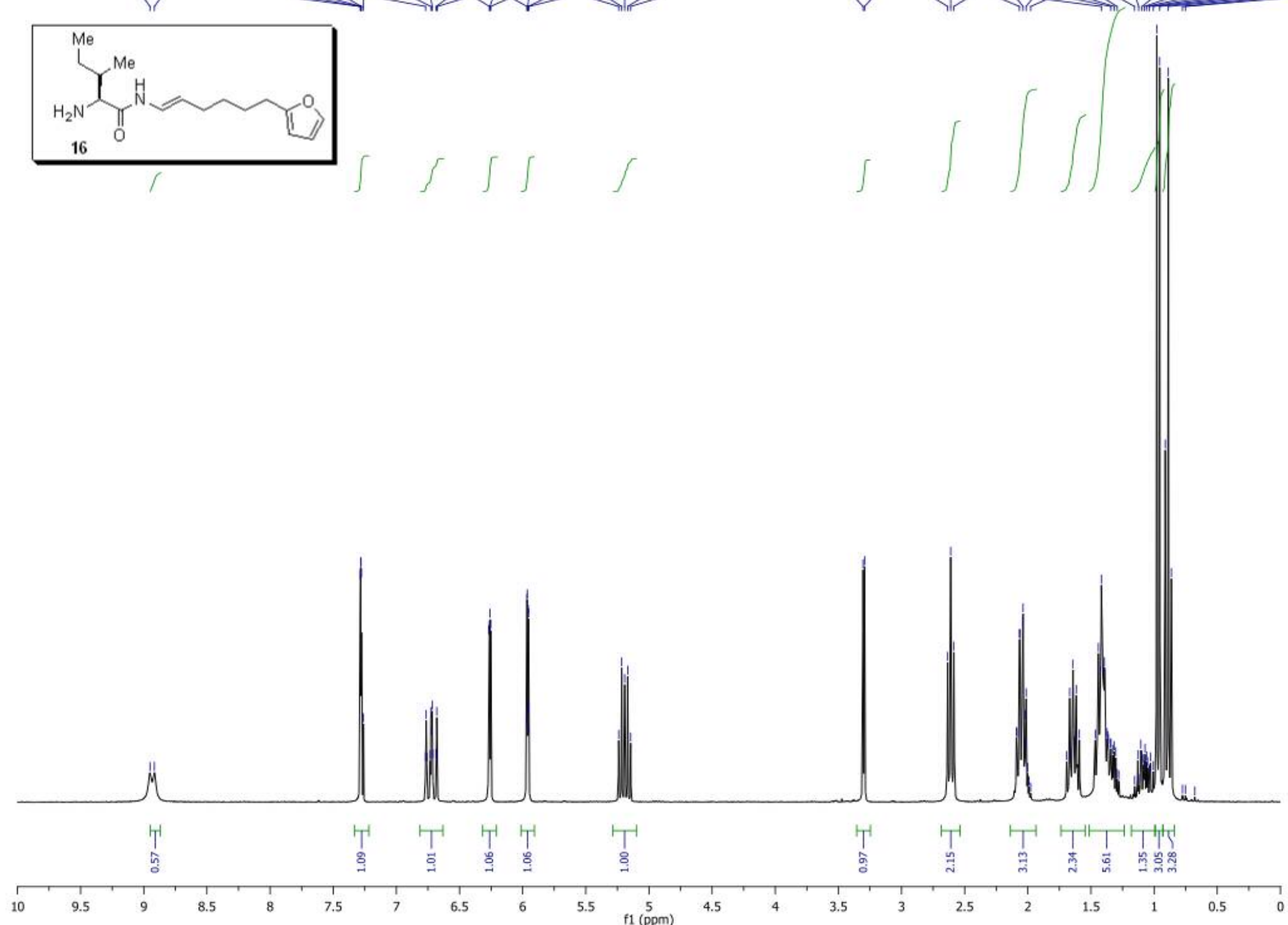
|

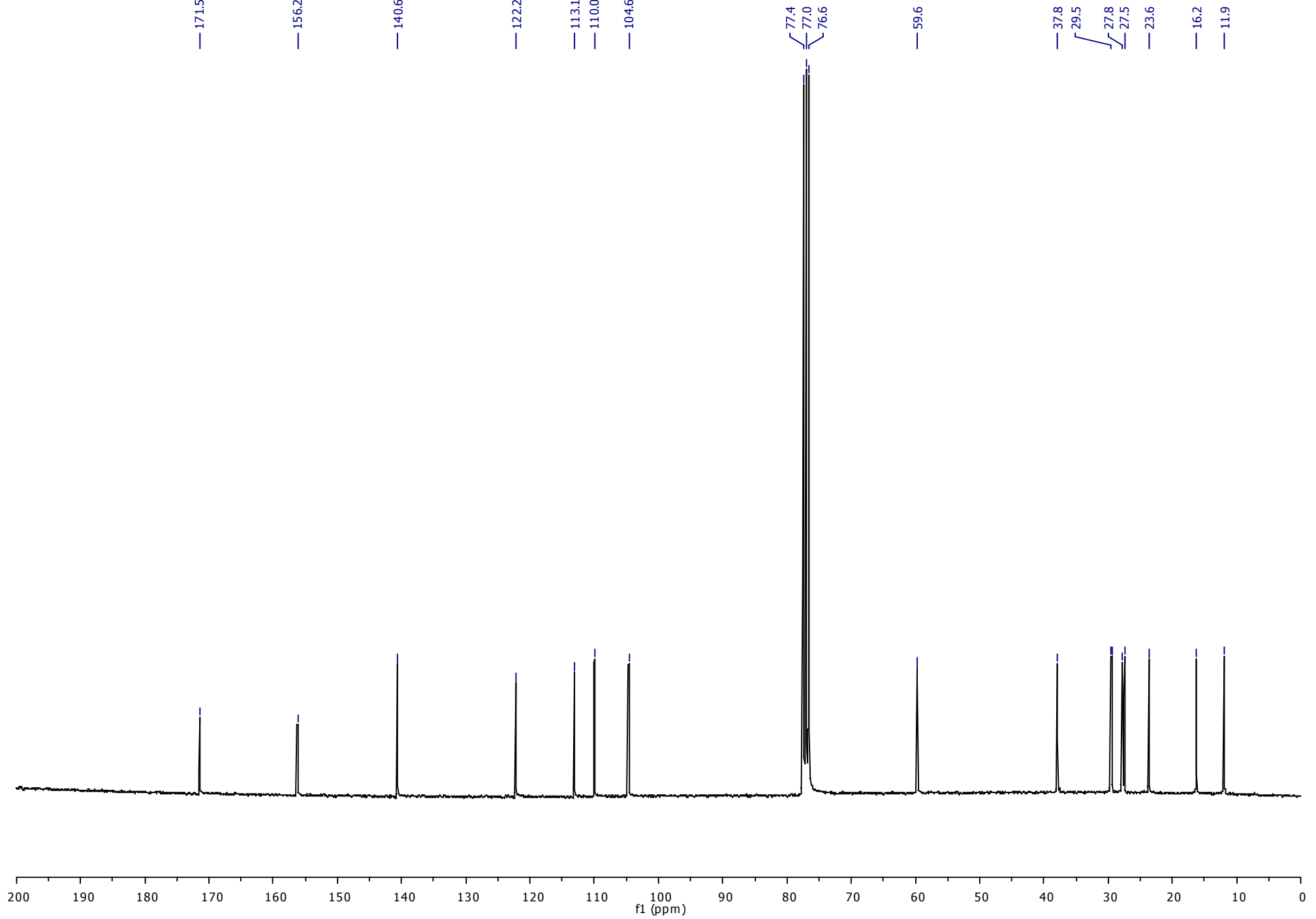

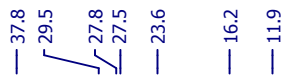



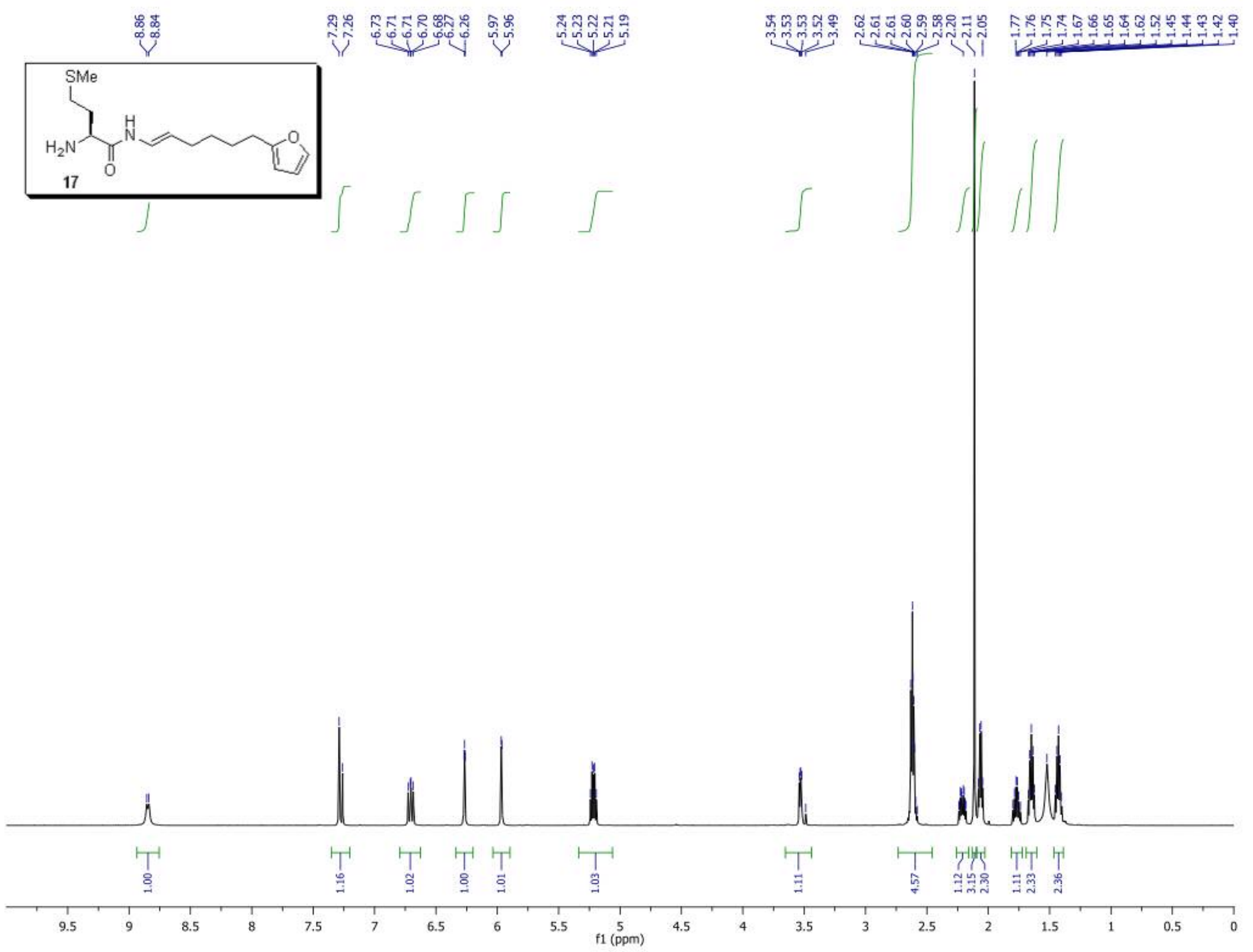


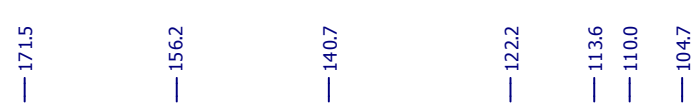

|imi

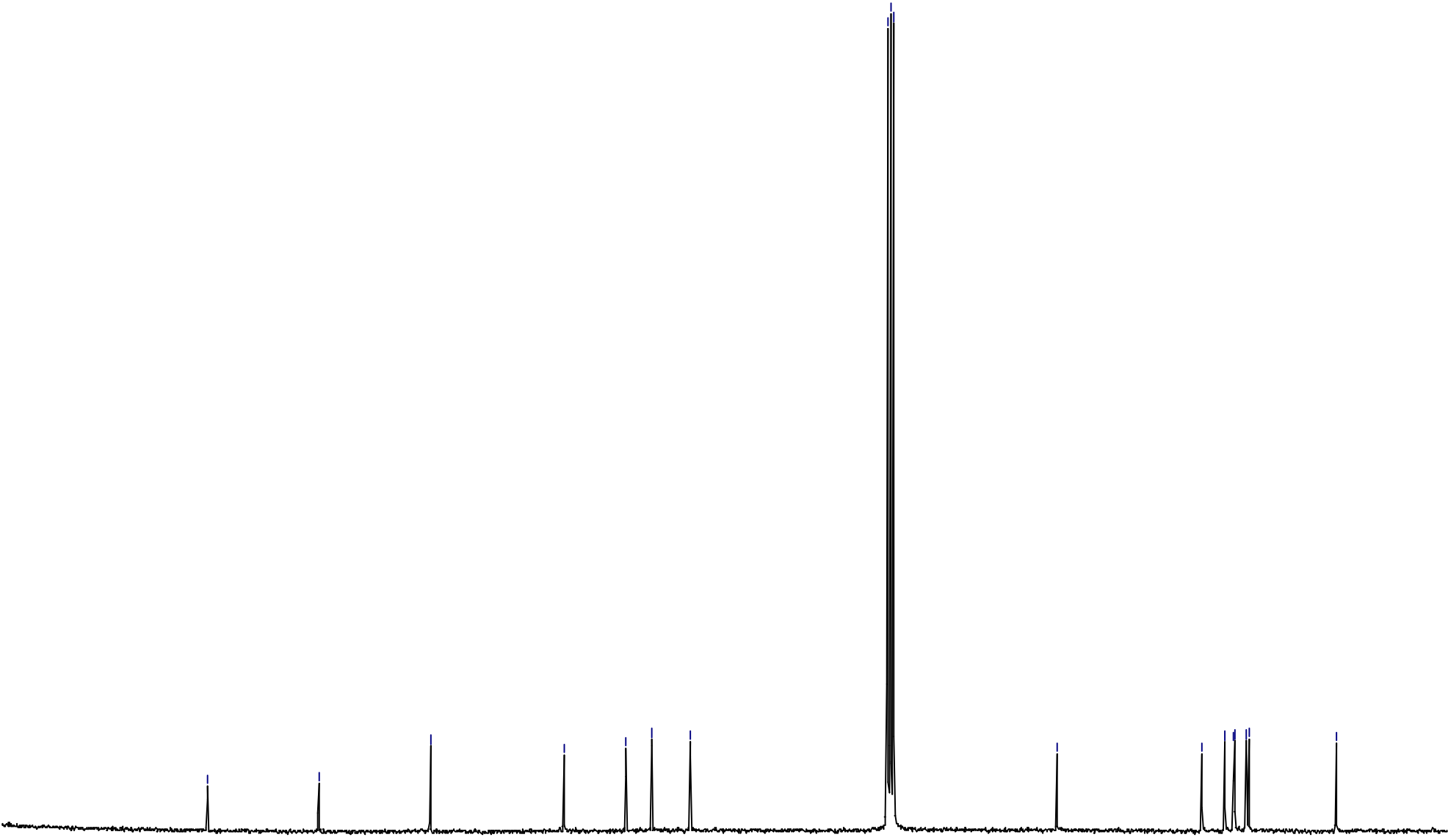




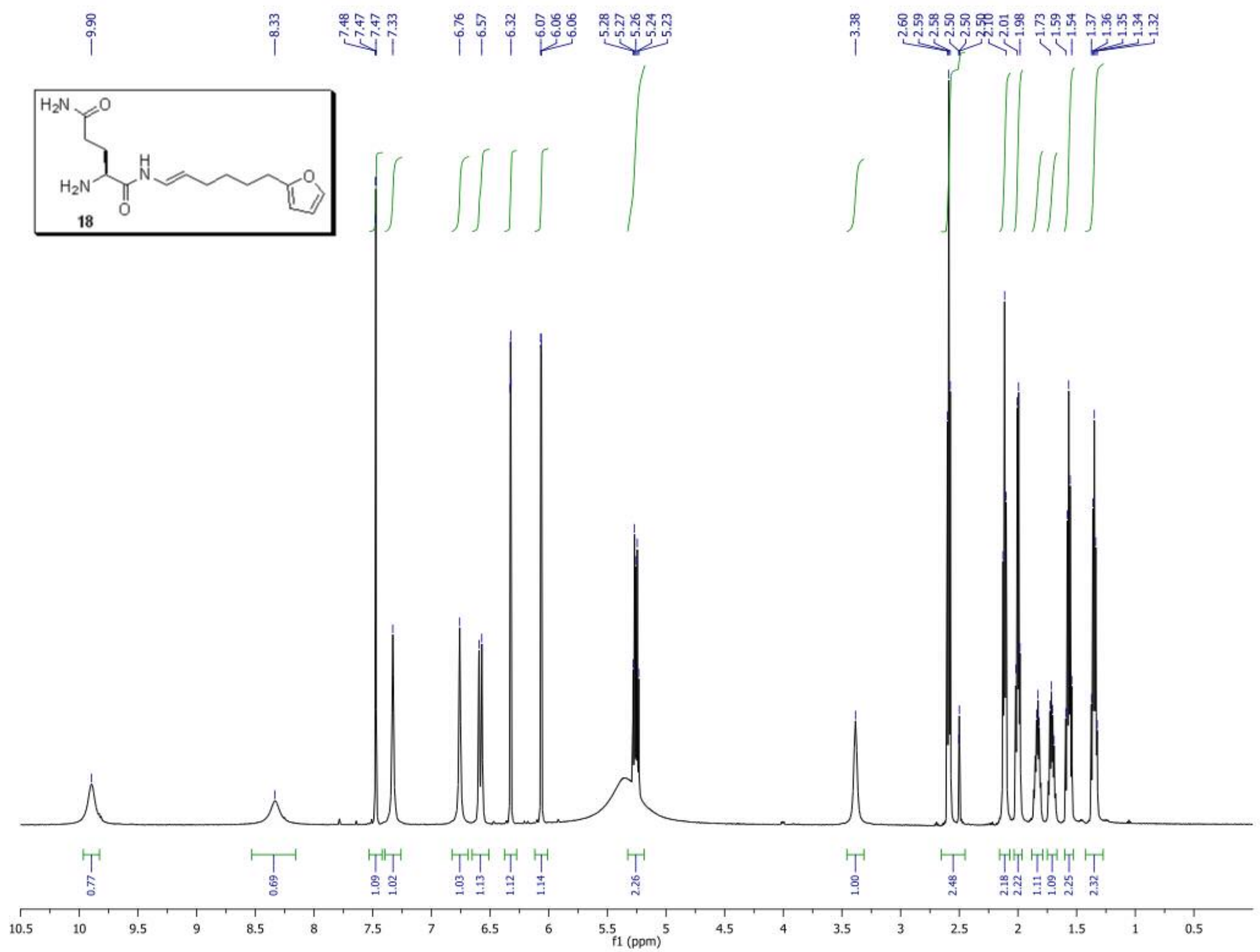




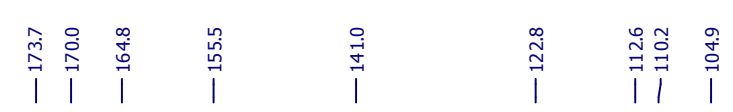

尊
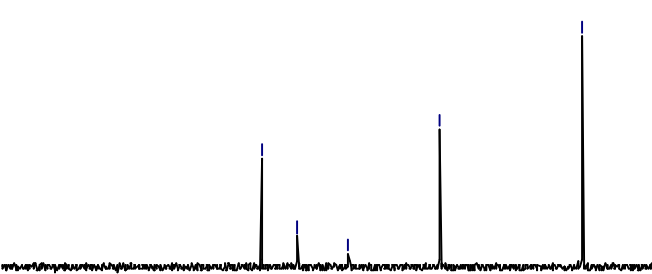

200

$190 \quad 180$

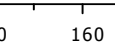

150

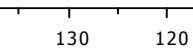

100

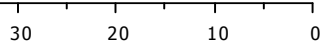




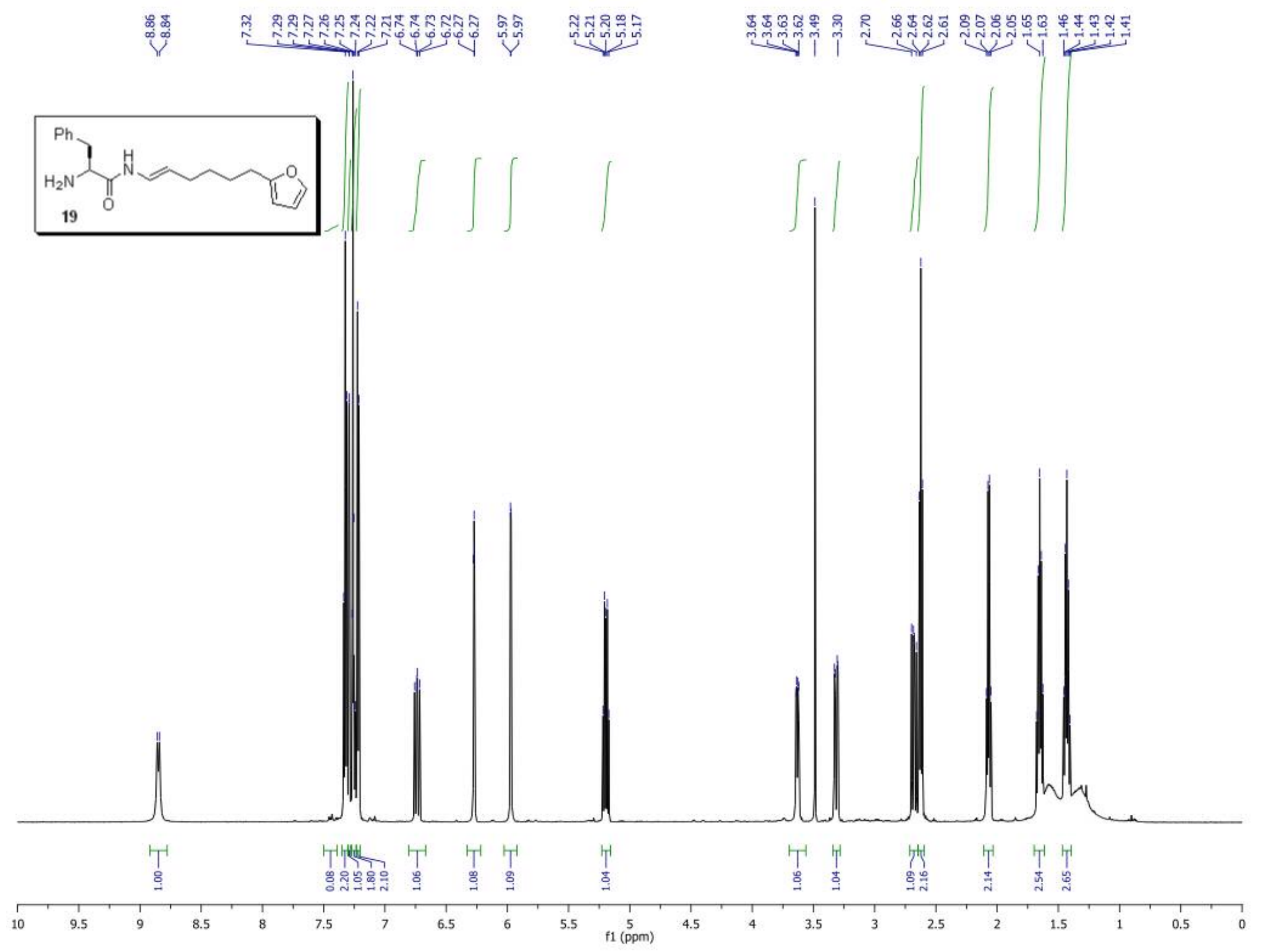




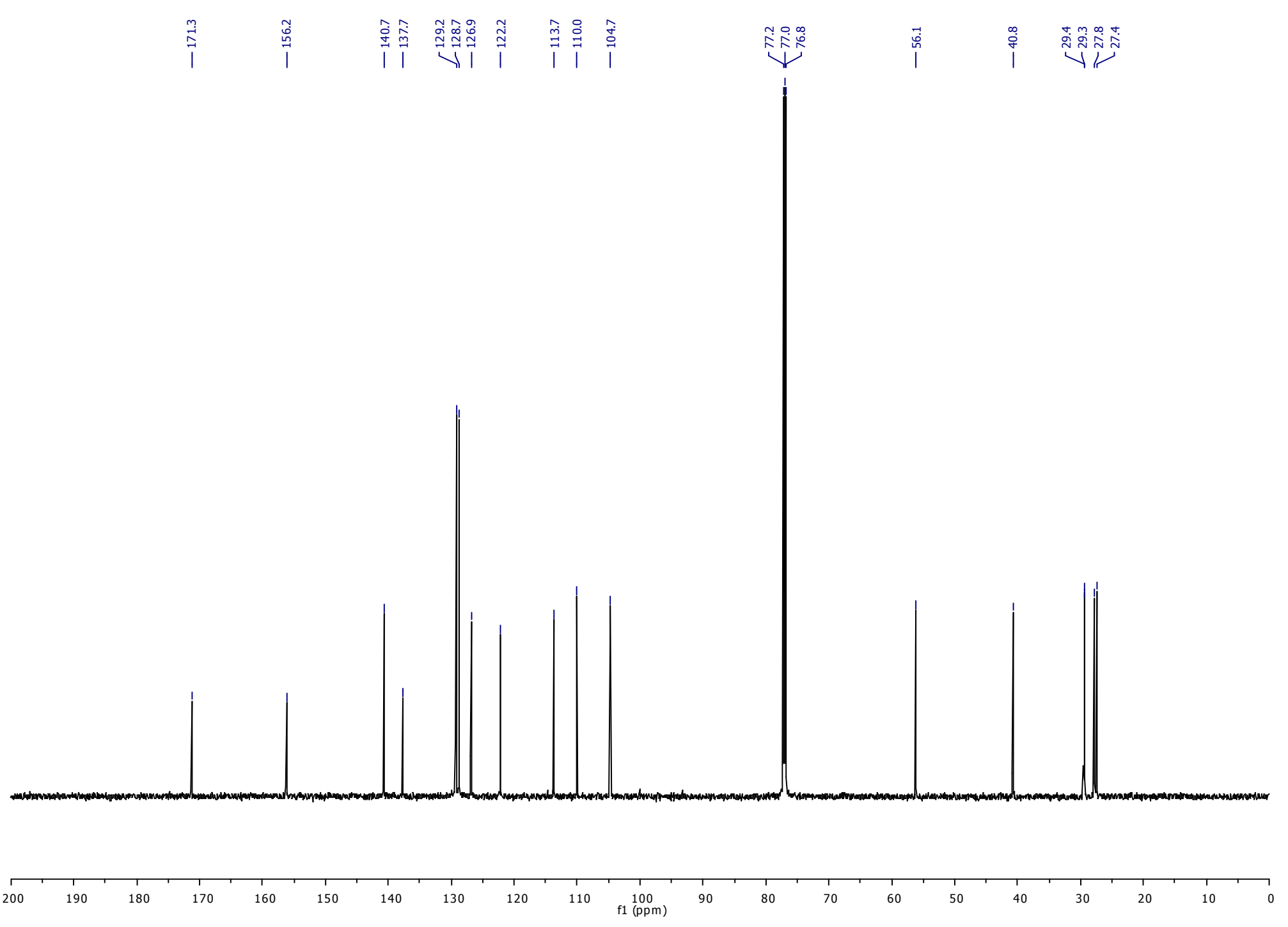




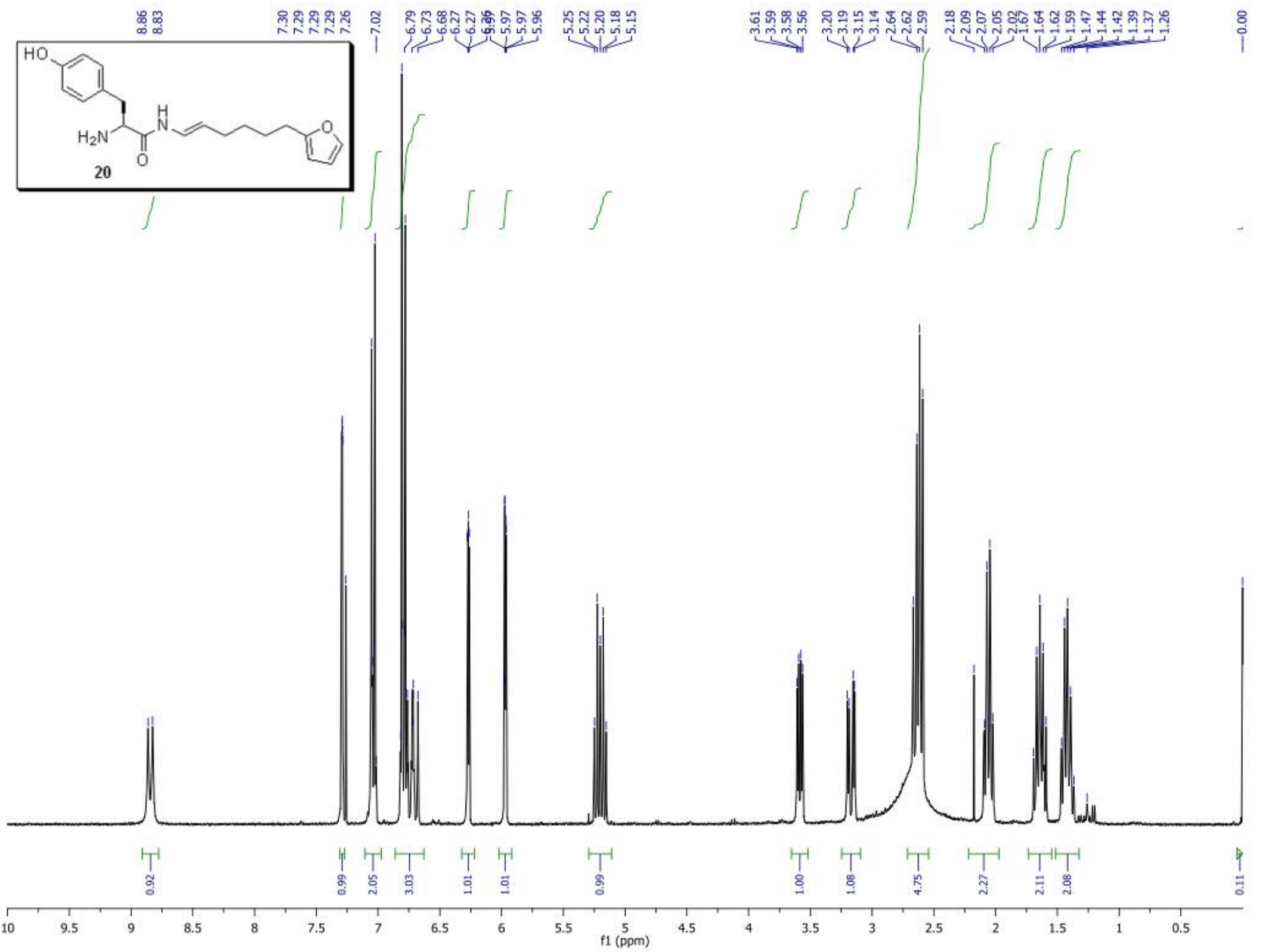




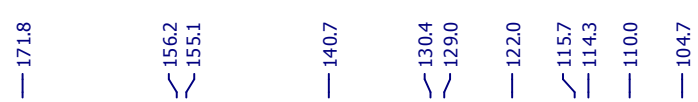

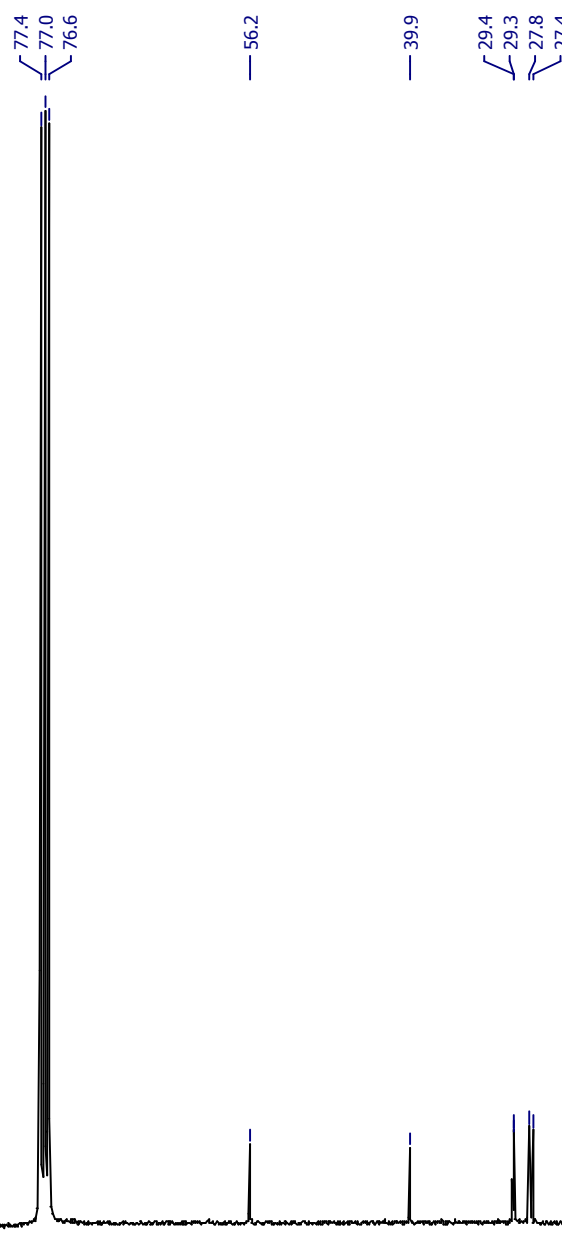

200

$190 \quad 180$

160

$150 \quad 140$

$130 \quad 120$

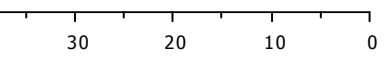




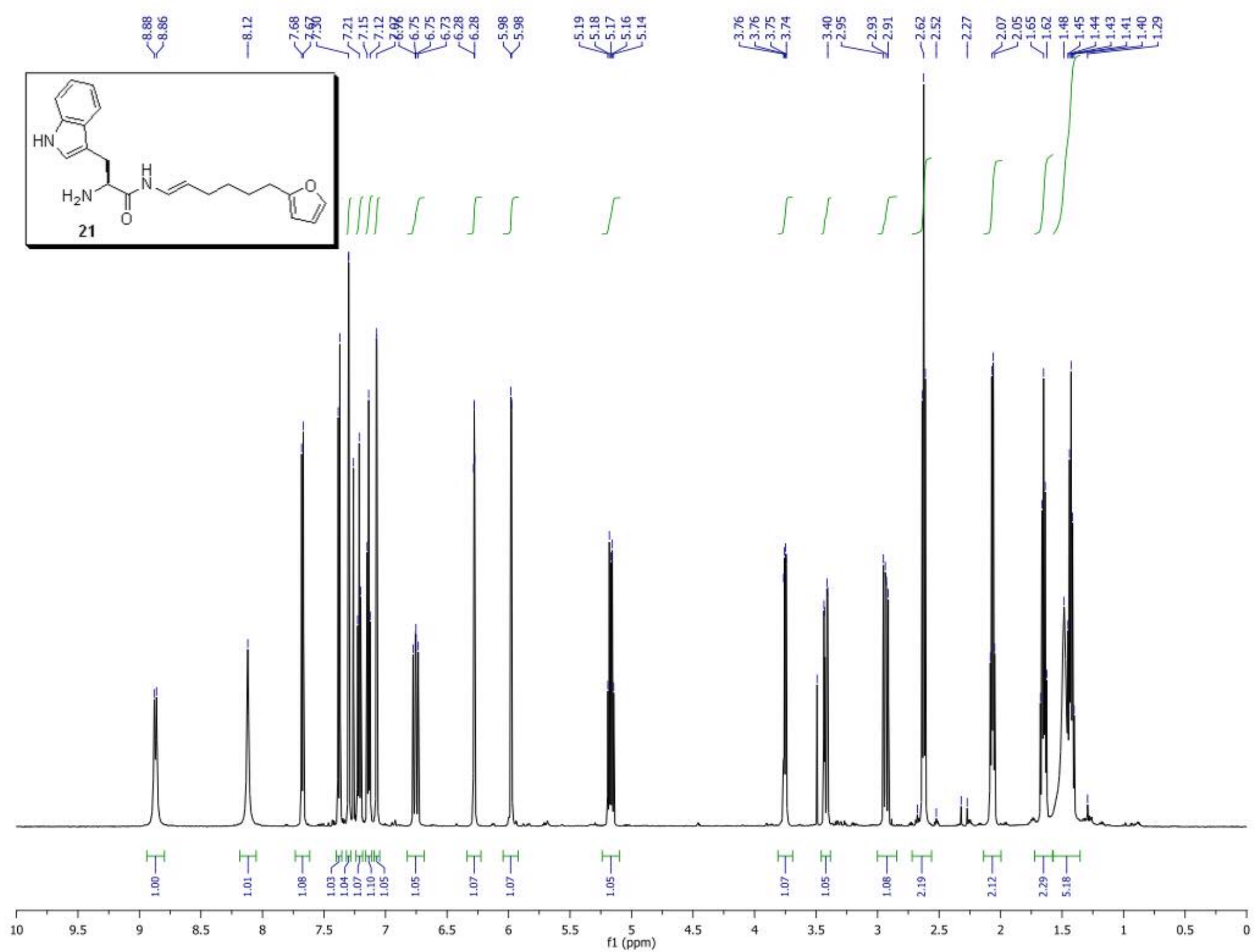



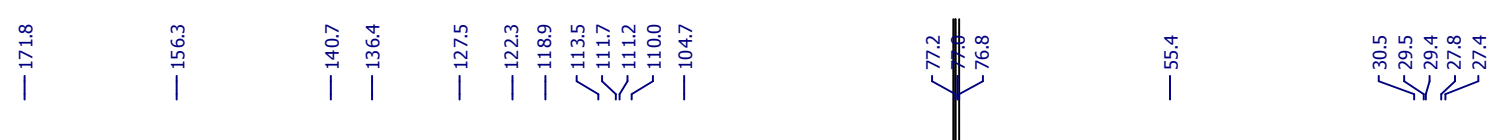

$200 \quad 190 \quad 180$

$110 \quad 100$ $70 \quad 60$
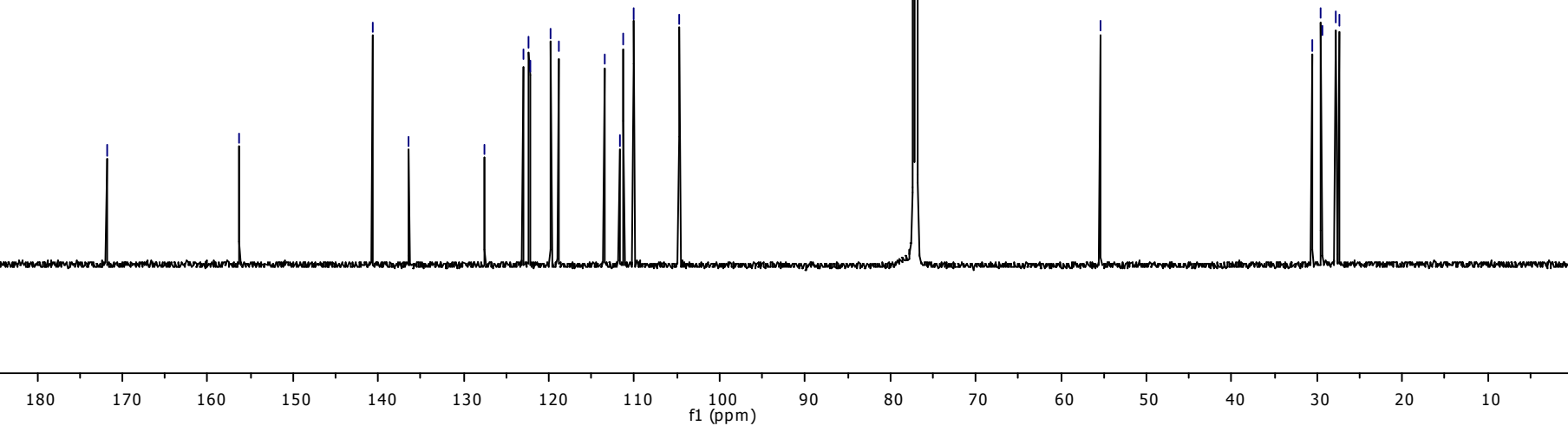


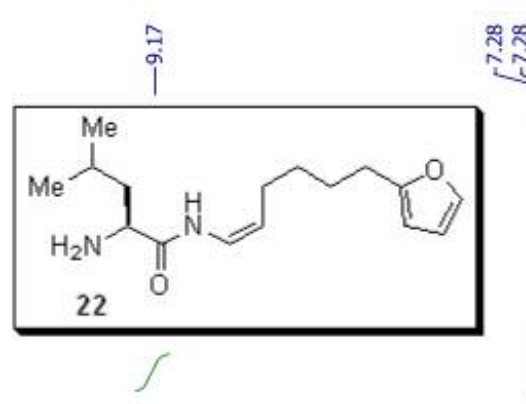

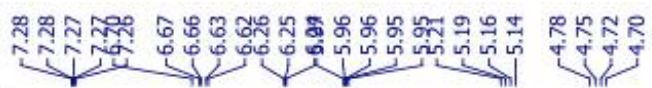

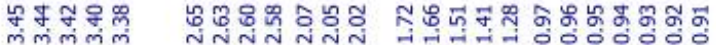 \\ पालm NतNa ,ith \\ तi}
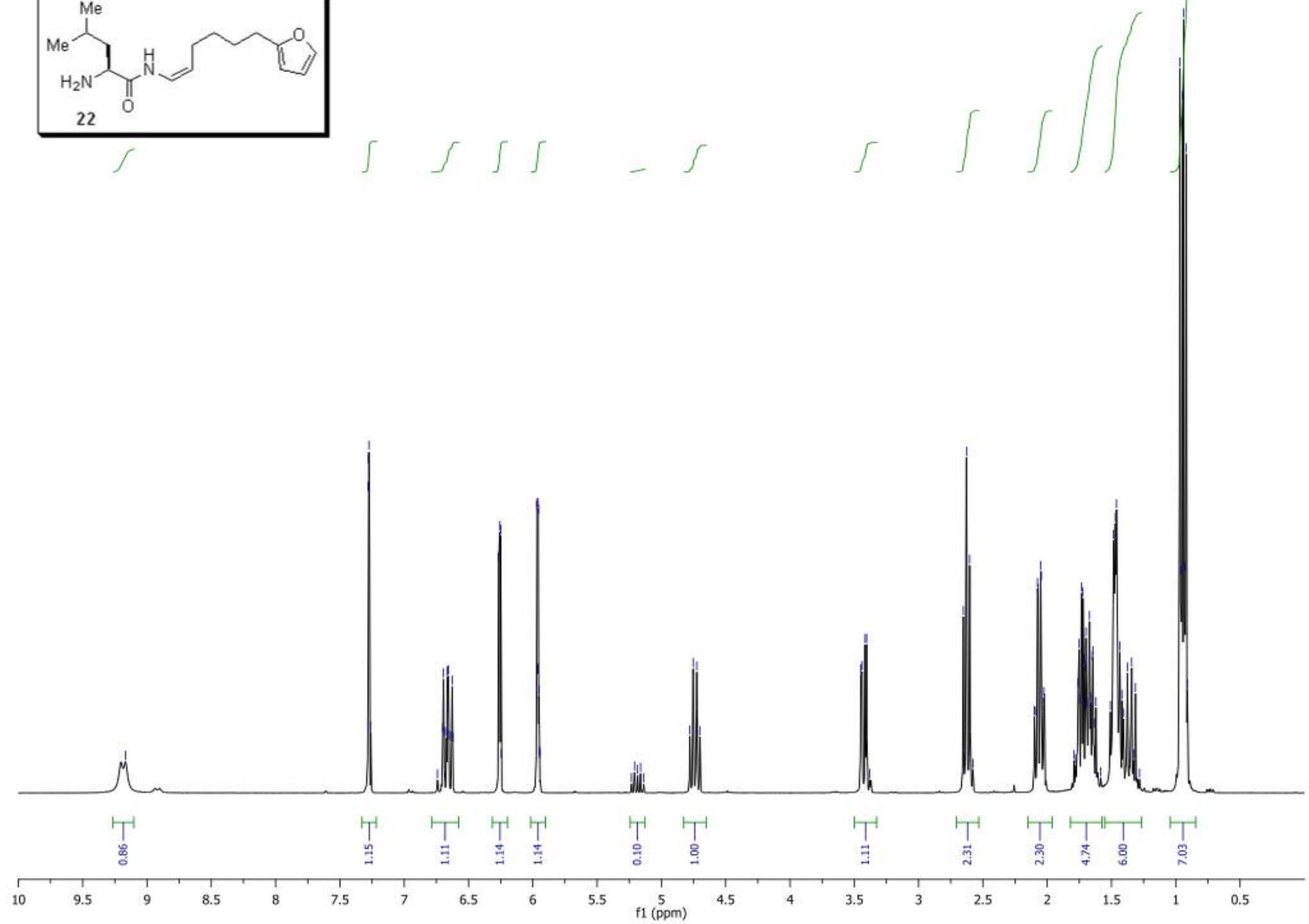


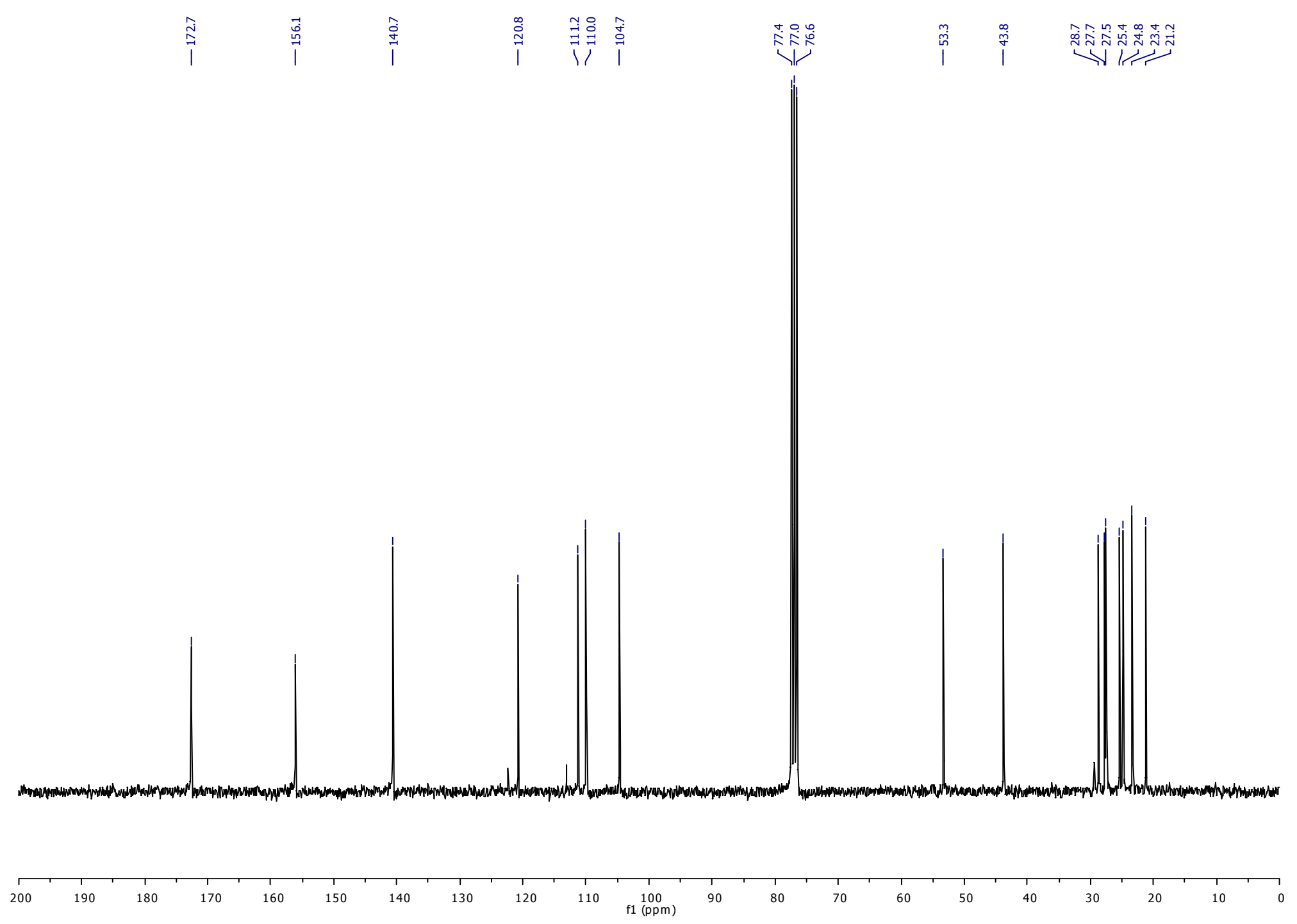



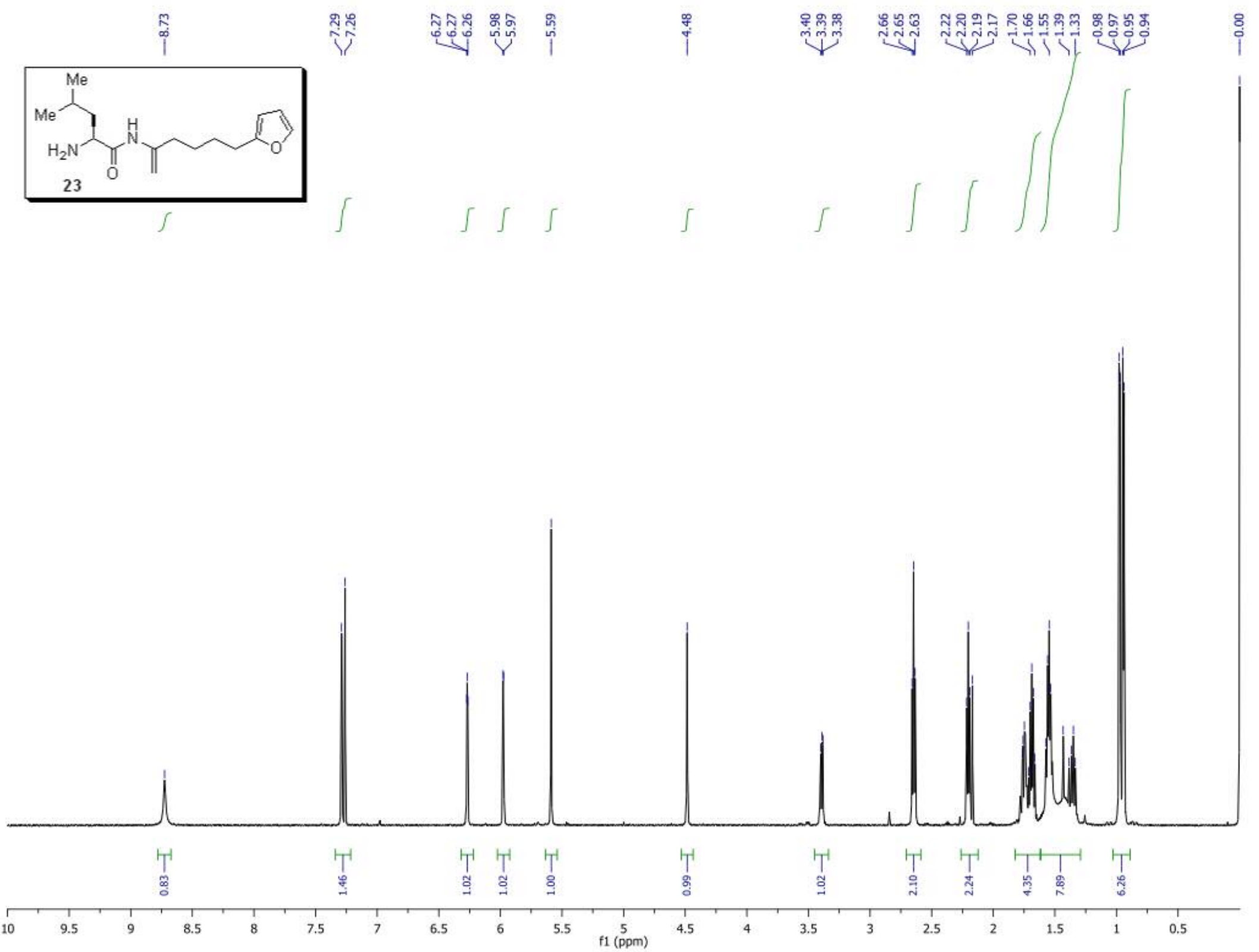

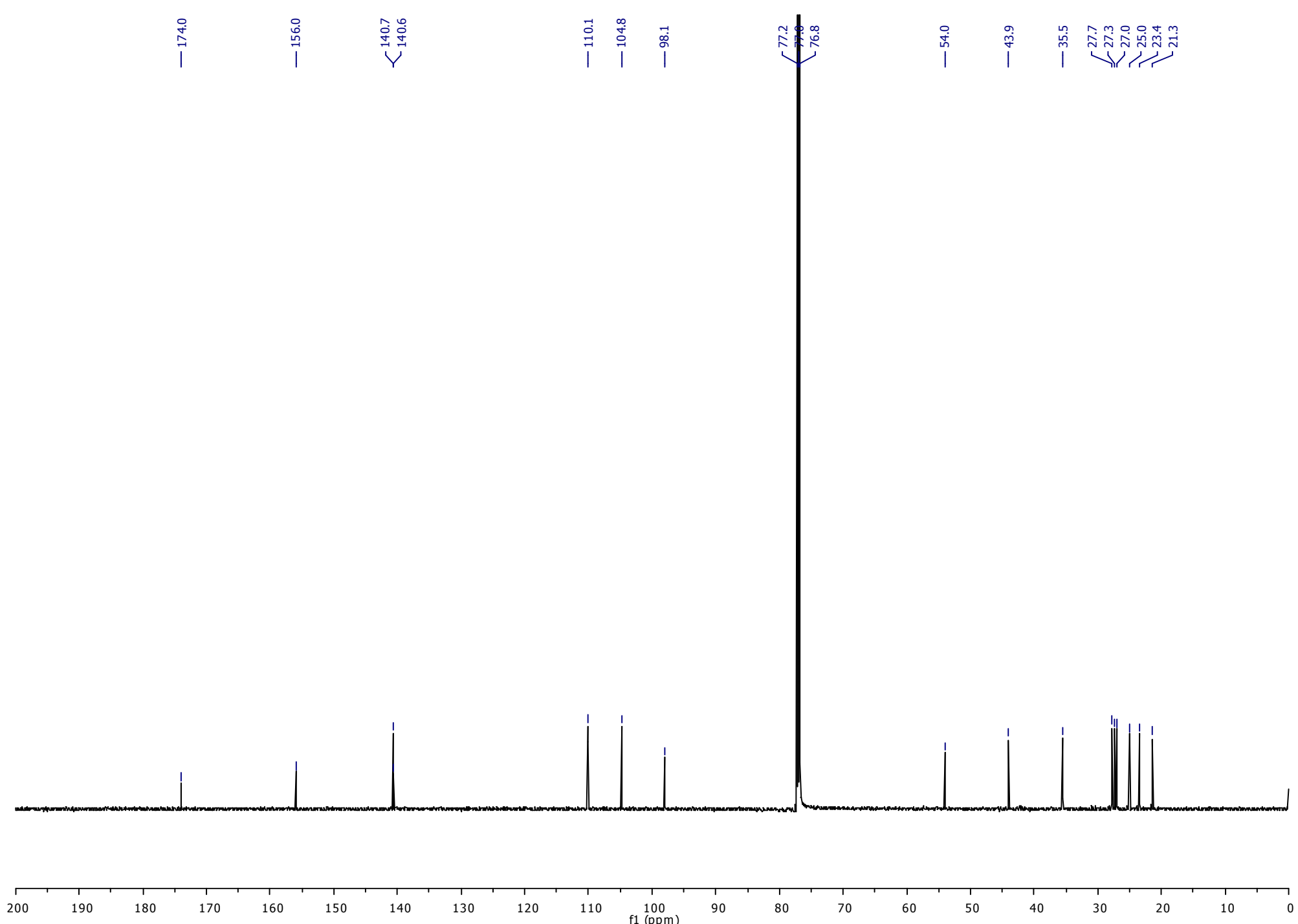


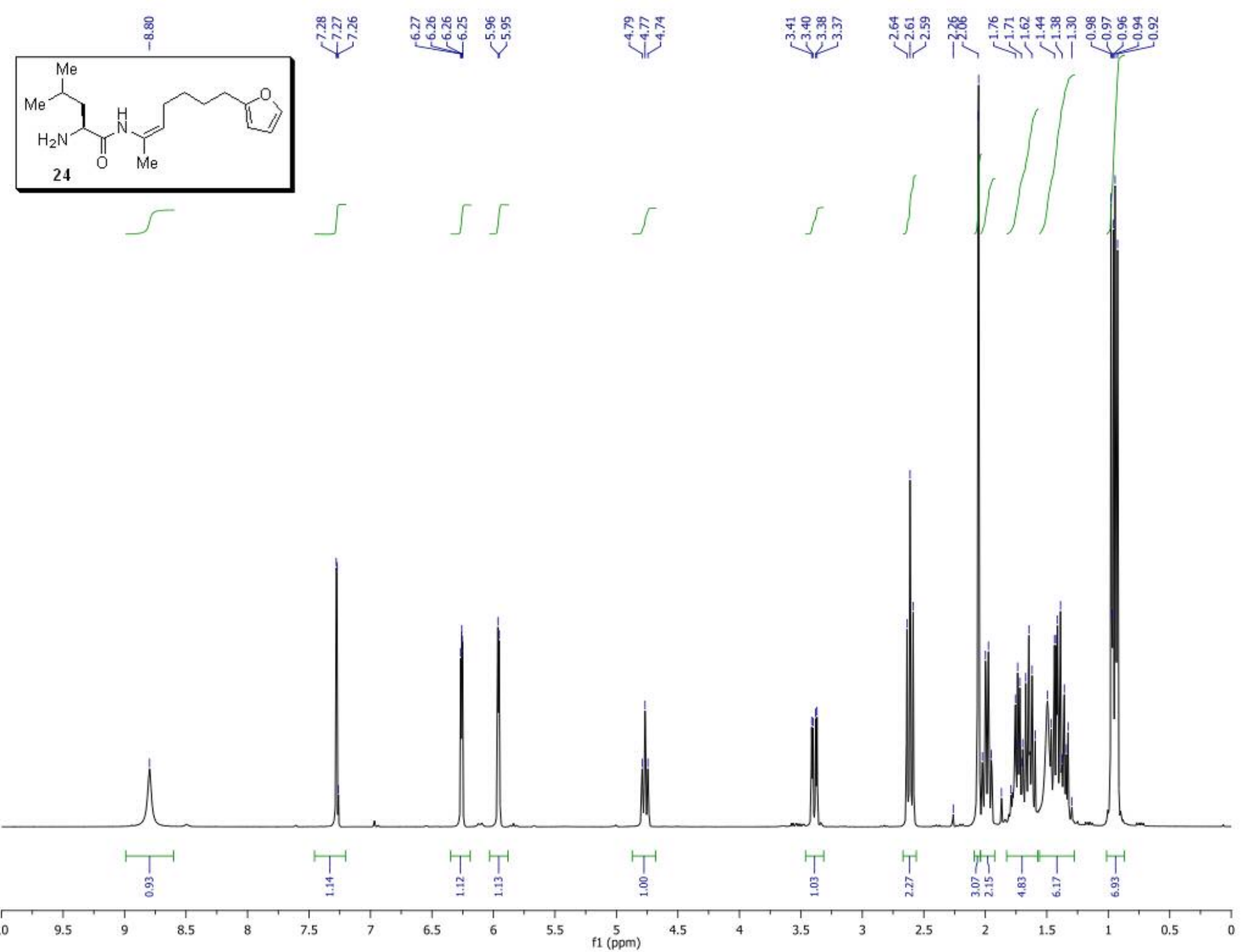




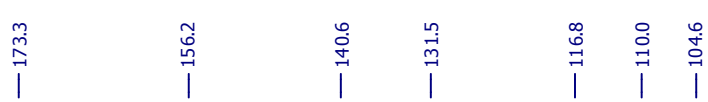

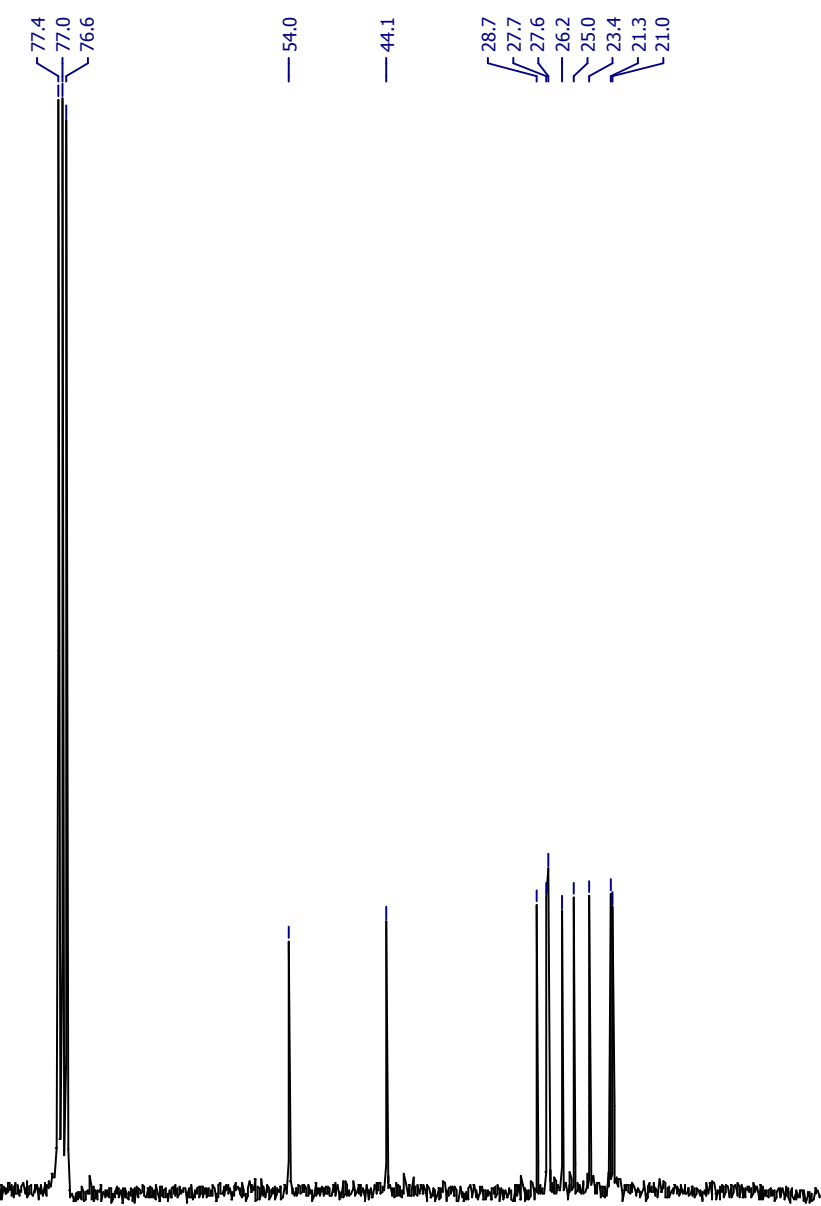

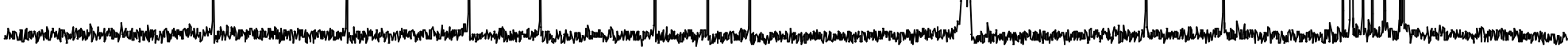

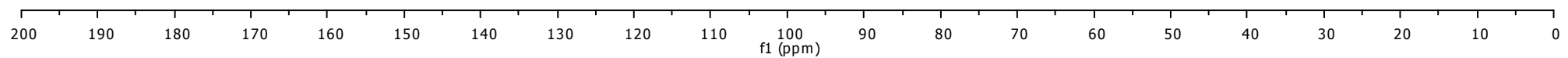



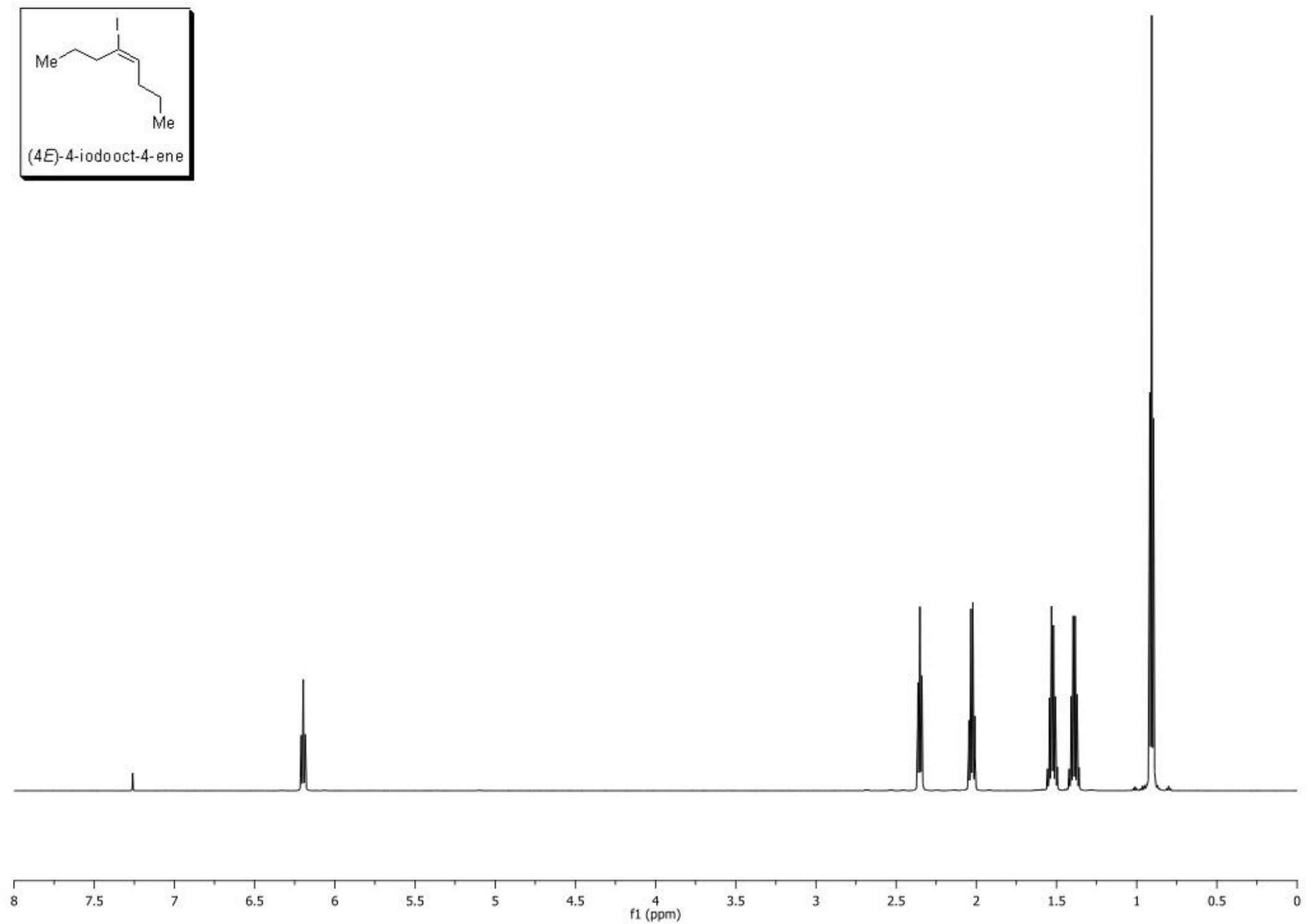

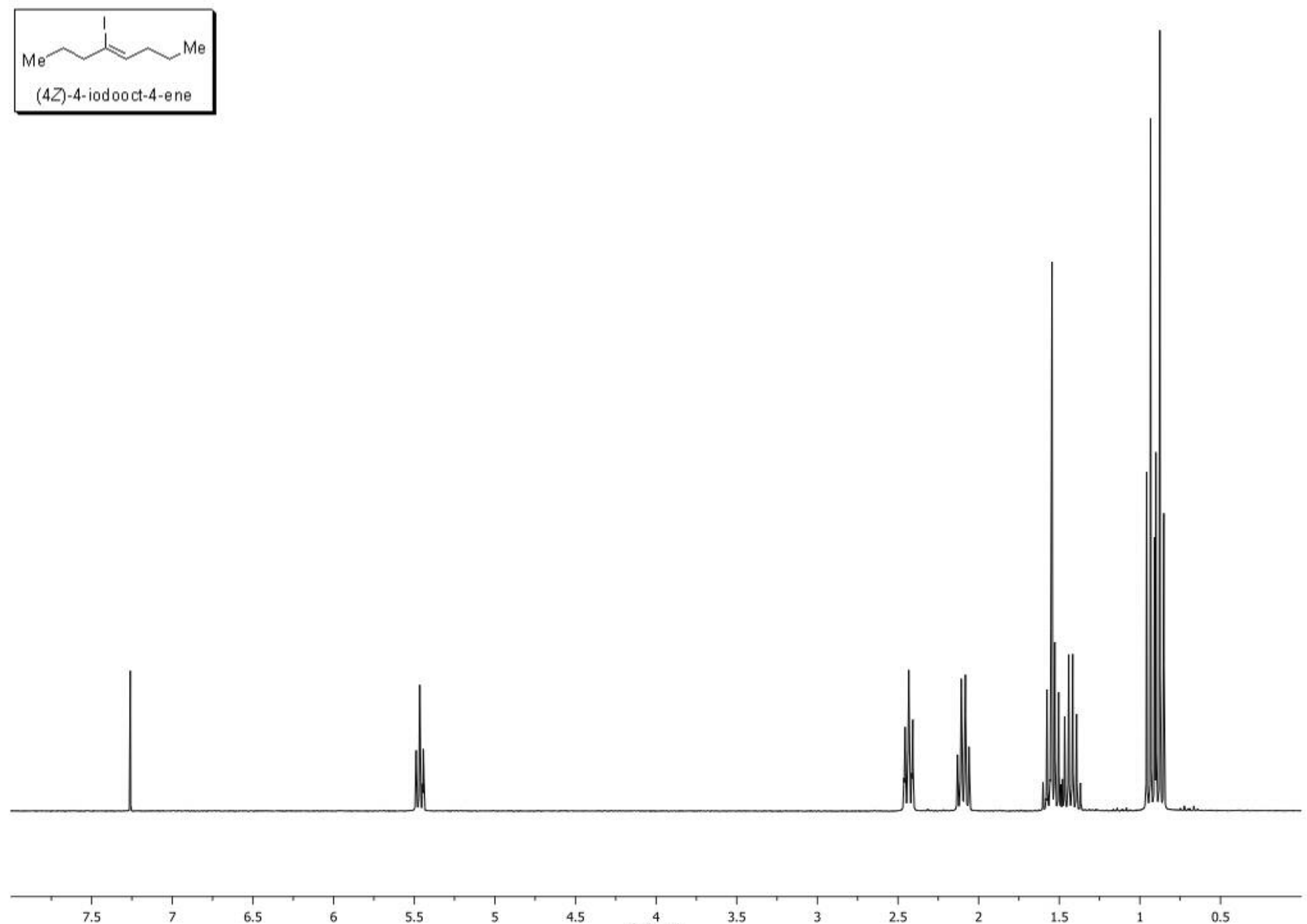

6.5

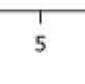

4.5 $\stackrel{4}{4}$

3.5

2.5

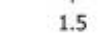


Cesati, et al.

Page S62
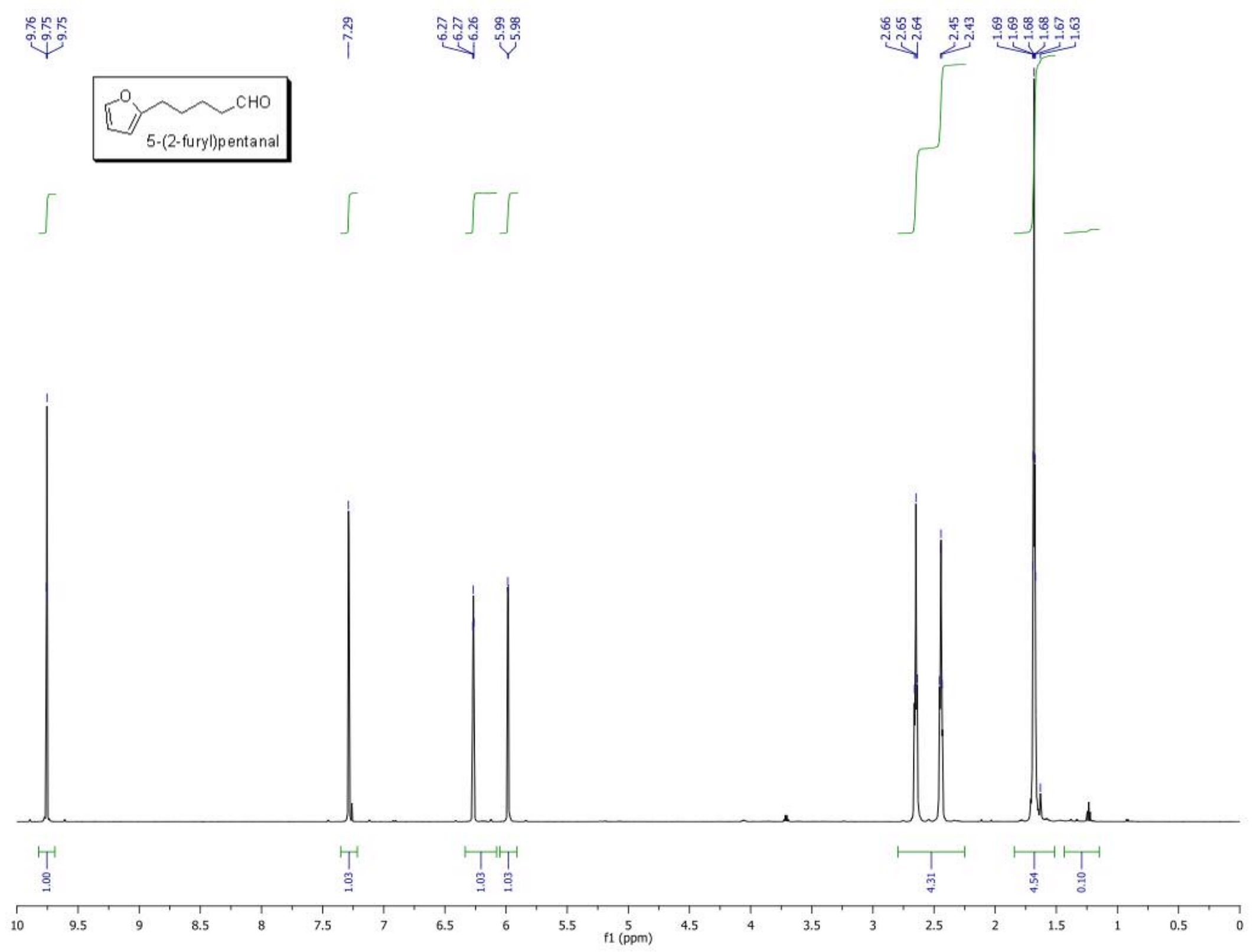


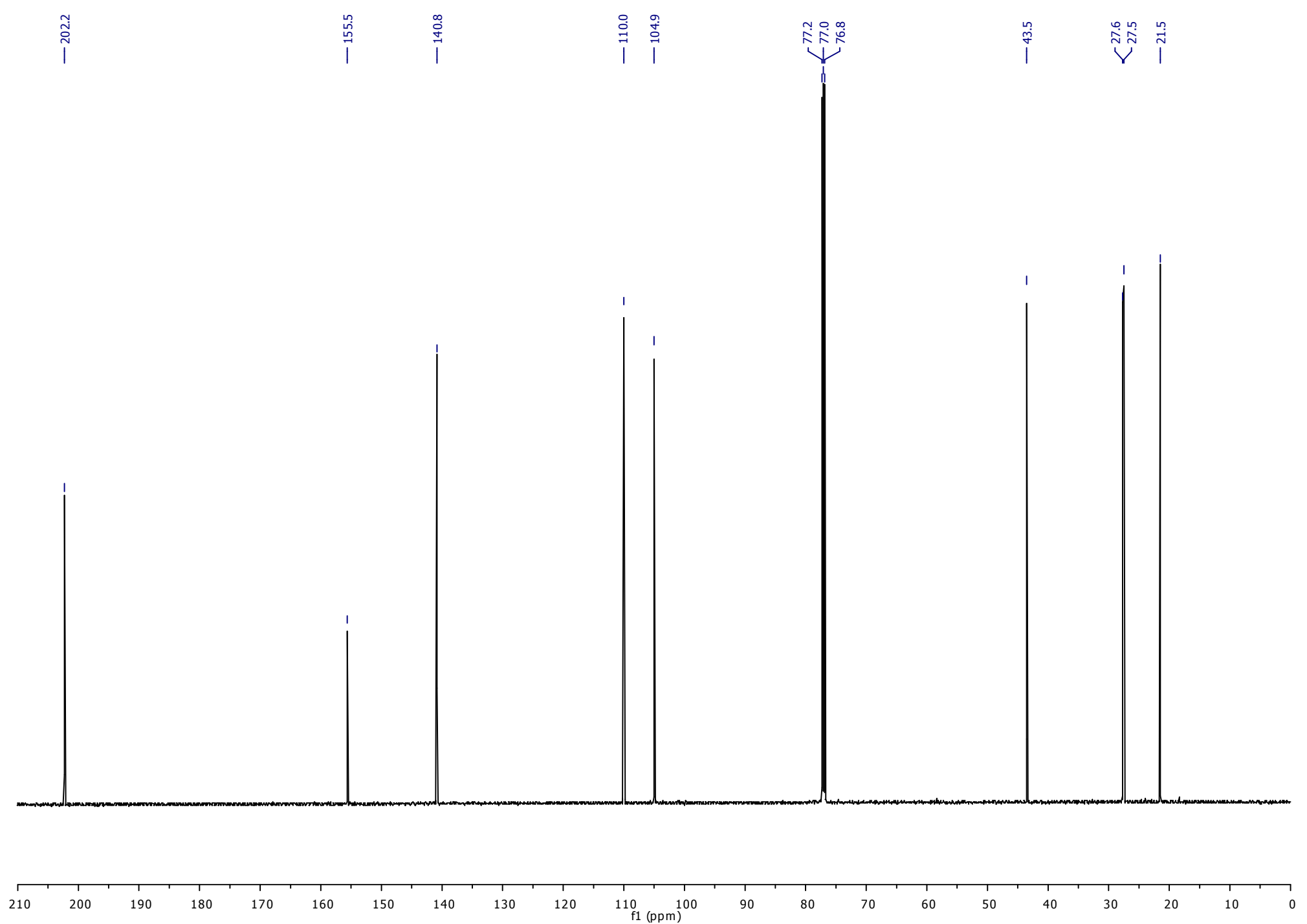




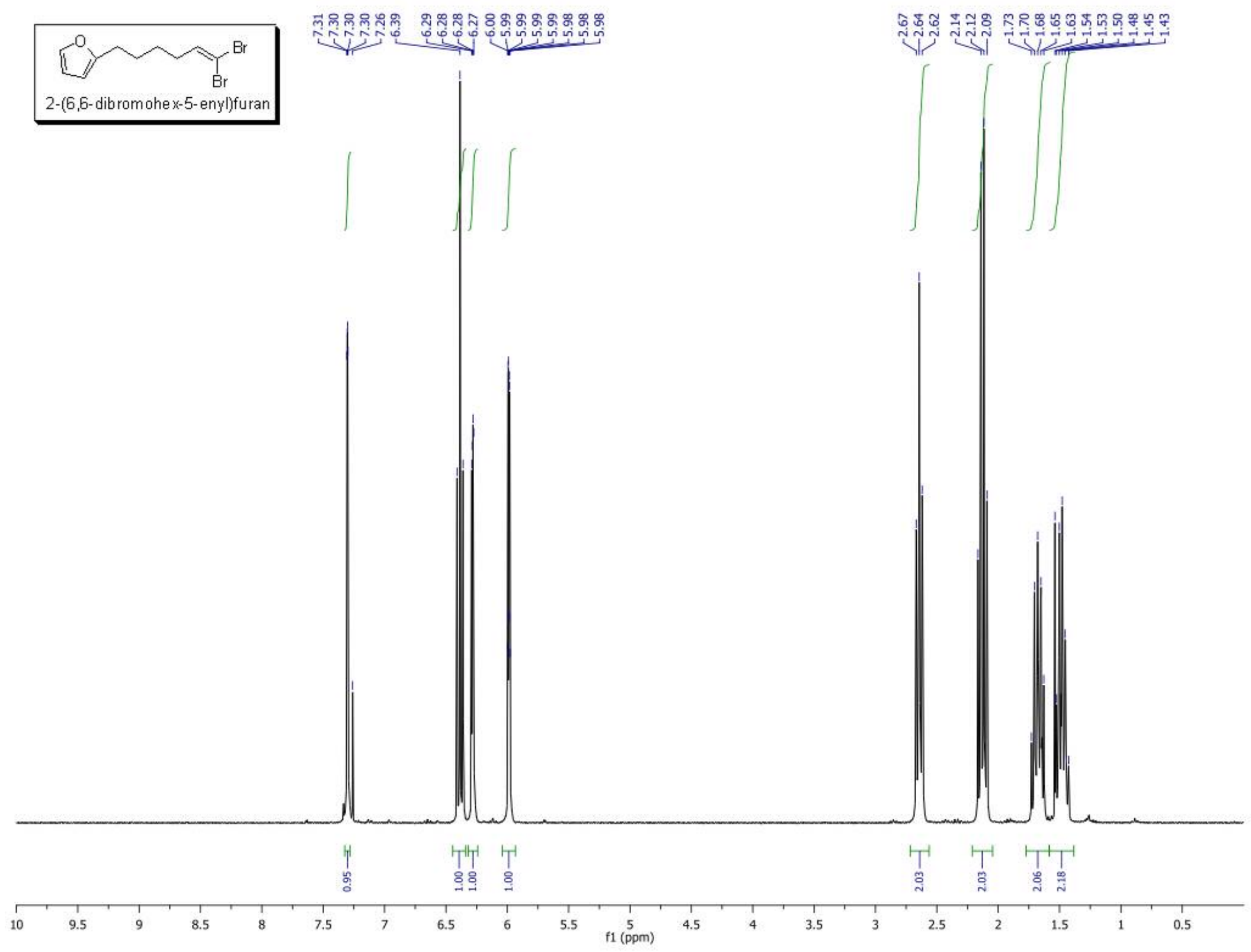




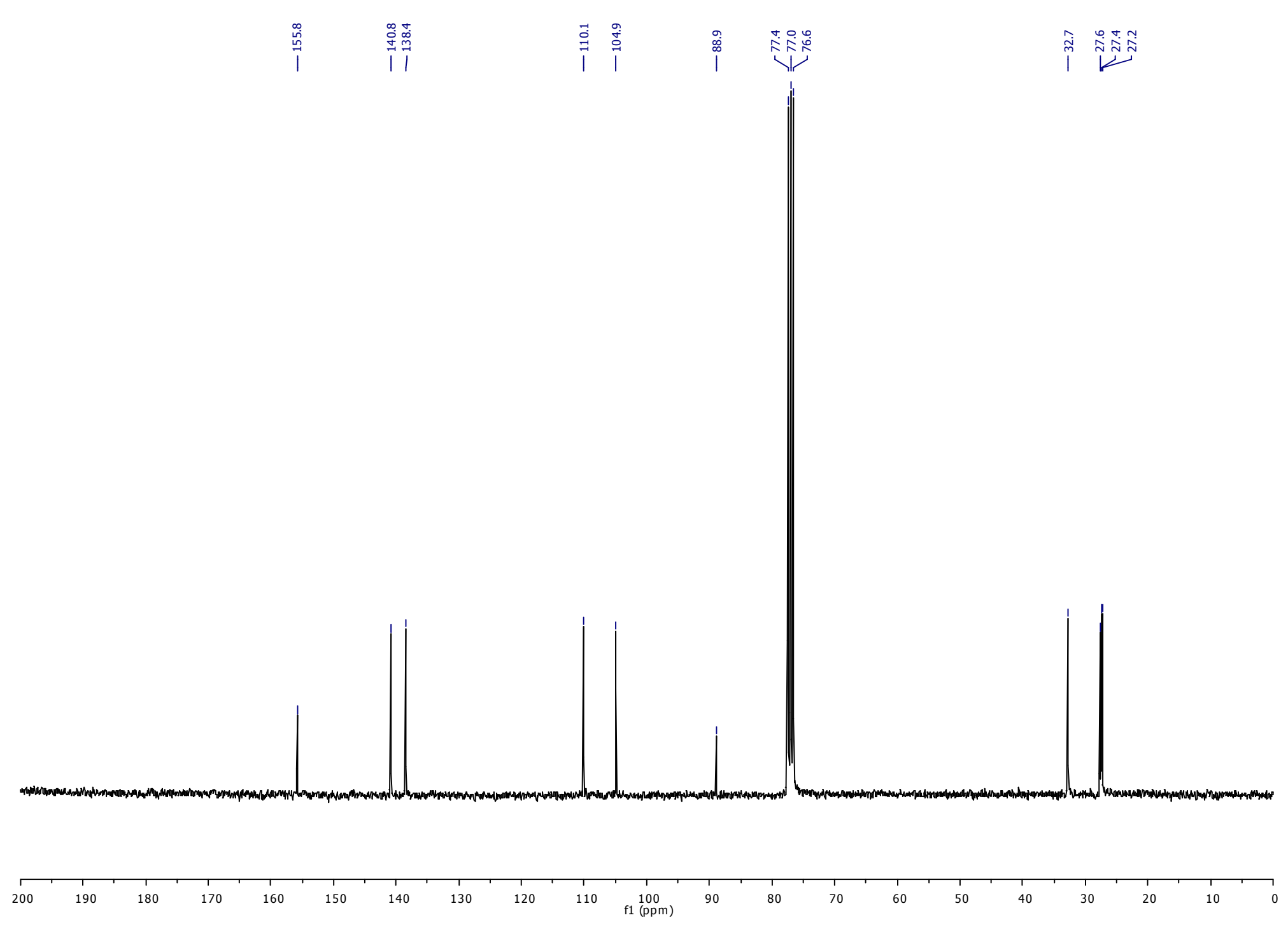




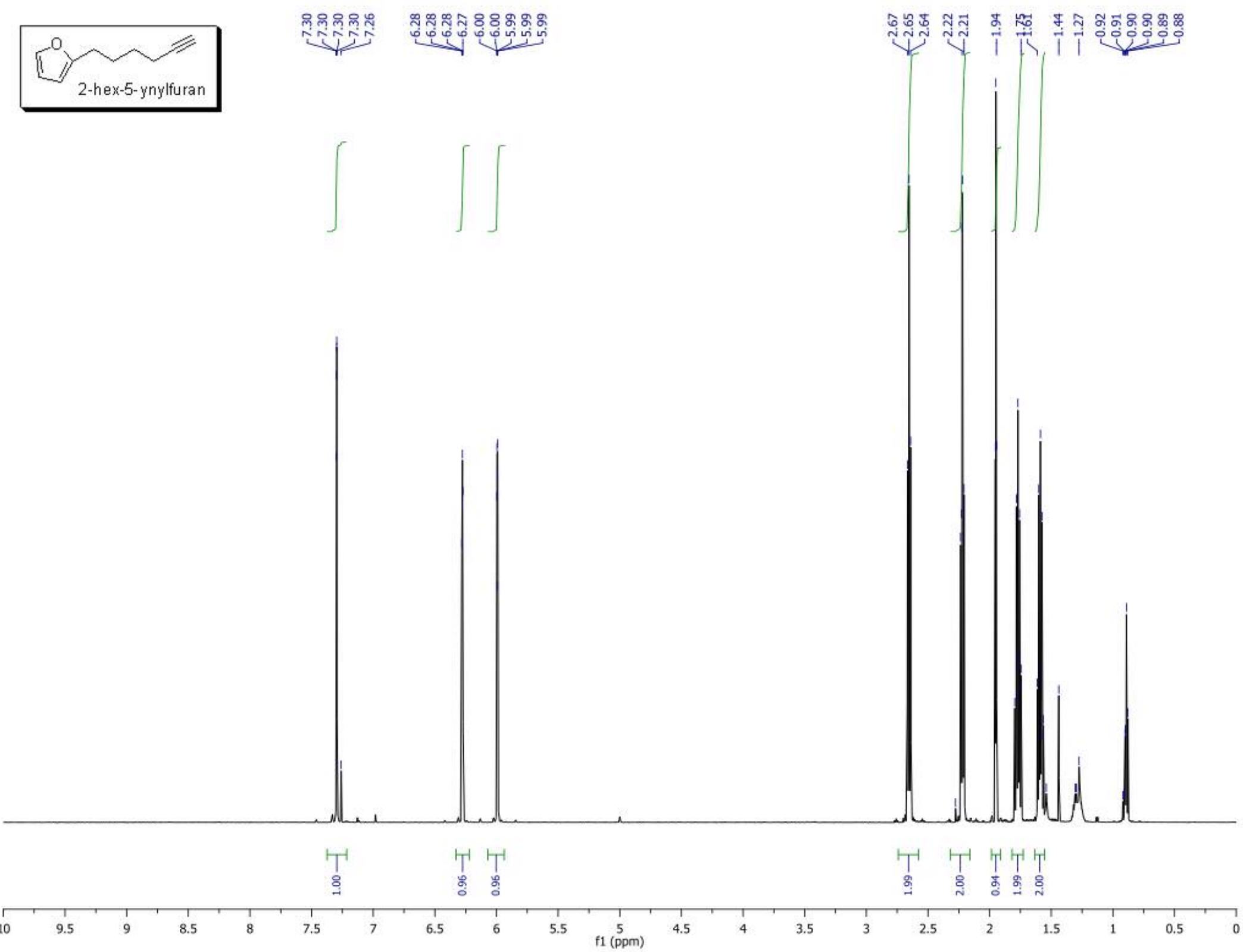




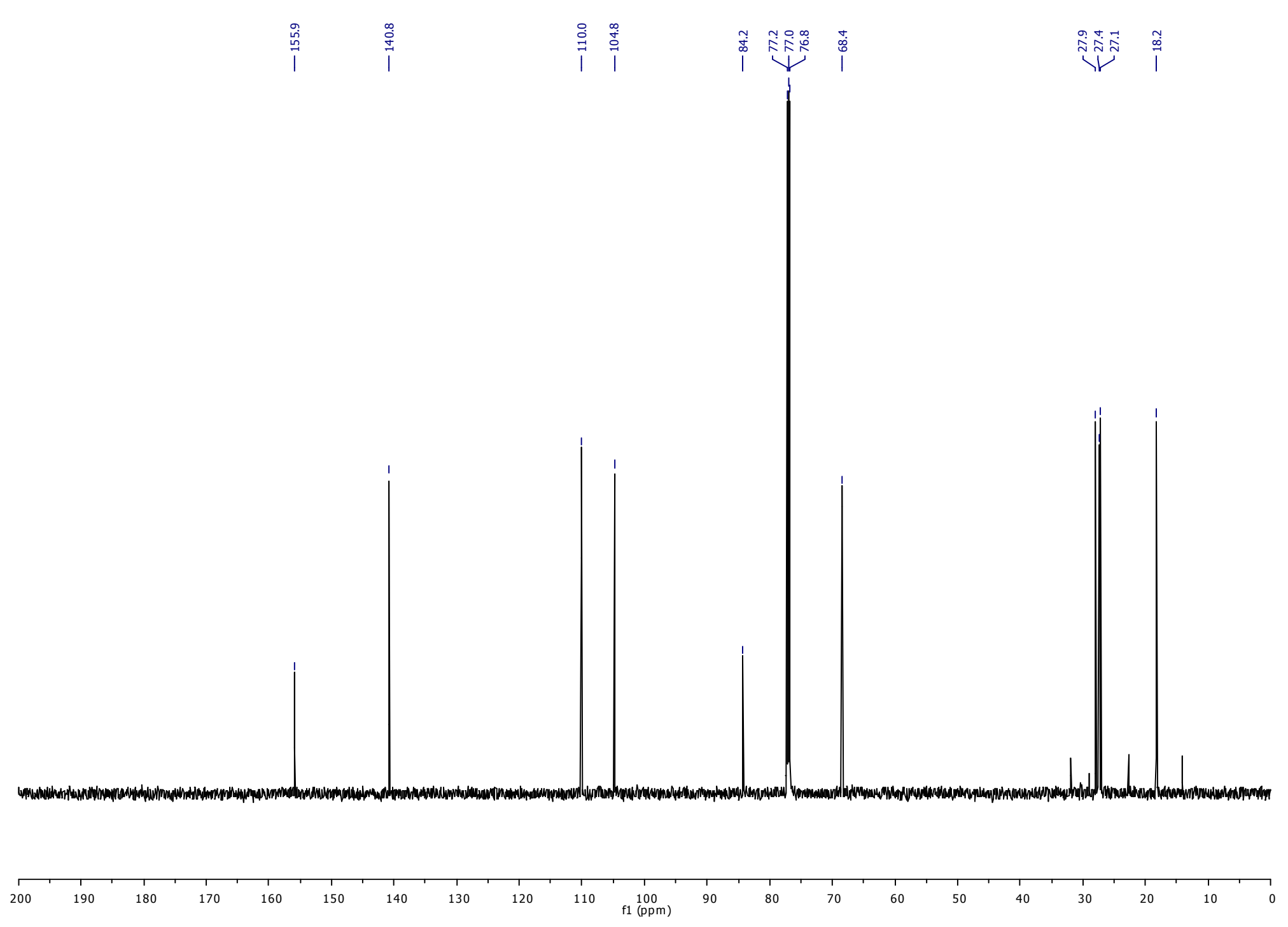




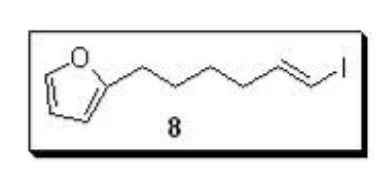

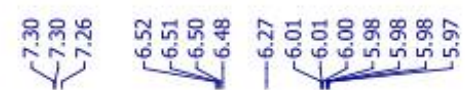

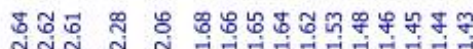

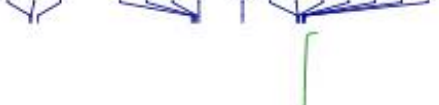

11

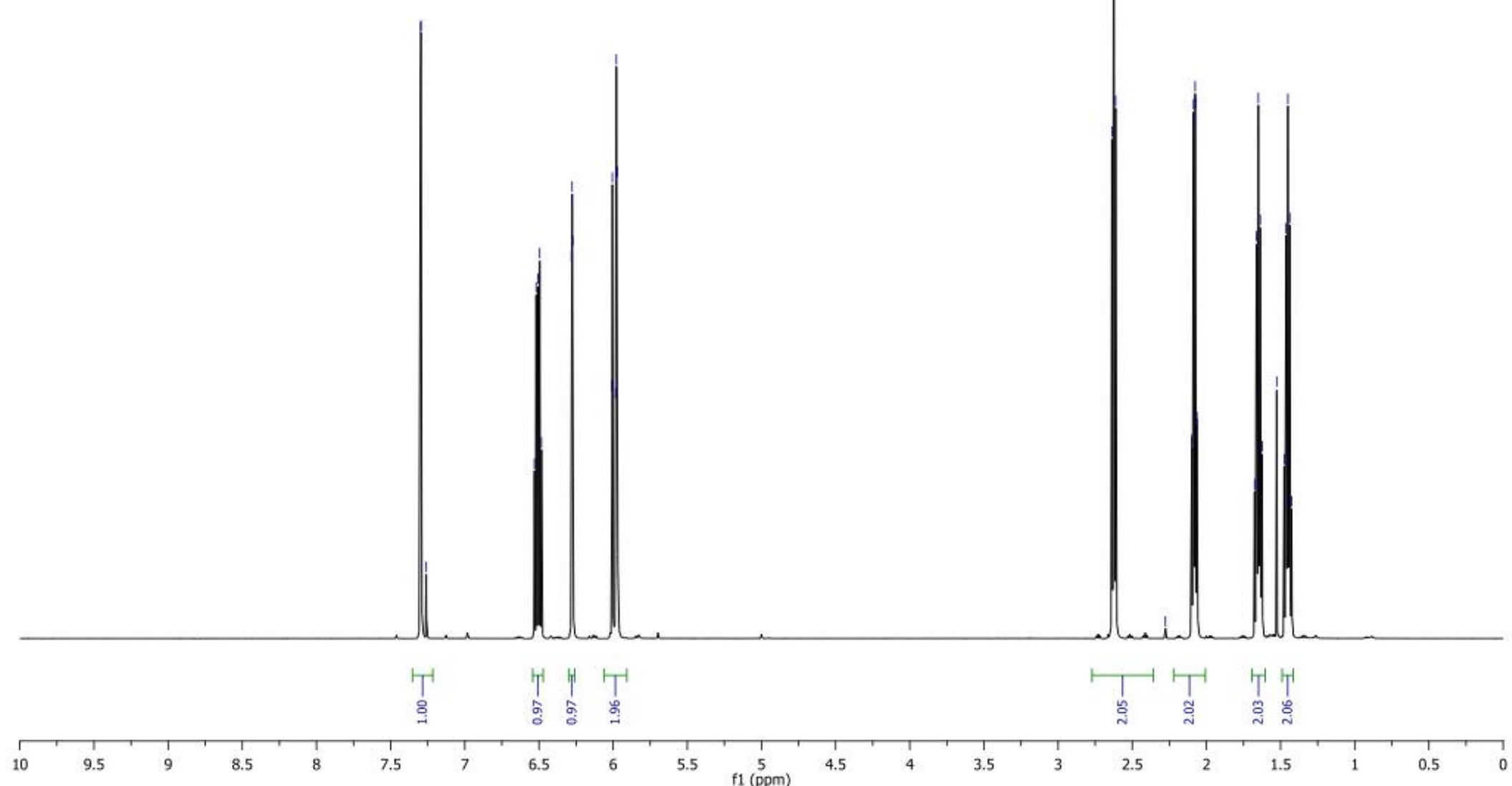




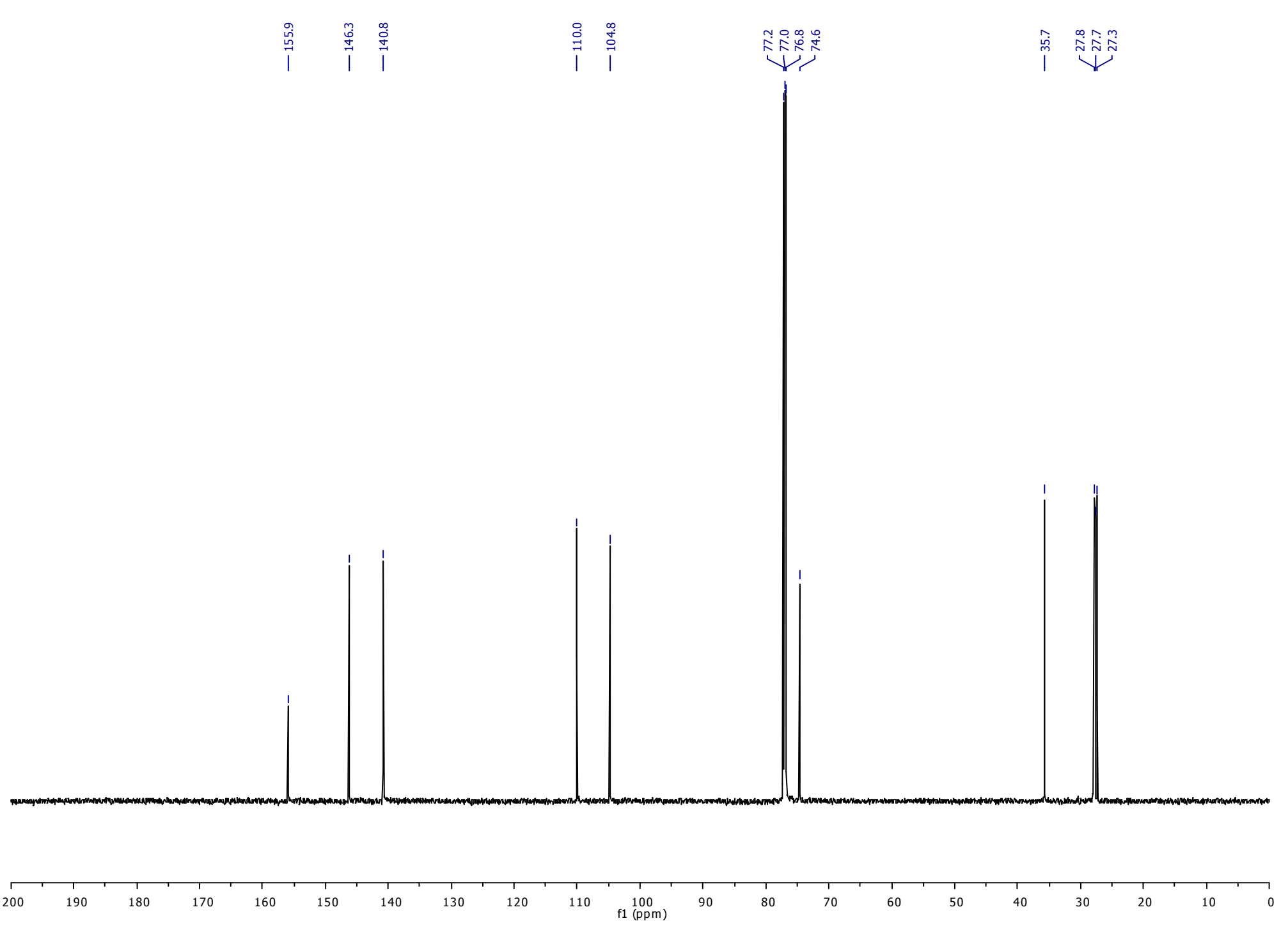




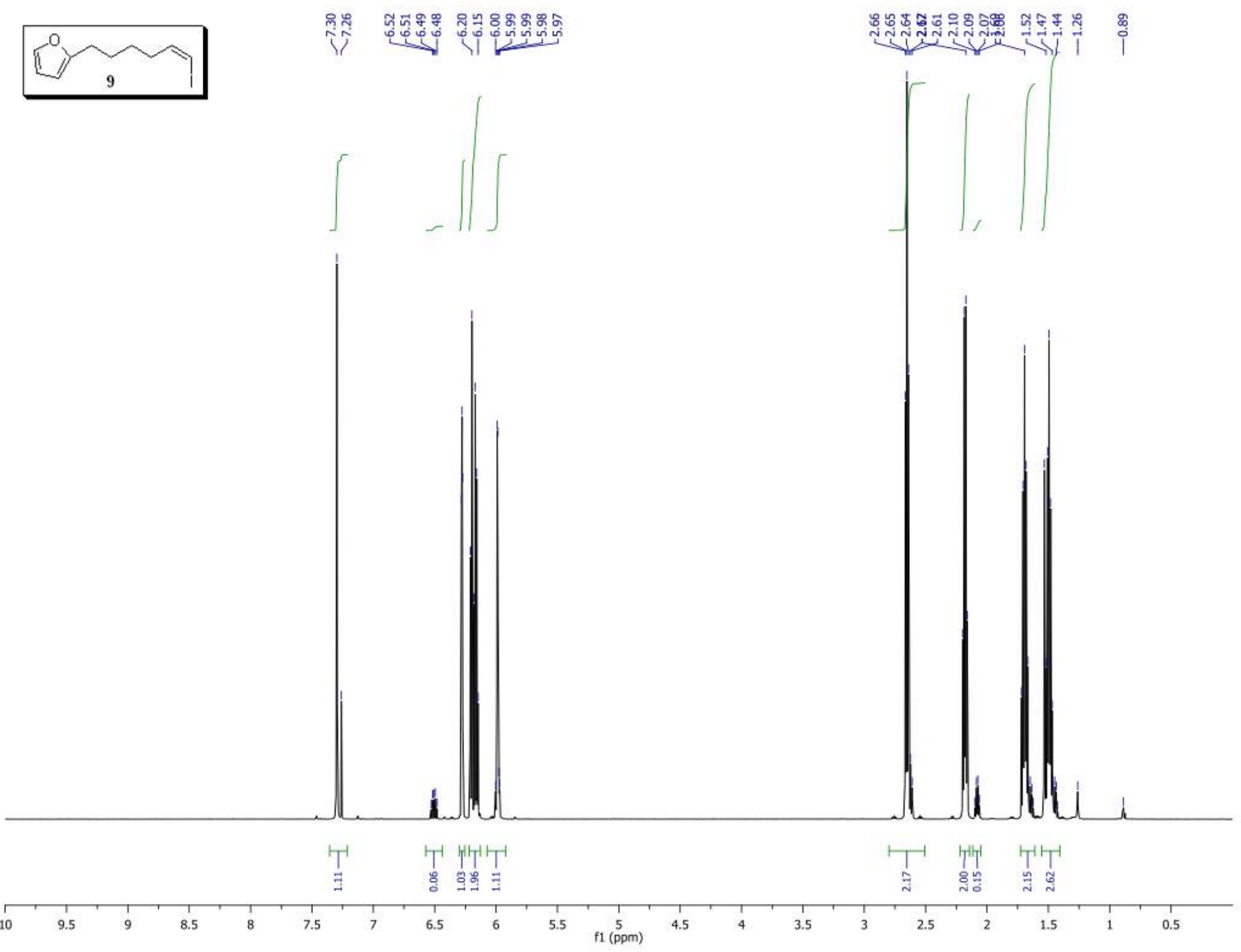




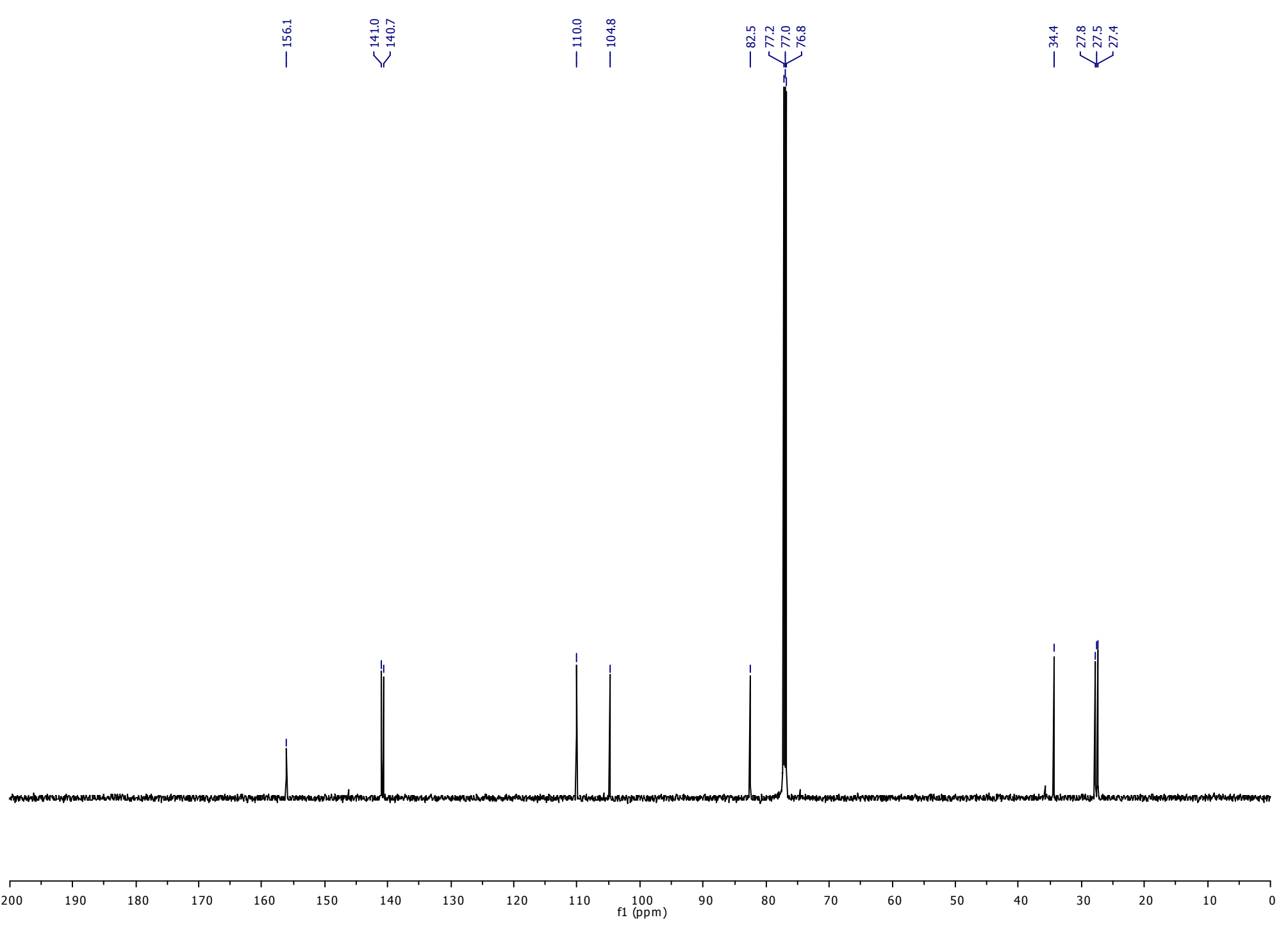



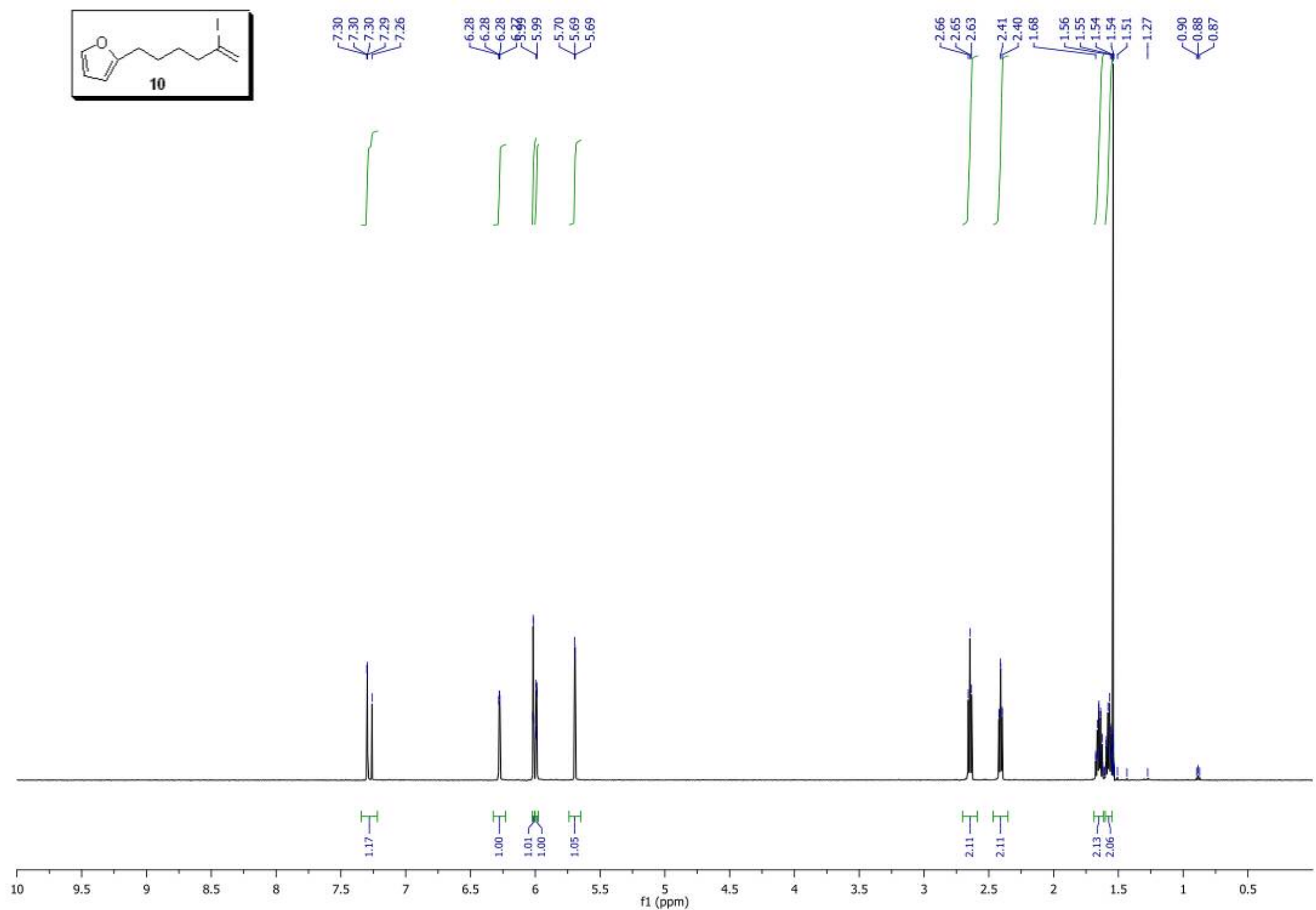
l

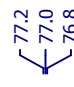

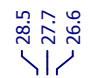
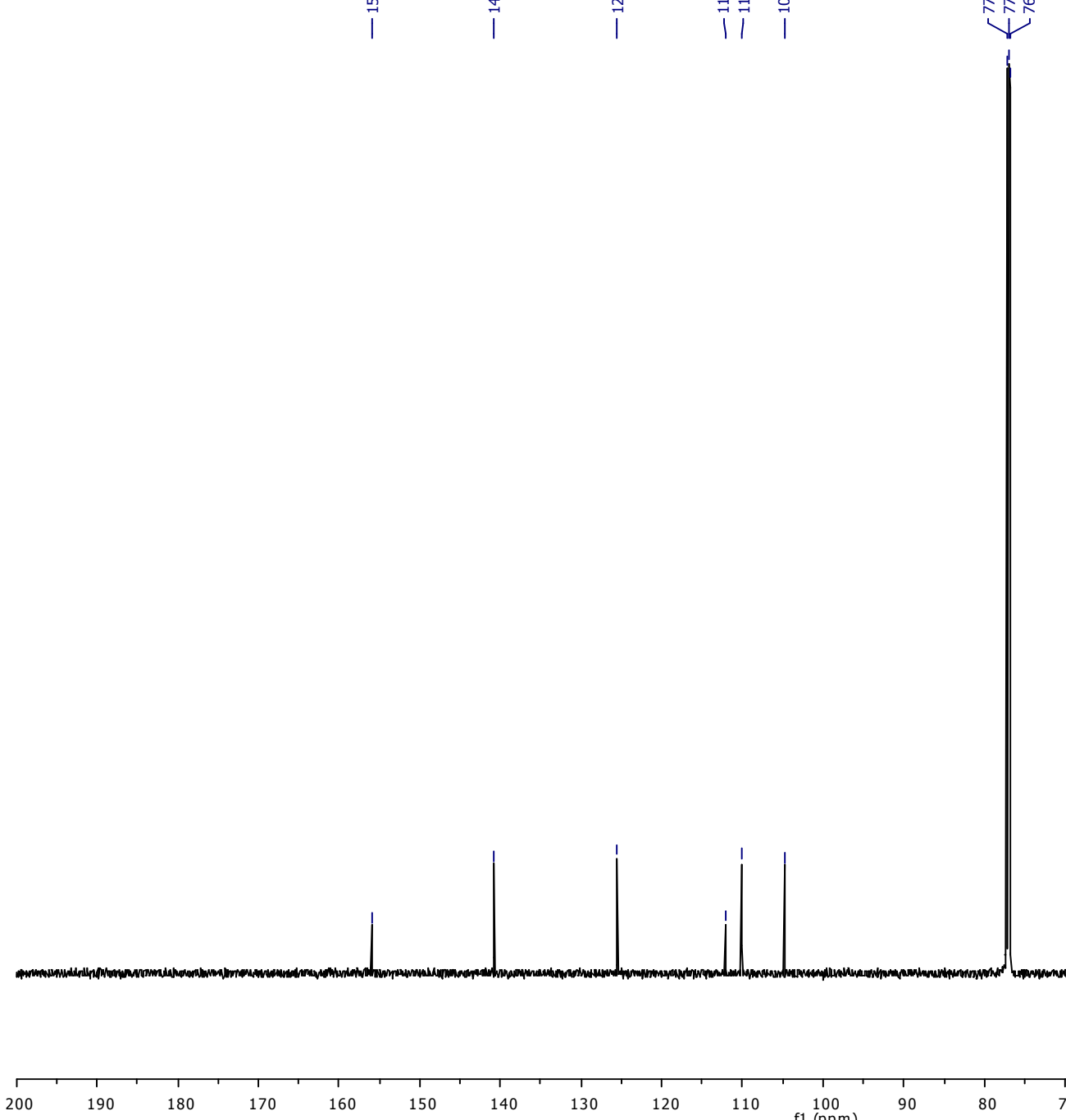

150

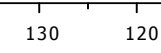

$110 \quad 100$
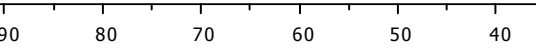

$30 \quad 20$

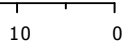




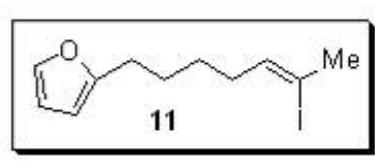

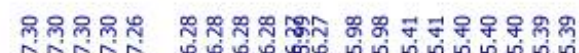

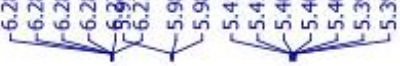

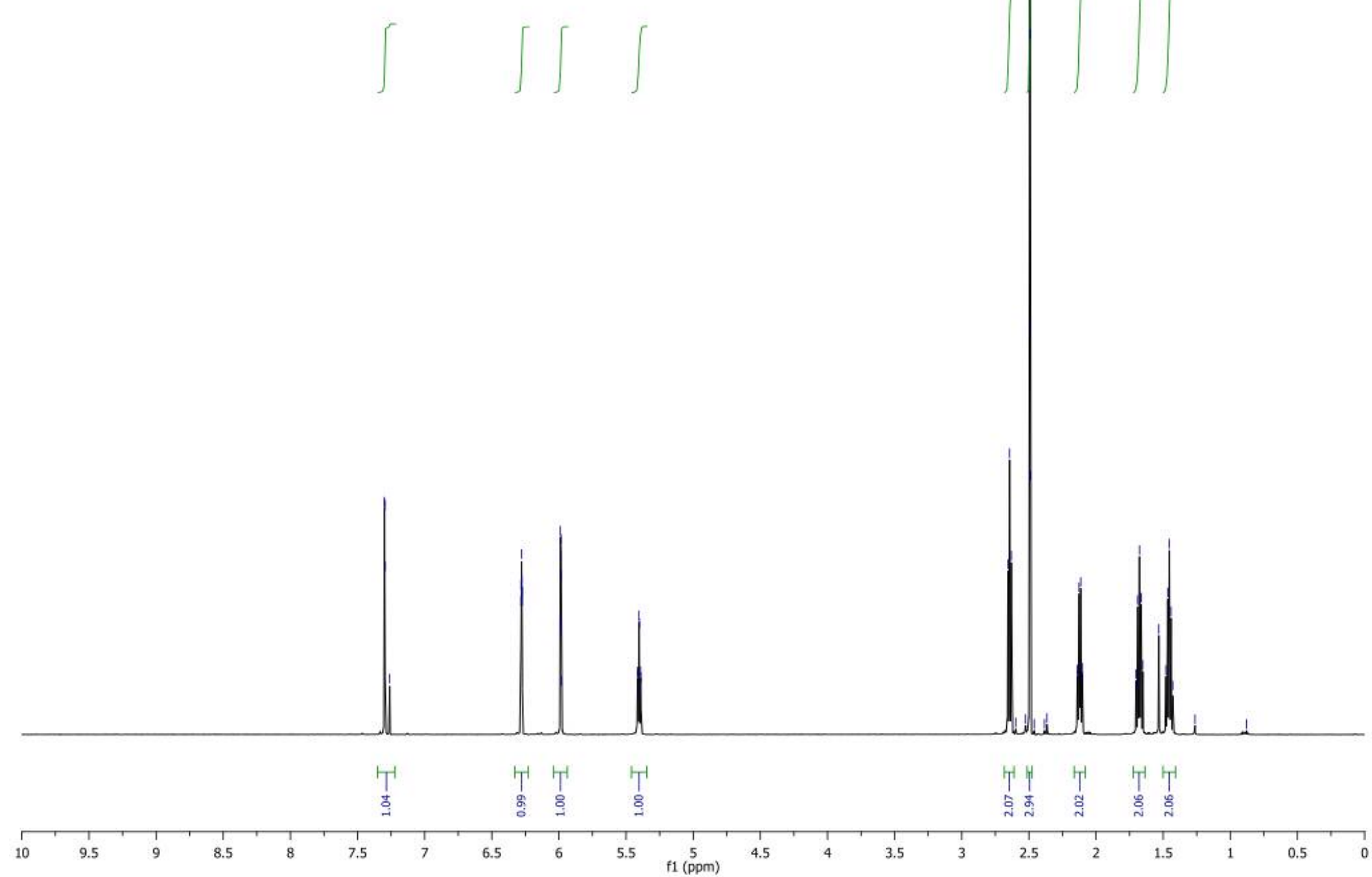

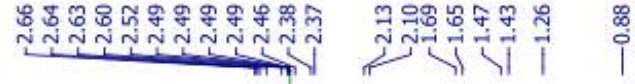




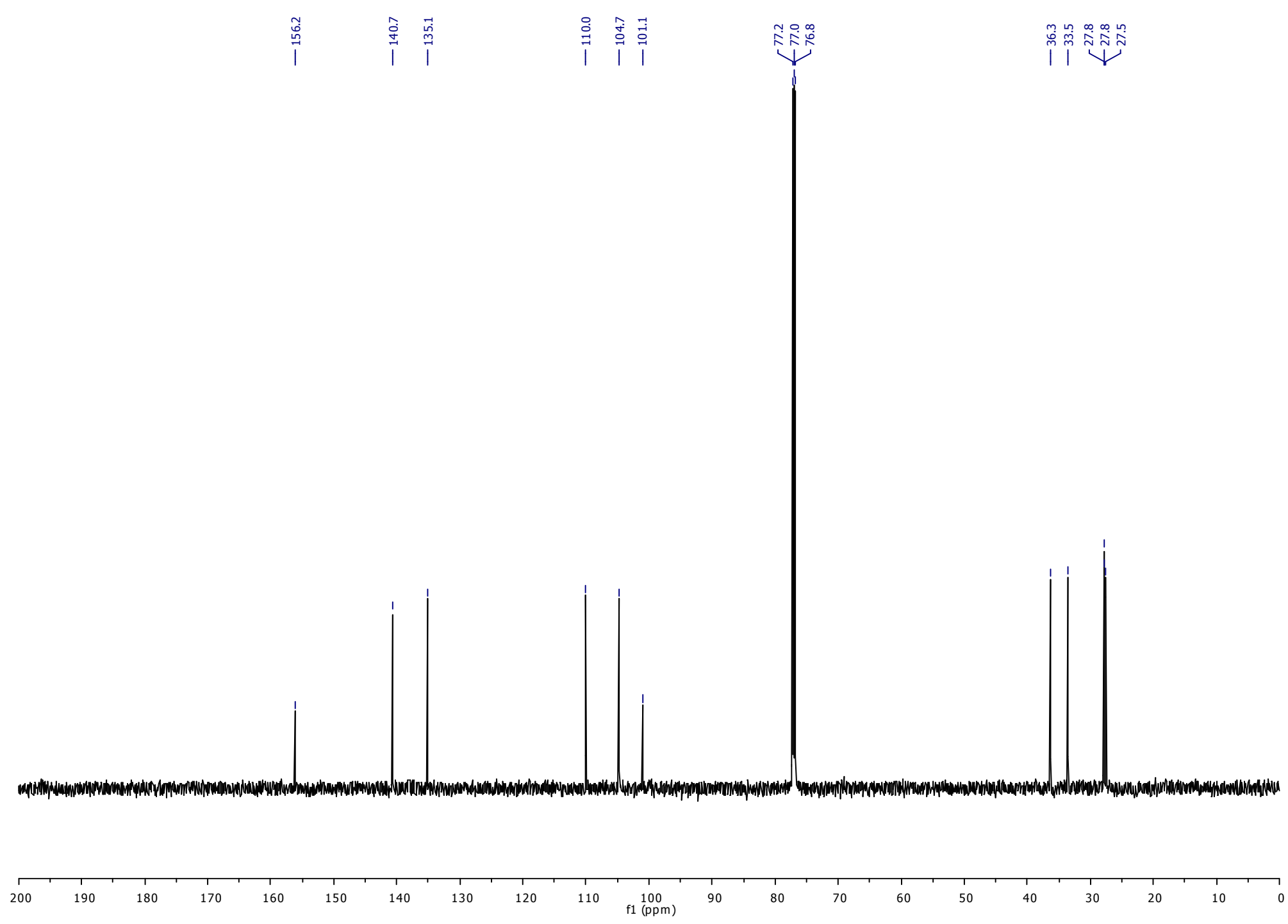



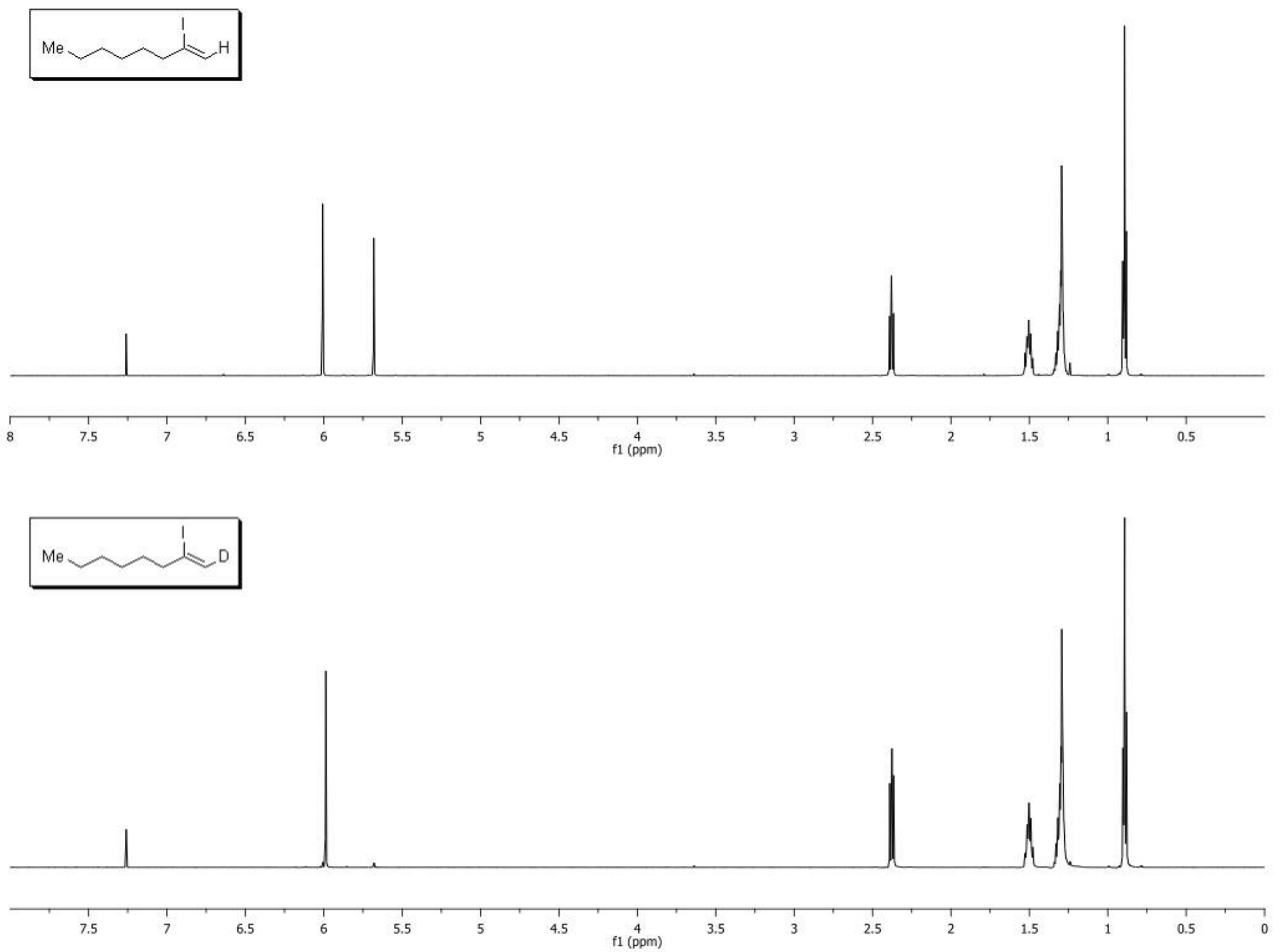

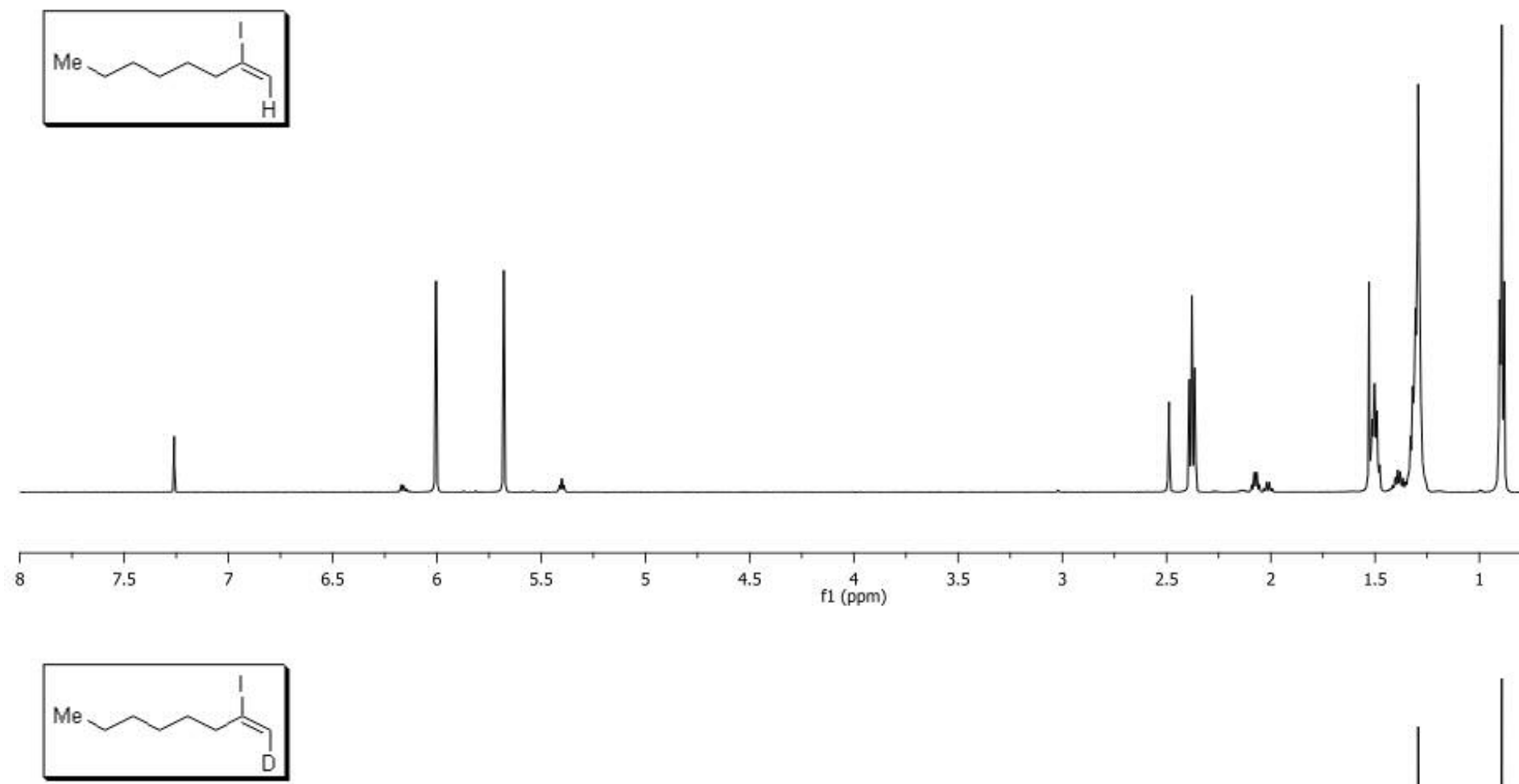

1.5
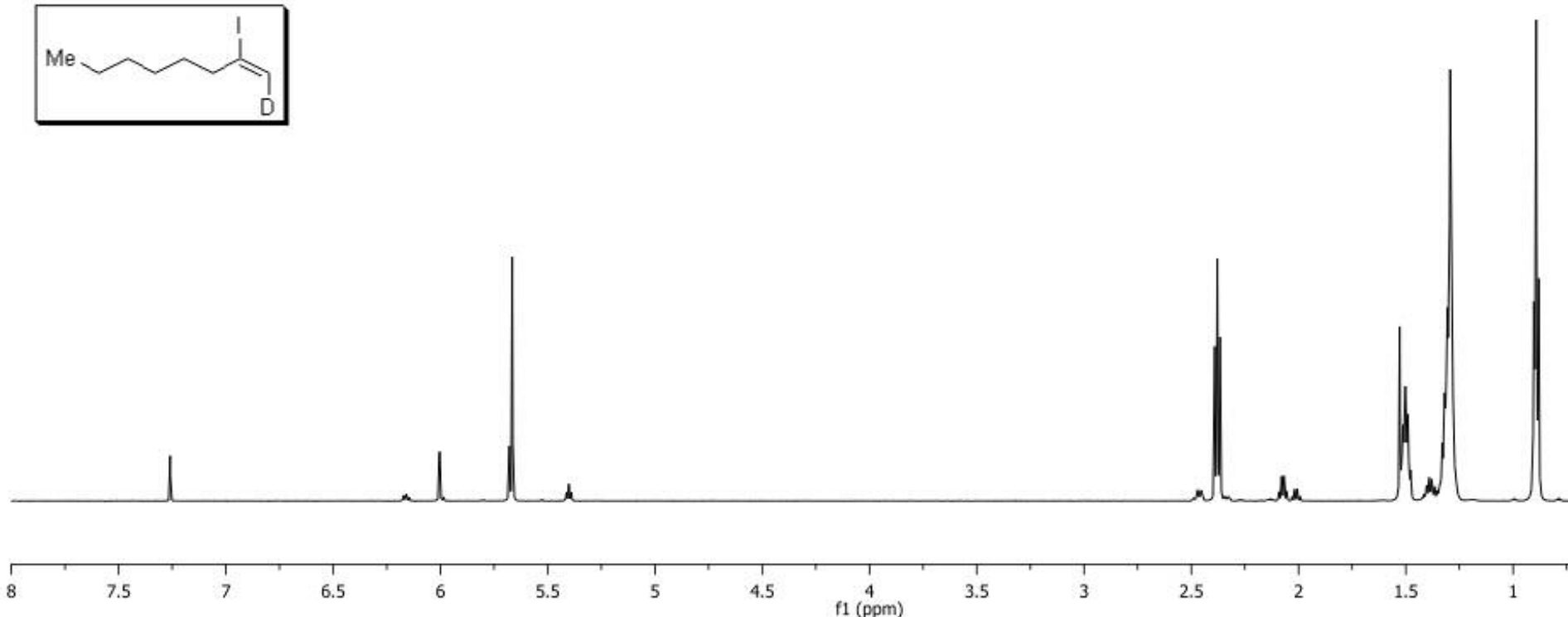

f1 $\stackrel{4}{4}$ 